\title{
Evaluation of Terrestrial Microcosms for Assessing the Fate and Effects of Genetically Engineered Microorganisms on Ecological Processes
}
J. K. Fredrickson
M. W. Ligotke
S. A. Bentjen
K. M. McFadden
H. Bolton, Jr.
P. Van Voris
S. W. Li

April 1989

Prepared for the

U.S. Environmental Protection Agency under a Related Services Agreement with the U.S. Department of Energy under Contract DE-AC06-76RLO 1830

Pacific Northwest Laboratory Operated for the U.S. Department of Energy by Battelle Memorial Institute 


\title{
DISCLAIMER
}

This report was prepared as an account of work sponsored by an agency of the United States Government. Neither the United States Government nor any agency thereof, nor Battelle Memorial institute, nor any or their employees, makes any warranty, expressed or implied, or assumes any legal liability or responsibility for the accuracy, completeness, or usefulness of any information, apparatus, product, or process disclosed, or represents that its use would not infringe privately owned rights. Reference herein to any specific commercial product, process, or service by trade name, trademark, manufacturer, or otherwise does not necessarily constitute or imply its endorsement, recommendation, or favoring by the United States Government or any agency thereof, or Battelle Memorial Institute. The views and opinions of authors expressed herein do not necessarily state or reflect those of the United States Government or any agency thereof.

\author{
PACIFIC NORTHWEST LABORATORY \\ operated by \\ BATTELLE MEMORIAL INSTITUTE \\ for the \\ UNITED STATES DEPARTMENT OF ENERGY \\ under Contract DE-AC06-76RLO 1830
}

\begin{tabular}{|c|c|}
\hline \multicolumn{2}{|c|}{ Printed in the United States of America } \\
\hline \multicolumn{2}{|c|}{ Available from } \\
\hline \multicolumn{2}{|c|}{ Nalional Technical Information Service } \\
\hline \multicolumn{2}{|c|}{ United States Department of Commerce } \\
\hline \multicolumn{2}{|c|}{5285 Port Royal Road } \\
\hline \multicolumn{2}{|c|}{ Springfield, Virginia $2216 \uparrow$} \\
\hline \multicolumn{2}{|c|}{ NTIS Price Coxdes } \\
\hline \multicolumn{2}{|c|}{ Microfiche A01 } \\
\hline \multicolumn{2}{|c|}{ Printed Copy } \\
\hline & Price \\
\hline Pages & Codes \\
\hline $001-025$ & $\mathrm{AOZ}_{2}$ \\
\hline $026-050$ & $\mathrm{~A} 03$ \\
\hline $057-075$ & $\mathrm{AO4}$ \\
\hline $076-100$ & AOS \\
\hline $101-125$ & $A \sqrt{6} 6$ \\
\hline $126-150$ & A07 \\
\hline 151.175 & $A 0 B$ \\
\hline $176-200$ & $A 09$ \\
\hline $20 T-225$ & A10 \\
\hline $226-250$ & A11 \\
\hline $251-275$ & A12 \\
\hline $276-300$ & A13 \\
\hline
\end{tabular}


PNL-6850

UC-11

EVALUATION OF TERRESTRIAL MICROCOSMS

FOR ASSESSING FATE AND EFFECTS OF GENETICALLY ENGINEERED MICROORGANISMS ON ECOLOGICAL PROCESSES

\author{
J. K. Fredrickson \\ S. A. Bentjen(a) \\ H. Bolton, Jr. \\ S. W. Li \\ M. W. Ligotke \\ K. M. McFadden \\ P. Van Voris
}

April 1989

Prepared for

the U.S. Environmental Protection Agency

under a Related Services Agreement

with the U.S. Deparment of Energy

under Contract DE-AC06-76RLO 1830

Pacific Northwest Laboratory

Richland, Washington 99352

(a) University of Idaho, Moscow, Idaho 



\section{EXECUTIVE SUMMARY}

The principal objective of this project was to evaluate and modify the existing U.S. Environmental Protection Agency's Office of Pesticides and Toxic Substances (EPA/OPTS) terrestrial microcosm test system and test protocols such that they can be used to determine the environmental fate and ecological hazards of genetically engineered microorganisms (GEMs). The intact soil-core microcosm represents terrestrial ecosystems, and when coupled with appropriate test protocols, such microcosms may be appropriate to define and limit risks associated with the intentional release of GEMs.

The terresurial microcosm test system was used to investigate the survival and transport of two model GEMs (Azospirillum lipoferum and Pseudomonas sp. Tn5 mutants) to various trophic levels and niches and through intact soil cores. Subsequent effects on nutrient cycling and displacement of indigenous microorganisms were evaluated. The model organisms were a diazotrophic root-colonizing bacterium ( $A$. lipoferum) and a wheat root growth-inhibiting rhizobacterium (Pseudomonas sp.). The transposable element $\mathrm{T}_{\mathrm{n}} 5$ was used as a genetic marker for both microorganisms in two separate experiments. The organisms were subjected to transposon mutagenesis using a broad host-range-mobilizable suicide plasmid.

The transposon $\mathrm{TnS}$ conferred levels of kanamycin resistance up to $500 \mu \mathrm{g} / \mathrm{ml}$ (Pseudomonas sp.), which allowed for selection of the bacteria from environmental samples. The presence of $\operatorname{Tn} 5$ DNA in the genome of the model GEMs also allowed the use of $\mathrm{Tn}^{5}$ gene probes to confirm and enumerate the microorganisms in different samples from the microcosms. Two types of root growth-inhibiting Pseudomonas sp. TnS mutants were obtained and used in microcosm studies: those that lacked the ability to inhibit either wheat root growth or the growth of other microorganisms in vitro (tox $x^{-}$) and those which retained these properties (tox ${ }^{+}$).

Intact soil cores for use as microcosms were obtained from the Palouse region of eastern Washington State and the Columbia Basin of south-central Washington State. The GEMs were either inoculated directly onto seeds (A. lipoferum) or mixed with the plow layer of soil (Pseudomonas sp.). GEM colonižation of the rhizosphexe, rhizoplane, and bulk soil was analyzed with respect to depth. Transport of the bacteria through the soil cores with percolating water, and the potential for bacterial transport by insects and earthworms, were anayzed. The concentration of soluble nutrients in microcosm leachates was analyzed to assess any impacts on soil nutrient fluxes caused by introduction of the bacteria. Potential ecological impacts in the form of niche displacement of indigenous thizosphere microorganisms were also measured. 
The studies with the two model GEMs, which had contrasting results, supported the usefulness of this microcosm design for studying fate and transport of a variety of genetically engineered bacteria that are intended for environmental reiease. The A. lipoferum mutants were relatively noncompetitive in the rhizosphere and were not detected in bulk soil, insect gut, or microcosm leachate. In contrast, the Pseudomonas sp. Tn 5 mutants extensively colonized the rhizosphere and rhizoplane and were present in the bulk soil throughout the entire soil core $(60 \mathrm{~cm}$ long). The Tn5 mutants were also detected in earthworms that were introduced into the microcosms. Colonization of the wheat seedling thizoplane by the to ${ }^{+}$mutants was greater than colonization by the tox- mutants, indicating that toxin production by the $P$ seudomonas sp. mutants provided a competitive advantage in the early stages of plant growth. In neither study were significant impacts on nutrient fluxes $(\mathrm{N}, \mathrm{C}, \mathrm{P}, \mathrm{S})$ or indigenous rhizosphere microflora (Rhizobium leguminosarum, nitrifying bacteria, total heterotrophic bacteria, or asymbiotic $\mathrm{N}_{2}$ fixing bacteria) observed from inoculation with the transposon mutants.

The contrast between the colonization and transport of these two microorganisms in intact soil-core microcosms indicates that this microcosm design is useful for testing GEMs to assess their environmental fate and potential ecological effects. Results from this research are being used to help develop guidelines and test protocols that can decrease risks associated with intentional release of GEMs.

This report is organized into three sections with two appendices to provide guidelines and protocols for using intact soil-core microcosms in Biotechnology Risk Assessment. Section 1.0 describes the results of the initial experiment using A. lipoferum $\operatorname{Tn} 5$ mutants as model GEMs. Section 2.0 focuses on nutrient dynamics in the soil cores and the potential for using nutrient efflux as a tool to monitor potential ecological effects from the release of genetically engineered microorganisms. Because of the limited transport and detection of A. lipoferum mutants used in the initial experiment, a second experiment was designed and conducted, using a root colonizing Pseudomonas sp. (Section 3.0) to obtain additional data and modify protocols to refine the utility of this microcosm design for Biotechnology Risk Assessment. This second experiment, although not included in the original proposal, was necessary to complete the principal objective, which was to modify the existing EPA/OPTS protocol (EPA/600/3-85/047) for terrestrial microcosms to allow the evaluation of genetically engineered microorganisms.

Appendix A includes the Standard Operating Procedures that were developed for this project. Appendix B includes the designs for a microcosm containment system (MCS) that was 
included as an option with the original proposal. A microcosm containment system was constructed from the first design presented in this appendix, and the second design reflects the changes deemed necessary after construction and testing of the prototype. 


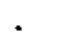

, 


\section{PAPERS AND PRESENTATIONS RESULTING FROM THEPROIECT}

Bentjen, S. A., J. K. Fredrickson, P. Van Voris, and S. W. Li. 1988. Use of intact soil-core microcosm for evaluating the fate and potential ecological effects from the release of Azospirillum lipoferum Tns mutants. In Abstracts of the 88th Annual Meeting, American Society for Microbiology, p. 284, Miami, Florida.

Bentjen, S. A., J. K. Fredrickson, P. Van Voris, and S. W. Li. 1989. Intact soil-core microcosms for evaluating the fate and ecological impacts from the release of genetically engineered microorganisms. Appl. Environ. Microbiol. 55:198-202.

Fredrickson, J. K., P. Van Voris, S. A. Bentjen, and H. Bolton, Jr. 1989. Terrestrial microcosms for evaluating the environmental fate and risks associated with the release of chemicals or genetically engineered microorganisms in the environment. In Hazard Assessment of Chemicals--Current Developments, Vol. 7, ed. J. Saxena. Chemisphere Publishing, Washington, D.C.

Fredrickson, J. K., P. Van Voris, S. A. Bentjen, and M. W. Ligotke. 1987. Terrestrial microcosm to evaluate fate and effects of genetically engineered microorganisms. In Abstracts of the 1987 Annual Meetings, p. 139. Society of Environmental Toxicology and Chemistry, Pensacola, Florida.

Fredrickson, J. K., S. A. Bentjen, H. Bolton, Jr., S. W. Li, and P. Van Voris. 1989. Fate of root growth-inhibiting Pseudomonas Tn5 mutants in intact soil-core microcosms. Submitted for publication.

Fredrickson, J. K., P. Van Voris, S. A. Bentjen, S. W. Li, and R. J. Seidler. 1988. Assessment of intact soil-core microcosms to evaluate the fate and ecological effects following inoculation with Azospirillum lipoferum transposon mutants. In Abstracts of the First International Conference on the Release of Genetically Engineered Microorganisms, p. 17, Cardiff, Wales, p. 17.

Fredrickson, J. K., H. Bolton, Jr., S. A. Bentjen, K. M. McFadden, S. W. Li, and P. Van Voris. 1989. Nutrient efflux from intact soil-core microcosms for evaluating the impacts of genetically engineered microorganisms on ecosystem processes. Submitted for publication.

Van Voris, P., J. K. Fredrickson, and M. W. Ligotke. 1987. Tertestrial microcosms and containment systems to evaluate ecosystem effects of genetically engineered microorganisms. Seminar presented at the 87th Annual Meeting of the American Society for Microbiology, Atlanta, Georgia. 


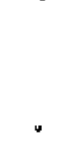




\section{CONTENTS}

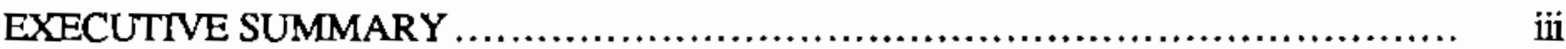

PAPERS AND PRESENTATIONS RESULTING FROM THE PROJECT............... vii

1.0 INTACT SOIL-CORE MICROCOSMS FOR EVALUATING THE FATE OF GENETICALLY ENGINEERED MICROORGANISMS IN THE

ENVIRONMENT.

2.0 NUTRIENT EFFLUX FROM INTACT SOIL-CORE MICROCOSMS FOR EVALUATING THE IMPACTS OF GENETICALLY ENGINEERED MICROORGANISMS ON ECOSYSTEM

3.0 FATE OF ROOT GROWTH-INHIBITING PSEUDOMONAS SP. Tn5 MUTANTS IN INTACT SOIL_CORE MICROCOSMS

APPENDDX A - STANDARD OPERATING PROCEDURES.

APPENDIX B - MICROCOSM CONTAINMENT CHAMBER DESIGN.

B. 1 


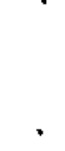




\section{FIGURES}

1.1 Plasmid Gel Electrophoresis (A) and Autoradiogram of Vacuum-Transferred DNA Hybridized with a pGS9 DNA Probe (B) $\ldots \ldots \ldots \ldots \ldots \ldots \ldots \ldots \ldots \ldots \ldots, \quad 1.8$

1.2 Agarose Gel Electrophoresis of Chromosomal Restriction Digests of $A$. lipoferum Tns Mutants (A) and Autoradiogram of Vacuum-Transferred DNA Hybridized with a pGS9 DNA Probe (B)

1.3 Rhizosphere Soil Populations of Nitrosomonas spp. (A) and Nitrobacter spp. (B) in Microcosms Inoculated with $A$. lipoferum Tn5 Mutants or Receiving Heat-Killed Cultures.

3.1 Populations of Pseudomonas sp. Tns Tox+ and Tox-Mutants in the Inoculated Surface Soil of Soil-Core Mictocosms Over time.

3.2 Rhizoplane, Rhizosphere, and Bulk Soil Populations of Pseudomonas sp. Tn5 Tox+ and Tox-Mutants with Depth in the Intact Soil Cores at Day $54 \ldots . .$.

3.3 Populations of Pseudomonas sp. Tns Tox+ and Tox-Mutants in Microcosm Leachate, Bulk, and Rhizosphere Soil and in the Rhizoplane at the Wheat Seedling Stage

3.4 Rhizoplane Populations of Total Bacteria with Depth at Day 54 in Soil-Core Microcosms Inoculated with $\mathrm{Tn} 5$ Mutants and Uninoculated Controls. 



\section{TABLES}

1.1 A. lipoferum Rhizosphere Populations, Plant Biomass, and Leaf Tissue Nitrogen Concentration, Before Plant Grain Fill ............................ $\quad 1.10$

1.2 A. lipoferum and Rhizobium leguminosarum Rhizosphere Populations and Plant Biomass After Plant Grain Fill.

2.1 Selected Properties of Soil Types Used as Intact Soil-Core Microcosms .......... 2.4

2.2 Leachate Analyses from First Sampling................................. 2.7

2.3 Leachate Analyses from Second Sampling................................... 2.8

2.4 Nutrient Concentration in Leaf Tissue of Maize and Spring Wheat at 33

Days 



\title{
1.0 INTACT SOIL-CORE MICROCOSMS FOR EVALUATING THE FATEOF GENEIICALLY ENGINEERED MICROORGANISMS DN THE ENVIRONMENT**
}

\section{S. A. Bentjen}

Department of Bacteriology and Biochemistry, University of Idaho, Moscow, Idaho

J. K. Fredrickson, P. Van Voris, and S. W. Li

Pacific Northwest Laboratory, Richland, Washington

\section{CONTENTS}

\author{
SUMMARY \\ INTRODUCTION \\ MATERIALS AND METHODS \\ Bacterial Cultures \\ Culture Media and Mainlenance \\ Bacterial Matings \\ Confumation and Characierization of TnS Insertion \\ Microcosms and Inoculation \\ Insects \\ Sampling Frequency and Methods \\ Enumeration of Azospirillum TnS Mutants \\ Soil Recovery \\ RESULTS \\ DISCUSSION \\ LITERATURE CITED
}

\section{SUMMARY}

Intact soil-core microcosms were studied to determine their applicability for evaluating the transport, survival, and potential ecosystem effects of genetically engineered microorganisms before they are released into the environment. Microcosms were planted with wheat and maize seeds and inoculated with Azospirillum lipoferum SpBr17 and SpRG20a TnS mutants, respectively. Heat-killed cells served as controls. Above-ground plant biomass and leaf tissue nitrogen were measured to determine inoculation effects on plant growth. Microcosm leachate, rhizosphere soil, plant endorhizosphere, and xylem exudate were sampled for $A$. lipoferum $\operatorname{Tn} 5$

\footnotetext{
*Portions of this work were previously published in Applied and Environmental Microbiology, 55:198-202.
} 
populations. Aphids and European corn borers were evaluated as potential vectors for A. lipoferum $\operatorname{Tn} 5$ dissemination. Whole pGS9 DNA probe hybridized to non-Azospirillum colonies in leachate, necessitating the use of a more specific DNA probe constructed from the nptII region of TnS. Azospirillum lipoferum TnS mutant populations, determined by most-probablenumber DNA hybridization, varied from undetectable to $10^{5}$ per gram of dry root in the rhizosphere, with smaller populations detected in the endorhizosphere. Maize plants with established $A$. lipoferum $\mathrm{Tn}$ S populations had higher nitrogen concentrations, but plant yield was unaffected. Rhizosphere populations of nitrifying bacteria (104 to $10^{5} / \mathrm{g}$ dry soil) and Rhizobium ( $10^{2}$ to $10^{4} / \mathrm{g}$ dry soil) were unaffected by inoculation with $A$. lipoferum $T n s$ mutants. These results indicate that microcosms maintain a high degree of ecosystem complexity and can serve as a representative model system to examine transmission through the ecosystem, rhizosphere and endorhizosphere colonization, potential displacement of other rhizosphere microorganisms, and effects on plant growth by genetically engineered microorganisms.

\section{INTRODUCTION}

Methods are needed to evaluate genetically engineered microorganisms (GEMs) in representative ecosystems to assess their fate and potential effects before they are released into the environment. Laboratory-contained microcosms that are composed of intact soil cores have potential as tools for risk assessment before field testing. Current philosophy in regard to the release of GEMs into the environment is that each organism should be regulated on the basis of the risk posed by that individual organism, rather than by how that organism was altered (27).

A standard test system must be adaptable to evaluate the release of a wide variety of microorganisms as well as detect possible detrimental effects on the ecosystem. Microcosms serve these purposes and can also be used to determine the efficacy of GEMs in a field-like sinuation without regulatory constraints. Intact soil-core microcosms have been used to study ecosystem stability (44), nutrient cycling (45), and the effect of utility wastes or other toxic substances on ecological processes $(43,13,42)$. Microcosms have also facilitated the study of microorganism and pollutant interaction in aquatic (31) and sediment ecosystems (14). Chemical substances are dispersed, diluted, or degraded following their introduction into the ecosystem, but microorganisms can reproduce and increase in concentration under favorable conditions. Therefore, microorganisms have the potential to spread and colonize habitats that may be unique to each genotype. 
Azospirillum lipoferum, a motile, diazotrophic root-colonizing bacterium that has been shown to increase plant biomass and nitrogen uptake when inoculated onto wheat (21) and maize $(15,28)$, was chosen as the test bacteria for this study. Azospirillum spp. are widely distributed in soils and can form asymbiotic associations with plant toots (32). The effects of Azospirillum inoculation on root development and function, which are variable, have been recently reviewed (29). The strains used in this study colonize the rhizosphere, endorhizosphere, and xylem of maize (24) and wheat (22).

Azospirillum Tn5 mutants were selected to enhance their detection and enumeration in the microcosms. The presence of $\mathrm{Tn}^{5}$ in the bacterial genome confers kanamycin resistance (18), which can be used as a selective marker and also as a unique DNA sequence to positively identify mutants by DNA hybridization with a $\mathrm{Tn} 5$-specific probe (11). In addition, $\mathrm{Tn} 5$ mutants have been shown to have a competitive advantage over their parent wild type, even in the absence of any apparent selective pressure (4).

Transposon mutants can serve effectively in studies to evaluate environmental fate and effects from the release of GEMs because they have been widely used as cloning vectors $(23,3)$, for mutagenesis studies of bacterial symbiosis with plants (36), for plant pathogen interactions $(7,9)$, and for deternining bacterial survival in soil (40). Moreover, transposon mutants of Pseudomonas syringae have potential use as biocontrol agents against Dutch elm disease (33). This study was initiated to determine the applicability of intact soil-core microcosms for evaluating transport of microorganisms through the ecosystem, their colonization of the rhizosphere and endorhizosphere, displacement of other indigenous rhizosphere microorganisms, and effects on plant growth.

\section{MATERIALS AND METHODS}

\section{Bacterial Cultures}

Escherichia coli MV12 containing the suicide plasmid pGS9 (11) was used as the $\mathrm{Tn} 5$ donor in matings. Azospirillum lipoferum strains SPRG20a [20a] and SpBr17 [17], ATCC 29708 and 29709, were purchased from the American Type Culture Collection, Rockville, Maryland. 


\section{Culture Media and Maintenance}

Luria-Bertani (LB) broth (25), containing 25 ppm each kanamycin sulfate (Sigma Chemical Co., St. Louis, Missouri) and chloramphenicol (Sigma), was used for maintenance of $E$. coli MV12. Nitrogen-free Azospirillum medium was used as the basal medium (1). Azospirillum cultures were maintained on Azospirillum medium (AM), which consisted of nitrogen-free Azospirillum medium amended with $1.0 \mathrm{~g} \mathrm{NH} 2 \mathrm{Cl}$ and $1.0 \mathrm{~g}$ yeast extract (Difco, Detroit, Michigan) per liter. Azospirillum $\mathrm{TnS}$ mutants were routinely cultured on AM amended with 25 ppm kanamycin $(\mathrm{Km})$ sulfate. Stock cultures of all bacteria were maintained at $-80^{\circ} \mathrm{C}$ in $50 \%$ glycerol.

\section{Bacterial Matings}

Log-phase A. lipoferum cultures were centrifuged; cells were washed in $0.85 \%$ sterile saline and resuspended in sterile saline to obtain approximately $10^{9} \mathrm{cell} / \mathrm{ml}$. For matings, $0.1 \mathrm{ml}$ E. coli MV12 donor and $0.4 \mathrm{ml} \mathrm{A}$. lipoferum 20a or $A$. lipoferum 17 recipients were mixed, then transferred onto a 47 -mm-diameter, 0.01- $\mu \mathrm{m}$ filter (Sartorious, Gottingen, F.R.G.) on 1.5\% Luria-Bertani agar. After mating, cells were suspended in 0.5 -ml sterile saline and spread onto $150 \times 15 \mathrm{~mm}$ plates of AM containing $25 \mathrm{ppm} \mathrm{Km}$ to select for transconjugates.

\section{Confirmation and Characterization of Tn 5 Insertion}

Putative Azospirillum $\mathrm{TnS}$ transconjugates were confirmed by spot-blotting an equal number of cells onto GeneScreen Plus (New England Nuclear Corp., Boston, Massachusetrs) and hybridizing them with whole pGS9 ${ }^{32} \mathrm{P}$ probe. Plasmid DNA was labeled with ${ }^{32} \mathrm{P}-\mathrm{dCTP}$ (New England Nuclear Corp.) using a nick translation kit (Bethesda Research Laboratories, Inc., Gaithersburg, Maryland). Plasmid gel electrophoresis was done by the procedure of Kado and Liu (19). Isolation of chromosomal DNA and restriction digests with EcoRI and HindmI (Intemational Biotechnologies Incorporated, New Haven, Connecticut) were achieved as described by Sadowsky (35). Transfer of restricted DNA onto GeneScreen Plus was by vacuum blot (American Bionetics, Emeryville, California) by the manufacturer's protocol.

Microcosms and Inoculation

Intact soil cores for use as microcosms were obtained as described by Van Voris (42) using a steel coring apparatus containing polyethylene pipe (Phillips Petroleum Co., Dallas, Texas). The 
intact soil cores, held inside the plastic pipe after removal from the driving tube, were placed in a housing on Buchner funnels [24-cm polypropylene (Dyna Lab, Rochester, New York) or 20-cm porcelain (Coors, Golden, Colorado)]. Two soil-plant combinations common to agricultural regions of eastem Washington were used. Cores $(17.8 \times 60 \mathrm{~cm})$ of Palouse silt-loam soil (finesilty, mixed, mesic Pachic Ultic Haploxeroll) from the Palouse region were planted with spring wheat (Triticum aestivum); cores $(25 \times 60 \mathrm{~cm}$ ) of Burbank sandy loam soil (sandy, skeletal, mixed, xeric Torriorthent) common to the Columbia Basin were planted with maize (Zea mays). Common local seed varieties [NC+3390 maize (Wilbur-Elis Seed Co., Pasco, Washington)] and Edwall spring wheat (USDA Research Station, Pullman, Washington)] were used.

Tns mutant cultures were washed in $0.85 \%$ sterile saline and suspended in sterile deionized water to obtain a density of $9 \times 10^{8}$ and $4 \times 10^{8} \mathrm{CFU} / \mathrm{ml}$ for $A$. lipoferum 17 or $20 \mathrm{a}$, respectively. Burbank soil microcosms were planted with four maize seeds per microcosm, each seed receiving $1.0 \mathrm{ml}$ of an equal mixture of three $A$. lipoferum $17 \mathrm{Tn} 5$ mutants. Palouse microcosms were planted with five seeds per microcosm with each seed receiving $1.0 \mathrm{ml}$ of a single $A$. lipoferum 20a TnS mutant. Heat-killed suspensions of the same cells served as controls. There were six replicates for each treatment in a completely randomized design, and one-way analysis of variance tables were calculated to determine if statistically significant differences $(p \leq .05)$ existed between measured parameters in inoculated versus control microcosms. Microcosms were maintained at a water potential of approximately $-0.03 \mathrm{MPa}$ and temperature of $22^{\circ} \mathrm{C}$, as monitored by soil temperature and moisture probes on line to a datalogger (21x, Campbell Scientific Co., Logan, Utah). Photoperiod was set for $12 \mathrm{~h}$ with initial light intensity at the soil surface 400 microeinsteins $/ \mathrm{m}^{2}$ (4100 K Ultralume Lamps, Phillips Lighting Corp., Bloomfield, New Jersey).

\section{Insects}

Insects were introduced onto plants after the first sampling. Ten European corn borers (Ostrinia nubialis) (French Agricultural Research Service, Lamberton, Minnesota), at the third to fourth instar, were placed on individual maize plants, and were confined to the lower stalk by loosely wrapping with chiffon. Approximately 50 to 100 aphids (Schizaphis sp.) indigenous to eastern Washington State were introduced onto wheat plants. After 12 and 21 days for com borers and aphids, respectively, insects were sampled, macerated in sterile deionized water, and assayed for $A$. lipoferum $\mathrm{Tn}_{\mathrm{S}}$ mutants. Approximately 25 aphids were removed from the wheat leaf surface, and 4 to 9 com borers were removed from the maize stem interior. 
Sampling Frequency and Methods

Three replicate microcosms from each treatment were sacrificed at 4 and 9 weeks to determine bacterial concentration and movement. Soil cores were removed from the pipe intact, and root samples with adhering soil were taken randomly throughout the core with care to avoid sampling those growing at the interface between the core and the pipe. Standard methods were used for sampling thizosphere soil (47). Rhizobium leguminosarum rhizosphere populations were enumerated by the most-probable-number (MPN) plant infectivity method of Weaver and Frederick (46) using peas (Pisum sativum) as the host plant. Nitrifying bacteria in the rhizosphere were enumerated by the MPN microtechnique of Rowe et al. (34). Endorhizosphere analysis for Tr5 mutants (30) was accomplished by placing washed wheat and maize root sections in $1.0 \%$ chloramine $\mathrm{T}$ (Sigma) for 15 and $60 \mathrm{~min}$, respectively, followed by a 30 -min wash in sterile 0.1 $M, \mathrm{pH} 7.0$ phosphate buffer. Roots were then rinsed three times with sterile deionized water, macerated, and evaluated for the presence of $A$. lipoferum $\operatorname{Tn} 5$ mutants.

Xylem exudate was collected after cutting plants $5 \mathrm{~cm}$ from the base of the stem with sterile scissors and letting fluid collect on the stem surface for several minutes; the fluid was then removed with a sterile piperte tip and spread-plated immediasely. Leachate was collected in sterile, acid-washed, deionized water-rinsed, 2-liter Erlenmeyer flasks after saturating the cores with deionized water. Leachate was placed at $4^{\circ} \mathrm{C}$ within $12 \mathrm{~h}$ of breakthrough and entry into the flasks. Plant sampling for top biomass was conducted according to standard methods (17). Leaf nitrogen concentration was determined by Kjeldahl analysis (5) before maize tasseling and wheat booting.

\section{Enumeration of Azospirillum Tns Mutants}

Rhizosphere, endorhizosphere, xylem exudate, insects, and leachate samples were analyzed for the presence and population of Azospirillum Tn5 mutants. Colony blots (12) as well as MPN-DNA hybridization (11) were used for enumeration. All blots were then hybridized with 32p-labeled probe and autoradiographed for enumeration. Because whole pGS9 probe proved nonspecific, a 30-base-pair sequence in the nptII region of $\mathrm{Tn} 5$ was used as a probe. The nptII probe was synthesized (Model 380A, Applied Biosystems, Foster City, Califomia) and purified by polyacrylamide gel electrophoresis with $15 \%$ polyacrylamide and $7 M$ urea according to the manufacturer's protocol. Kinase end-labeling (25) with [32P]ATP (New England Nuclear) routinely achieved $10^{8} \mathrm{dpm} / \mu \mathrm{g}$ DNA. 


\section{Soil Recovery}

To determine the optimal medium for enumeration of $A$. lipoferum $\mathrm{Tn} 5$ cells in soil, Azospirillum Tns cultures were washed and spiked into Palouse soil at $10^{3}$ and $10^{5} \mathrm{cells} / \mathrm{g}$ soil. Soils were incubated at $4^{\circ} \mathrm{C}$ for $1 \mathrm{~h}$. A. lipoferum $\mathrm{Tn} 5$ cells were enumerated by plate count colony blot and MPN-DNA hybridization, as described previously, using nitrogen-free Azospirillum medium and AM amended with 150 and $200 \mathrm{ppm} \mathrm{Km}$ and cycloheximide (Sigma).

\section{RESULTS}

Azospirillum $\operatorname{Tn} 5$ transconjugates were obtained at a frequency of approximately $10^{-9}$. All Tn5 mutants were stable after 50 generations of growth in AM broth without $\mathrm{Km}$ (data not shown). Both A. lipoferum 20a and 17 wild-type strains harbor two plasmids (Figure 1.1A). The A. lipoferum Tn5 mutants chosen for this study harbored only the two indigenous plasmids, ensuring that pGS9 was not present as an extrachromosomal element (Figure 1.1A). Two of the mutants [20a-2 and 17-6], however, maintained $\mathrm{Tn} 5$ in the smaller of the two indigenous plasmids (Figure 1.1B). These plasmids may be present in multiple copies and can be mechanically broken when subjected to the detection protocol used (19). Whole chromosomal DNA restriction digests (Figure 1.2) with EcoRI and $H$ indIII, which give 0 and 2 cuts in Tn5, respectively (18), demonstrated that each mutant had a single copy of TnS inserted uniquely in the genome (Figure 1.2). The one exception was mutant 17-6, which possessed pGS9 vector sequences, as demonstrated by the increase in the total number of HindIII-generated fragments hybridizing to pGS9, three of which correspond to the same size as HindIII-generated fragments of pGS9.

The optimal medium for the recovery of Azospirillum $\operatorname{Tn} 5$ mutants when spiked into Palouse soil was AM containing $150 \mathrm{ppm} \mathrm{Km}$ and $200 \mathrm{ppm}$ cycloheximide. Higher concentrations of antibiotics inhibited the Tn5 mutants. When $150 \mathrm{ppm}$ streptomycin was added in addition to $150 \mathrm{ppm} \mathrm{Km}$, growth of the mutants was also inhibited; therefore, streptomycin was not used as an additional selective marker for the Tns mutants. The use of nitrogen-free medium selected against nonnitrogen fixers but also limited the growth of Azospirillum and therefore the amount of DNA available for hybridization when compared to $\mathrm{AM}$, which provided nitrogen and yeast extract. All Tn5 mutants used in this study were able to grow on nitrogen-free medium, indicating that nitrogen fixation functions were not affected by the transposon insertion. As many as $3.0 \%$ of the Azospirillum Tn5 mutants spiked into soil were enumerated by colony blots; the limit of detection was approximately $10^{3} \mathrm{CFU} / \mathrm{g}$ dry soil. Although not evident in the initial soil recovery 


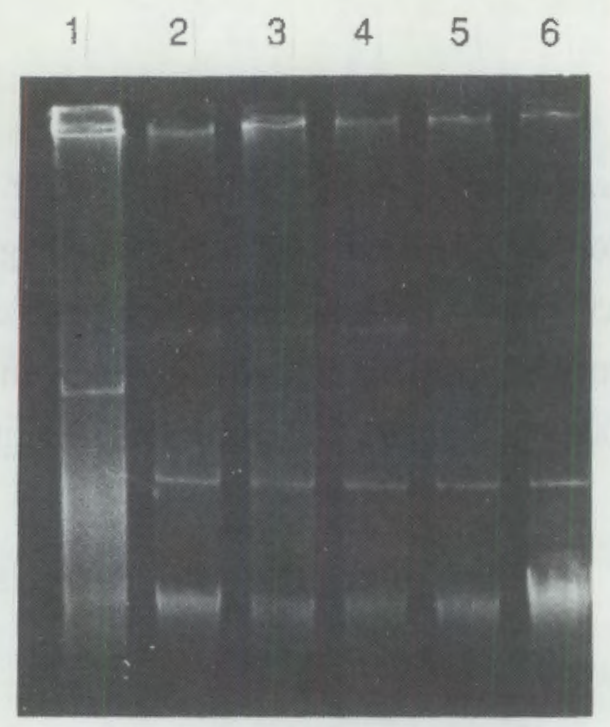

(A)

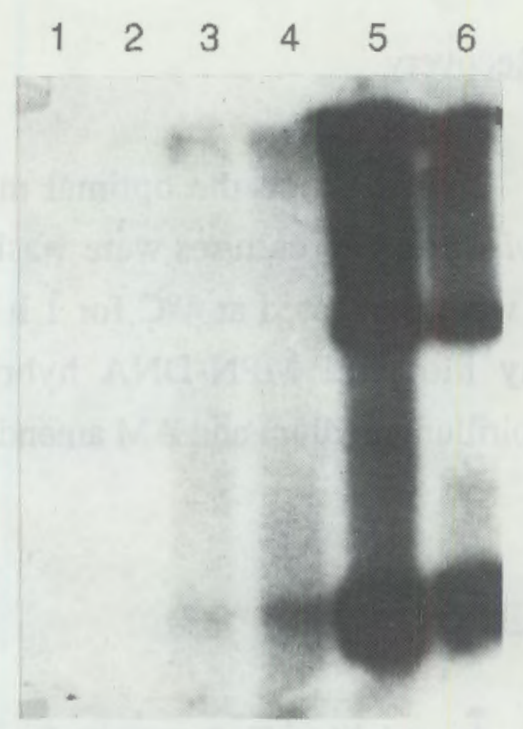

(B)

Figure 1.1. Plasmid Gel Electrophoresis (A) and Autoradiogram of Vacuum-Transferred DNA Hybridized with a pGS9 DNA Probe (B). Lanes contain: Pseudomonas putida mt-2 with the TOL plasmid (117 Kb) as a size reference (1); A. lipoferum 17 wild type (2); and Tn5 mutants 17-1 (3); $17-3(4) ; 17-6(5)$; and 20a-2 (6).

experiment, leachate from microcosms receiving heat-killed cells contained bacteria other than Azospirillum that were homologous to pGS9. To determine if the homology resulted from $\operatorname{Tn} 5$ sequences in indigenous soil bacteria or from vector sequences, a 30-base-pair sequence in the nptII region of $\mathrm{Tn} 5$ was used as a probe. Isolated bacteria homologous to the probe when spotblotted and hybridized with pCU101 (pGS9 without the Tn5 DNA sequence) gave a strong hybridization signal, while a duplicate blot did not hybridize with the 30 -mer nptII probe, indicating homology was with vector sequences (data not shown).

Rhizosphere populations of the Azospirillum $\mathrm{Tn} 5$ mutants in the inoculated microcosms were variable, ranging from undetectable to $10^{5} / \mathrm{g}$ dry weight (Table 1.1). Endorhizosphere populations as determined by MPN-DNA blots at midpoint sampling were below the detection limit for wheat roots, ranging from $5.5 \times 10^{3}$ to $6.5 \times 10^{3} \mathrm{CFU} / \mathrm{g}$ dry maize root in the Burbank soil microcosms. Populations determined by plate count and MPN manifold blot were generally in agreement, although the latter gave more consistent and slightly higher (typically $50 \%$ ) values. The background of bacteria with the ability to grow on AM amended with antibiotics ranged from nearly none (on insect samples) to $106 / \mathrm{g}$ soil in the Palouse rhizosphere; thus, the detection limit of mutant populations in rhizosphere samples was lower. No Azospirillum $\mathrm{Tn} 5$ mutants were detected in leachate, xylem exudate, insects, or earthworms found fortuitously during microcosm sampling. 



Figure 1.2. Agarose Gel Electrophoresis of Chromosomal Restriction Digests of A. lipoferum Tn5 Mutants (A) and Autoradiogram of Vacuum-Transferred DNA Hybridized with a pGS9 DNA Probe (B). Lanes 1 through 5 contain HindIII restriction digests of Tn5 mutants 17-1 (1); 17-3 (2); 17-6 (3); 20a-2 (4); and A. lipoferum 17 wild type (5). Lanes 6 through 10 contain EcoRI restriction digests of $\mathrm{Tn} 5$ mutants $17-1$ (6); 17-3 (7); 17-6 (8); 20a-2 (9); and A. lipoferum 17 wild type (10).

The mean plant leaf tissue nitrogen concentration (Table 1.1) was higher for the inoculated maize plants than for the controls. This difference was not statistically significant, although there was a relationship between the presence of Azospirillum and tissue nitrogen concentration in the replications (Table 1.1). Available nitrogen, as reflected in the nitrate concentration in the initial leachate from control microcosms, was significantly higher $(p \leq .05)$ for Palouse soil $(x=287$ $\mathrm{ppm})$ than for the Burbank soil $(\mathrm{x}=130 \mathrm{ppm})$. There was no significant difference in the number 
Table 1.1. A. lipoferum Rhizosphere Populations, Plant Biomass, and Leaf Tissue Nitrogen Concentration, Before Plant Grain Fill

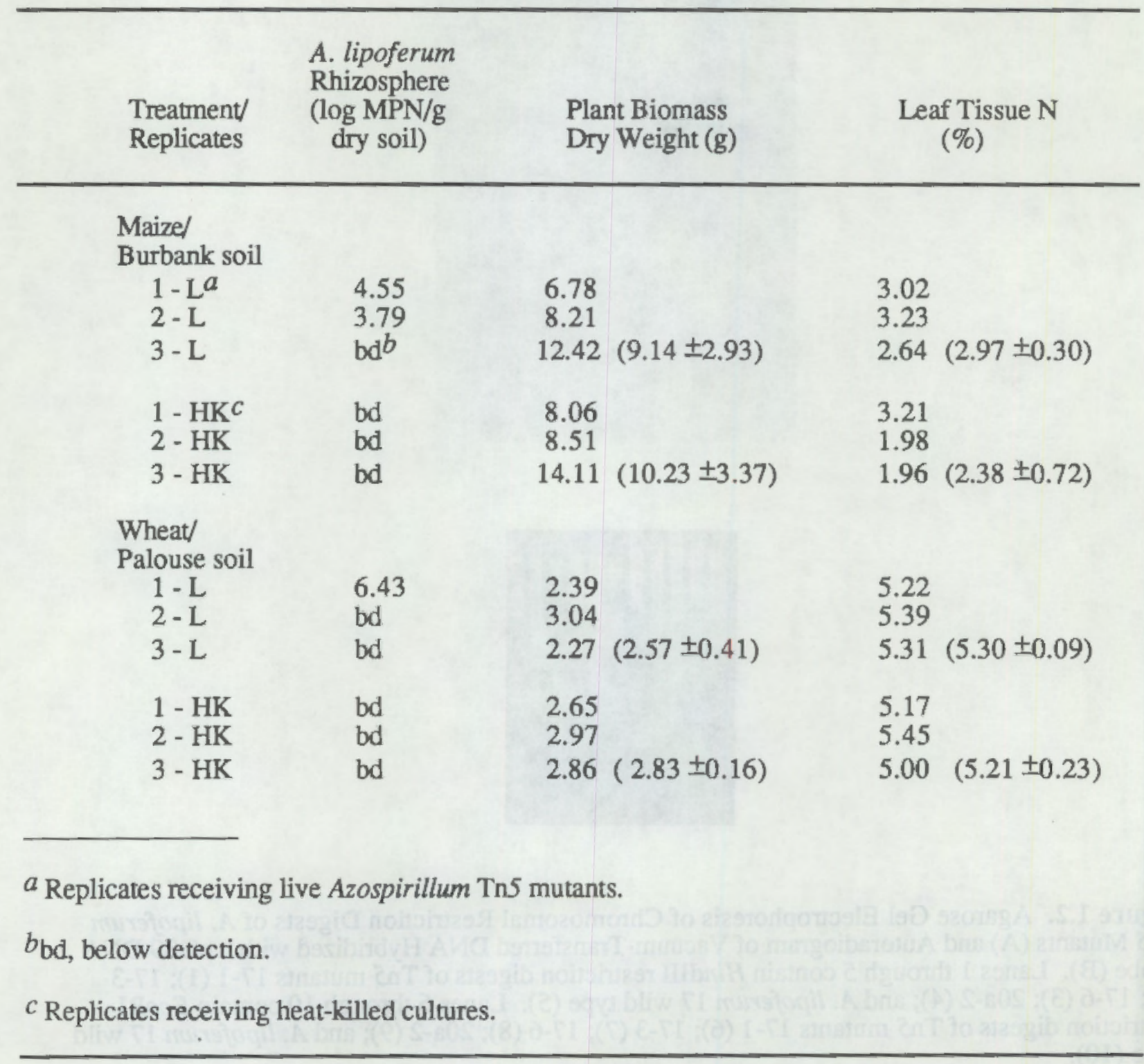

of tillers per wheat plant in the inoculated microcosms (1.32) versus control microcosms (1.29), or between plant top biomass of maize or wheat at either sample point (Tables 1.1 and 1.2). Although plant top biomass means of wheat in control and inoculated microcosms were not significantly different, a decrease in top biomass of maize plants with established rhizosphere Azospirillum populations was observed as each of the individual replications with measurable Azospirillum populations had lower plant biomass (Tables 1.1 and 1.2). 
Table 1.2. A. lipoferum and Rhizobium leguminosarum Rhizosphere Populations and Plant Biomass After Plant Grain Fill

$\begin{array}{lllr} & \text { A. lipoferum } & & \\ & \text { Rhizosphere } & & \text { Rhizobium } \\ \text { Population } & \text { Plant Biomass } & \text { Rhizosphere } \\ \text { Treatment/ } & \text { (log MPN/g } & \text { Population } \\ \text { Replicates } & \text { dry soil) } & \text { Dry Weight }(\mathrm{g}) & \text { Po }\end{array}$

Maize/

Burbank soil

$4-\mathrm{L}^{a}$

$5-\mathrm{L}$

3.78

$6-\mathrm{L}$

bd $b$

4.23

47.4

64

$47.9(53.1 \pm 9.4)$

$4-\mathrm{HK}^{c}$

bd

5 - HK

bd

73.1

57.4

bd

$59.4(63.3 \pm 8.6)$

$-$

$-$

$-$

6 - HK

d

Wheat/

Palouse soil

4- $\mathrm{L}^{a}$

$5-\mathrm{L}$

4.40

3.75

20.3

2.58

6-L

bd

18.5

3.23

$13.4(17.4 \pm 3.6)$

$2.42(2.74 \pm 0.43)$

4. $\mathrm{HK}^{\mathrm{C}}$

bd

15.6

5 - HK

bd

20.5

bd

$14.7(16.9 \pm 3.1)$

3.31

2.84

$4.30(3.48 \pm 0.75)$

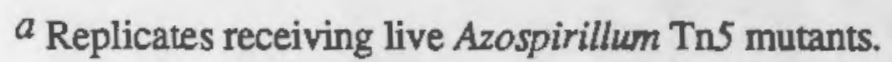

$b$ bd, below detection.

$c$ Replicates receiving heat-killed cultures.

Rhizobium leguminosarum populations were present in the wheat rhizosphere of the Palouse soil microcosms, but were not influenced by inoculation with the A. lipoferum 17 Tn 5 mutant (Table 1.2). Rhizosphere populations of Nitrosomonas spp. were similar for all treatments, while Nitrobacter spp. populations were consistently higher in wheat rhizosphere than in the maize rhizosphere (Figure 1.3). Neither Nitrosomonas spp. nor Nitrobacter spp. rhizosphere populations were influenced by A. lipoferum inoculation in either the Palouse or Burbank soil microcosms (Figure 1.3). 

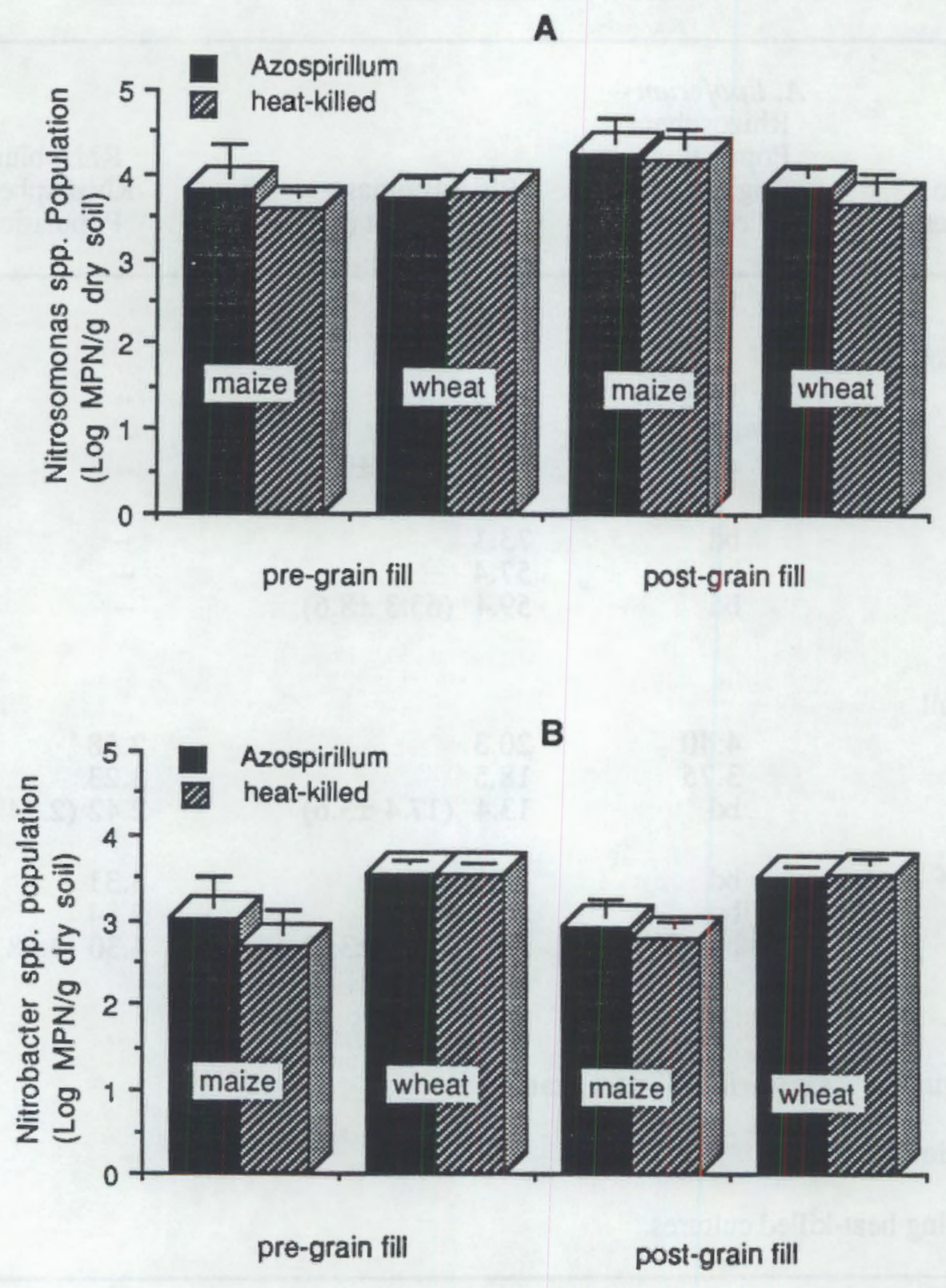

Figure 1.3. Rhizosphere Soil Populations of Nitrosomonas spp. (A) and Nitrobacter spp. (B) in Microcosms Inoculated with A. lipoferum Tn 5 Mutants or Receiving Heat-Killed Cultures. Error bars represent $5 \%$ confidence intervals. 


\section{DISCUSSION}

The frequency of $\mathrm{Tn} S$ insertions $\left(10^{-9}\right)$ into the $A$. lipoferum strains, although low in comparison with other gram-negative bacteria (37), are similar to those previously observed for Azospirillum (41). Media and antibiotic concentrations used were not completely selective, allowing growth of Azospirillum but not suppressing growth of all indigenous soil microorganisms. This limited the detection of A. lipoferum $\mathrm{Tn}$ s mutants in soil to approximately $10^{3} / \mathrm{g}$ soil.

Xylem exudate and insects had low background populations of kanamycin-resistant ( $\left.\mathrm{Km}^{\mathrm{I}}\right)$ bacteria, as did Burbank microcosm leachate samples; hence, the TnS mutants, if present and culturable, would have been readily detected by colony hybridization or MPN-DNA hybridization. Because of a high background of $\mathrm{Km}^{\mathrm{I}}$ bacteria in Palouse soil able to grow on $\mathrm{AM}$, the relatively slow growing $A$. lipoferum population may have been outcompeted, limiting its detection in the rhizosphere populations to approximately $10^{3} \mathrm{CFU} / \mathrm{g}$ dry soil. Endorhizosphere samples and insect macerates from the maize plants contained a fungus that grew on AM agar with $200 \mathrm{ppm}$ of cycloheximide. This fungal growth may have masked $\mathrm{T} \Omega$ mutant populations in those samples.

MPN-DNA hybridization was more effective for enumerating A. lipoferum $\operatorname{Tn} 5$ bacteria when high background levels of $\mathrm{Km}^{\mathrm{T}}$ bacteria were present. In some samples, positive signals were obtained at low dilutions in microdilution plate blots while no positive colonies were detected on colony blots of dilution plates of the same samples. Presumably, the static broth provided Azospirillum more favorable conditions for growth and competition with other $\mathrm{Km}^{\mathrm{T}}$ bacteria. Azospirillum seemed to be especially overgrown by the indigenous $\mathrm{Km} r$ bacteria on solid media. Typically, the indigenous $\mathrm{Km}^{\mathrm{r}}$ bacteria would appear after 2 days of incubation at $27^{\circ} \mathrm{C}$ where a minimum of 3 days was required for Azospirillum colonies. Additionally, not all colonies blotted efficiently, requiring their purification and isolation before hybridization with $\mathrm{Tn} S$ probe for confirmation.

The nptII probe was used because preliminary studies with whole pGS9 probe showed a high background of indigenous bacteria with homology to the suicide vector. Studies with Pseudomonas putida TnS mutants added to dried and remoistened Palouse soil enumerated by MPN-DNA hybridization did not reveal homology of indigenous bacteria with whole pGS9 probe (11). In that study, either homologous bacteria were not able to grow on the media used for $P$. putida TnS selection, or the bacteria were not present because of air-drying of soil. Probe 
specificity and preliminary studies with appropriate controls are essential before usage for enumeration of specific bacterial populations in environmental samples.

Although Azospirillum rhizosphere populations were not uniform among replicate microcosms, a pattem was evident. Of the three replicate Palouse and Burbank microcosms receiving live inoculum at each sampling, two microcosms had detectable rhizosphere populations of $A$. lipoferum $\operatorname{Tn} 5$, while populations were below detection levels in one microcosm.

Variability of Azospirillum Tn5 rhizosphere populations between replicates probably resulted from inherent differences in the microcosms. Intact soil cores, because they are removed as discrete pieces from the field, contain inherent variation that represents the complexity of that ecosystem. Examples of macroscopic differences observed in some microcosms and not others include visible layers of Mt. St Helens ash from the 1980 enuption, the emergence of mushrooms, and the presence of earthworms. Microscopic differences could include variable distribution of indigenous soil bacteria (e.g., antibiosis) and distribution of nutrients.

The potential for niche displacement of rhizosphere populations of nitrifying bacteria and Rhizobium in the microcosms was also evaluated because of their involvement in biochemical nitrogen cycling and the ability of Rhizobium sp. to be stimulated in the rhizosphere of nonhost plants. These bacteria occupy the same physical medium (rhizosphere and bulk soil) so that any antibiosis or other deleterious effect on indigenous microbial populations from inoculation of Azospirillum Tn5 mutants would likely be evident on those species. Although changes in the rhizosphere populations of nitrifying bacteria and Rhizobium leguminosarwm were not observed in the inoculated microcosms, their consistent presence and low variability between replicates make them good indicators of ecosystem stability.

Plant growth effects from inoculation with Azospirillum have been attributed to $\mathrm{N}_{2}$ fixation (26), production of plant growth homones (39), and increased nutrient uptake at the roots (26). The expression of these traits and limited root colonization likely contribute to the variability in plant growth response common to Azospirillum studies. This suggests that the extent of Azospirillum root colonization may be the main factor controlling plant growth response.

Edaphic factors have been shown by others to strongly influence Azospirillum interaction with plants. Azospirillum inoculation of wheat in soils high in nitrogen or with high levels of nitrogen applied as a fertilizer have shown decreased effect on plant dry weight $(20,21)$ and nitrogen incorporation into plant tissue (2) in comparison with those grown under low nitrogen 
conditions. Maize grown in Burbank soil, low in nitrogen relative to Palouse soil, showed a greater response to inoculation as indicated by an increase in plant leaf nitrogen in those replicates with detectable Azospirillum Tn5 mutants (Table 1.1), although top dry weight was not affected. However, O'Hara et al. (28) tested seven nonindigenous strains of A. brasilense under greenhouse conditions and found that none extensively colonized the endorhizosphere and that yields were relatively constant, regardless of population size and location on roots.

Bacterial strain plant specificity must also be considered when examining the growth response of Azospirillum-inoculated plants. Soil and plant combinations used in this study may not have been conducive to expression of those bacterial genes that promote plant growth, such as $\mathrm{N}_{2}$ fixation (8), or production of plant growth factors $(39,16)$, by the specific Azospirillum strains used. As with wheat, plant genotype-Azospirillum interactions have been shown to be strain specific for maize (15).

Effects on plant growth (10) as well as on ecosystem processes (13) are likely to be dependent on the size of the microbial population. The inoculum concentration in this study was relatively small $\left(10^{8}-10^{9} \mathrm{CFU} / \mathrm{seed}\right)$ in comparison with most other studies. An optimum Azospirillum inoculation concentration has been shown for maize that was 10 fold less than the competing Pseudomonas population (10). Increasing the concentration of Azospirillum past the optimum population can offset beneficial effects to the plant.

In field plot experiments spanning 3 years, significant increases in wheat grain yield between treatments were not found even though there were increases as great as $31 \%$ in individual plots (2). This observed field variability is consistent with the variability in root colonization and plant growth effects observed in the microcosms, indicating that the intact cores have retained some degree of field complexity.

Undisturbed soil samples have been shown to allow some bacterial passage through the macropores (38), suggesting the potential for microbial leaching and subsequent transport in groundwater. The close association and adhering of Azospirillum with roots and low levels of inoculum likely limited their leaching through the soil cores in this study. A. lipoferum strains were chosen for their reported xylem mobility $(24,22)$; hence, there was a potential for tansmission from the plant vascular system to phytophagous insect vectors. In the specific Azospirillum soil-plant combination used in this study, extensive bacterial movement and colonization was not observed. Although the possibility exists that mutations incurred by the insertion of $\mathrm{Tn} S$ influenced the competitive ability of the bacteria, and therefore xylem mobility, it 
is more likely that the migration of Azospirillum mutants into the xylem is uncommon and occurs only under specific conditions. Transposon insertions have been shown to impair the relative competitiveness of Rhizobium (6) and, therefore, could have had a negative impact on the competitive ability of the A. lipoferum mutants used in this study. However, this is less likely for Palouse soil-core microcosms because a mixture of three different mutants was used for inoculation. Additionally, Tns mutant bacteria have been provided a selective advantage in comparison with the wild type (4).

We have demonstrated that intact soil-core microcosms maintain many of the features useful for evaluating GEM transmission through the ecosystem, rhizosphere and endorhizosphere colonization, potential displacement of other rhizosphere microorganisms, and effects on plant growth. This is illustrated by the detection problems realized during hybridization of pGS9 to indigenous $\mathrm{Km}^{\mathrm{I}}$ bacteria, whereas no such problem was encountered when using dried stock soil for preliminary recovery studies. This phenomenon is indicative of the higher order of ecosystem complexity maintained by use of intact soil-core microcosms (44). Other aspects of environmental release not evaluated in this study that may be evaluated using soil-core microcosms include GEM persistence and gene transfer. A major advantage of microcosms for GEM evaluation is their easy replication, necessary to determine the probability of finding a given effect or population for risk assessment. The use of intact soil cores allows the testing and comparison of GEM fate and effects in a number of different soil types, including those at the site intended for field testing.

\section{LITERATURE CITED}

1. ATCC. 1984. ATCC Media Handbook, 1st ed., ed. R. Cote, p. 42. American Type Culture Collection, Rockville, Maryland.

2. Baldani, V. L. D., J. I. Baldani, and J. Dobereiner. 1987. Inoculation of field-grown wheat (Triticum aestivum) with Azospirillum spp. in Brazil. Biol. Fertil. Soils 4:37-40.

3. Barry, G. 1986. Permanent insertion of foreign genes into the chromosomes of soil bacteria. BiofTechnology 4:446-449.

4. Biel, S. W., and D. L. Hartl. 1983. Evolution of transposons: Natural selection for Tn5 in Escherichia coli K12. Genetics 103:581-592.

5. Bremner, J. M., and C. S. Mulvaney, 1982. In Methods of Soil Analysis, Part 2 Chemical and Microbiological Properties, 2 d ed., eds. A. L. Page, R. H. Miller, and D. R. Keeney, pp. 595-564. American Society of Agronomy, Madison, Wisconsin. 
6. Brockman, F. J. 1987. Application of Plasmid Profile Analysis and Transposon Markers for Studying the Diversity and Ecology of Rhizobium leguminosarum. M.S. Thesis, Dept. of Agronomy and Soils, Washington State University, Pullman, Washington.

7. Cuppels, D. A. 1986. Generation and characterization of Tns insertion mutations in Pseudomonas syringae pv. tomato. Appl. Environ. Microbiol.51:323-327.

8. Dobereiner, J., and J. M. Day. 1976. Associative symbioses in tropical grasses: characterization of micoorganisms and dinitrogen-fixing sites. In Proceedings of the 1st International Symposium on Nitrogen Fixation, eds. W. E. Newton and C. J. Nyman, pp. 518-537. Washington State University Press, Pullman, Washington.

9. Douglas, C. J., W. Halperin, and E. W. Nester. 1982. Agrobacterium tumefaciens mutants affected in attachment to plant cells. J. Bacteriol. 152:1265-1275.

10. Fallik, E., Y. Okon, and M. Fischer. 1988. Growth response of maize roots to Azospirillum inoculation: Effect of organic matter content, number of rhizosphere bacteria and timing of inoculation. Soil Biol. Biochem. 20:45-49.

11. Fredrickson, J. K., D. F. Bezdicek, F. E. Brockman, and S. W. Li. 1988. Enumeration of $\mathrm{Tn} 5$ mutant bacteria in soil by MPN-DNA hybridization and antibiotic resistance. Appl. Environ. Microbiol. 54:446-453.

12. Gergen, J. P., R. H. Stern, and P. C. Wensink 1979. Filter replicas and permanent collections of recombinant DNA plasmids. NucleicAcids Res. 7:2115-2137.

13. Gillett, J. W., S. A. Levin, M. A. Harwell, M. Alexander, D. A. Andow, and A. M. Stern. 1985. Potential impacts of environmental release of biotechnology products: Assessment, regulation, and research needs. ERC-075, Ecosystems Research Center, Ithaca, New York.

14. Heitkamp, M. A., J. P. Freeman, and C. E. Cemiglia. 1987. Napthalene biodegradation in environmental microcosms: Estimates of degradation rates and characterization of metabolites. Appl. Environ. Microbiol. 53:129-136.

15. Hegazi, N. A., M. Monib, H. A. Amer, and E.-S. Shokr. 1983. Response of maizeplants to inoculation with azospirilla and (or) straw amendment in Egypt. Can.J. Microbiol. 29:888-894.

16. Jain, D. K., and D. G. Patriquin. 1985. Characterization of a substance produced by Azospirillum which causes branching of wheat root hairs. Can.J. Microbiol. 31:206-210.

17. Jones, J. B., and W. J. Steyn. 1973. Sampling, handling, and analyzing plant tissue. In Soil Testing and Plant Analysis, eds. L. M. Walsh and J. D. Beaton, pp. 249-270. Soil Science Society of America, Madison, Wisconsin.

18. Jorgensen, R. A., S. J. Rothstein, and W. S. Reznikoff. 1979. A restriction enzyme cleavage map of $\mathrm{Tn} S$ and location of a region encoding neomycin resistance. Mol. Gen. Genet. 177:65-72.

19. Kado, C.I., and S.-T. Liu. 1981. Rapid procedure for detection and isolation of large and small plasmids. J. Bacteriol. 145:1365-1373. 
20. Kapulnik, Y., Y. Okon, and Y. Henis. 1987. Yield response of spring wheat cultivars (Triticum aestivum and $T$. turgidum) to inoculation with Azospirillum brazilense under field conditions. Biol Fertil. Soils 4:27-35.

21. Kapulnik,Y., S. Sarig, I. Nur, and Y. Okon. 1983. Effect of Azospirillum inoculation on yield of field-grown wheat. Can. J. Microbiol. 29; 895-899.

22. Kavimandan, S. K., N. S. Subba Rao, and A. V. Mohrir. 1978. Isolation of Spirillum lipoferum from the stems of wheat and nitrogen fixation in enrichment cultures. Curr. Sci. (Bangalore) 47:96-98.

23. Krishnapillai, V., A. Puhler, and E. Lanka. 1986. Molecular cloning into Tn5 and integration into the Pseudomones aerugenosa chromosome: A tool for heterologous gene expression. J. Gen. Microbiol. 132:707-715.

24. Magalhaes, F. M. M., D. Patriquin, and J. Dobereiner. 1979. Infection of field-grown maize with Azospirillum spp. Rev. Brasil. Biol. 39:587-596.

25. Maniatis, T., E. F. Fritch, and J. Sambrook. 1982. Molecular Cloning: A Laboratory Manual. Cold Spring Harbor Laboratory, Cold Spring Harbor, New York.

26. Mertens, T., and D. Hess. 1984. Yield increases in spring wheat (Triticum aestivum L.) inoculated with Azospirillum lipoferum under greenhouse and field conditions of a temperate region. Plant Soil 82:87-99.

27. National Academy of Sciences. 1987. Introduction of Recombinant DNA-Engineered Organisms into the Environment: Key Issues. National Academy Press, Washington, D.C.

28. O'Hara, G. W., M. R. Davey, and J. A. Lucas. 1981. Effect of inoculation of Zea mays with Azospirillum brasilense strains under temperate conditions. Can. J. Microbiol. 27:871-877.

29. Okon, Y., and Y. Kapulnik. 1986. Development and function of Azospirillum-inoculated roots. Plant Soil 90:3-16.

30. Patriquin, D. G., and J. Dobereiner. 1978. Light mictoscopy observations of tetrazoliumreducing bacteria in the endorhizosphere of maize and other grasses in Brazil. Can.J. Microbiol. 29:734-742.

31. Pritchard, P. H., and A. W. Bourquin. 1984. The use of microcosms for evaluation of interactions between pollutants and mictoorganisms. Adv. Microb. Ecol. 7:133-215.

32. Reinhold, B., T. Hurek, E.-G. Niemann, and I. Fendrik. 1986. Close association of Azospirillum and diazotrophic rods with different root zones of Kallar grass. Appl. Environ. Microbiol. 52:520-526.

33. Roberts, L. 1987. New questions in Strobel case. Science 237:1097-1098.

34. Rowe, R., R. Todd, and J. Waide. 1977. Microtechnique for most-probable number analysis. Appl. Environ. Microbiol. 33:675-680.

35. Sadowsky, M. J., R. E. Tully, P. B. Cregan, and H. A. Keyser. 1987. Genetic diversity of Bradyrhizobium japonicum sergroup 123 and its relation to genotype-specific nodulation of soybean. Appl. Environ. Microbiol. 53:2624-2630. 
36. Selvaraj, G., I. Hooper, S. Shantharam, V. N. Iyer, L. Barran, R. Wheatcroft, and R. J. Watson. 1987. Derivation and molecular characterization of symbiotically deficient mutants of Rhizobium meliloti. Can. J. Microbiol. 33:739-747.

37. Selvaraj, G., and V. N. Iyer. 1983. Suicide plasmid vehicles for insertion mutagenesis in Rhizobium meliloti and related bacteria. J. Bacteriol. 156:1292-1300.

38. Smith, M. S., G. W. Thomas, R. E. White, and D. Ritonga. 1985. Transport of Escherichia coli through intact and disturbed soil columns. J. Environ. Qual. 14:87-91.

39. Tien, T. M., M. H. Gaskins, and D. H. Hubbell. 1979. Plant growth substances produced by Azospirillum brasilense and their effect on growth of pearl millet (Pennisetum americanum L.). Appl. Environ. Microbiol. 37:1016-1024.

40. Van Elsas, J. D., A. F. Dijkstra, J. M. Govaert, and J. A. Van Veen. 1986. Survival of Pseudomonas fluorescens and Bacillus subtilis introduced into two soils of different texture in field microplots. FEMS Microb. Ecol. 38:151-160.

41. Van Stockem, M., K. Michiels, J. Vanderleyden, and A. P. Van Gool. 1987. Transposon mutagenesis of Azospirillum brasilense and Azospirillum lipoferum: Physical analysis of Tn5 and Tn5-Mob insertion mutants. Appl. Environ. Microbiol. 53:410-415.

42. Van Voris, P. 1988. Standard guide for conducting a terrestrial soil-core microcosm test. Standard E-1197. In Annual Book of ASTM Standards, Vol. 11.04, pp. 743-755. American Society for Testing Standards, Philadelphia, Pennsylvania.

43. Van Voris, P., M. F. Arthur, and D. A. Tolle. 1982. Evaluation of terrestrial microcosms for assessing ecological effects of utility wastes. EPRI Pub. No. EA-2364, Electric Power Research Institute, Palo Alto, California.

44. Van Voris, P., R. V. O'Neill, W. R. Emanuel, and H. H. Shugart Jr. 1980. Functional complexity and ecosystem stability. Ecology 61:1352-1360.

45. Van Voris, P., M. F. Arthur, D. A. Tolle, Morris, J. P., and M. Larson. 1983. Use of microcosms for monitoring nutrient cycling in agroecosystems. In Nutrient Cycling in Agricultual Ecosystems, pp.171-182. Special Pub. 23, University of Georgia College Agricultural Experimental Station, Tifton, Georgia.

46. Weaver, R. W., and L. R. Frederick. 1982. Rhizobium. In Methods of Soil Analysis, Part 2 - Chemical and Microbiological Properties, 2nd ed., eds. A. L. Page, R. H. Miller, and D. R. Keeney, pp. 1043-1067. American Society of Agronomy, Madison, Wisconsin.

47. Wollum, A. G. 1982. Cultural methods for soil microorganisms. In Methods of Soil Analysis, Part 2 - Chemical and Microbiological Properties, 2 d ed, eds. A. L. Page, R. H. Miller, and D. R. Keeney, pp. 781-802. American Society of Agronomy, Madison, Wisconsin. 
• 
2.0 NUTRIENT EFFLUX FROM INTACT SOL-CORE MICROCOSMS FOR EVALUATING THE IMPACTS OF GENETICALLY ENGINEERED MICROORGANISMS ON ECOSYSTEM PROCESSES

J. K. Fredrickson, K. M. McFadden, S. W. Li, and P. Van Voris

Pacific Northwest Laboratory, Richland, Washington

S. A. Bentjen

Department of Bacteriology and Biochemistry, University of Idaho, Moscow, Idaho

CONTENTS

SUMMARY
INTRODUCTION
MATERIALS AND METHODS
Soil-Core Microcosms
LEACHATE NUTRIENT ANALYSIS
PLANT NUTRIENT ANALYSIS
RESULTS AND DISCUSSION
Microcosm Leachate Analysis
Plant Tissue Nutrient Concentrations
LTTERATURE CITED

SUMMARY

Nutrient expor from intact soil-core microcosms in leachate or by plant uptake was evaluated as a means to assess the ecosystem impacts from the environmental release of genetically modified root-colonizing bacteria Intact cores of two soil types, including a Burbank sandy loam and a Palouse silt loam, were excavated for use as microcosms, seeded with corn or wheat, respectively, and inoculated with Azospirillum lipoferum $\mathrm{Tn} 5$ mutants. Microcosms were leached at 33 and 67 days after seeding, and the leachate was analyzed for sulfate, phosphate, ammonium, nitrite, nitrate, dissolved organic carbon, and inorganic carbon. Statistically significant differences in leachate nutrient concentrations were observed between soil types, but differences caused by inoculation with the genetically altered bacteria were not observed. The one exception was a significant difference in the amount of dissolved organic carbon (and total carbon), probably because heat-killed cells were added to the control. Plant uptakes of $\mathrm{N}, \mathrm{P}, \mathrm{S}, \mathrm{B}, \mathrm{Cu}, \mathrm{Fe}, \mathrm{Mg}, \mathrm{Mn}$, and $\mathrm{Zn}$ were also not affected by inoculation, but the coefficients of variation tended to be lower than for the leachate analyses. The measurement of nutrient expor from microcosms, in particular 
that of carbon and nitrogen, may be used as a holistic indicator of ecosystem impacts resulting from the release of genetically engineered microorganisms.

\section{INTRODUCTION}

One major concern regarding the release of recombinant microorganisms to the environment is the potential for unforeseen ecosystem impacts (20). An ecological impact can be considered as a measurable detrimental effect on either the organisms or the processes within the ecosystem. Microorganisms can therefore impact an ecosystem through, for example, pathogenicity of component flora and fauna or through displacement or distuption of other microorganisms that carty out ecologically important functions or processes. Some of the most important ecosystem functions catalyzed by microorganisms involve nutrient cycling. Efficient nutrient cycling in an ecosystem may be determined by measuring nutrient fluxes and concentrations in various ecosystem pools (e.g., soils, microorganisms, plants) or by measuring specific biochemical activities directly involved in nutrient cycling (decomposition, microbial respiration, $\mathrm{N}_{2}$ fixation, nitrification, denitrification).

Field testing of genetically engineered microorganisms currently requires a permit, and applications are reviewed on a case-by-case basis. On the basis of past experience, the potential for introduced microorganisms, recombinant or otherwise, to have a negative impact on an ecosystem appears low. Past attempts to introduce Rhizobium spp. (17), microbial biocontrol agents, or microbial fertilizers to benefit crop growth have demonstrated the difficulty of establishing introduced microorganisms in soils or the rhizosphere. However, once microorganisms are released into the environment, they are not readily recalled or eliminated, and an a priori assessment of zero risk obviously cannot be made. Introduced organisms can also compete with indigenous organisms or fill an unoccupied niche. Microorganisms have been introduced into ecosystems in which they had not previously existed and then have survived, multiplied, and had negative impacts $(11,20)$. In addition, there are examples of single gene changes in microbial plant pathogens that have allowed them to overcome the host's natural defense mechanisms (5). Therefore, it is desirable to determine the potential for ecosystem impacts from genetically engineered microorganisms before their release to the environment.

Microcosms have been used for a variety of purposes in environmental studies, including organism toxicity testing (16), the fate of chemicals (15), chemical ecosystem impacts (18), and nutrient cycling (24), and have been suggested for use in biotechnology risk assessment (3). 
Recently, a standardized procedure from the ASTM intact soil-core microcosm test protocol (23) was modified to assess the fate of and potential ecological effects from the release of genetically engineered microorganisms. This procedure also allows for measurement of nutrient efflux in leachate as a means for evaluating nutrient cycling processes within the intact soil cores.

Azospirillum lipoferum, a motile, diazotrophic root-colonizing bacterium, was chosen as the test bacteria for this study because it has been shown to increase plant biomass and nitrogen uptake when inoculated onto wheat (9) and corn (7) roots. The objectives of this study were to determine the impact from inoculation with Azospirillum lipoferum Tn5 mutants on the efflux of nutrients from agricultural soil-core mictocosms through leaching and uptake by wheat (Triticum aestivum) and corn (Zea mays) and the usefulness of these measurements for monitoring ecological effects from the release of genetically engineered microorganisms.

\section{MATERIALS AND METHODS}

\section{Soil-Core Microcosms}

Intact soil cores $17.8 \mathrm{~cm}$ in diameter and $60 \mathrm{~cm}$ deep (23) were obtained from the U.S. Department of Agriculture, Agricultural Research Service (USDA-ARS) Palouse Conservation Field Station near Pullman, Washington, for use as microcosms. The cores consisted of a Palouse silt loam soil (fine-silty, mixed, mesic Pachic Ultic Haploxeroll) taken from a field low on the landscape. The cores were taken by pushing a steel coring device with Driscopipe liner into the soil by means of a hydraulic ram mounted on the back of a tractor with dual flotation tires filled with water for added weight. The steel coring barrel moved easily through the upper $30 \mathrm{~cm}$, which had been moistened by recent rains; however, the rest of the core was taken with more difficulty as the B horizon was high in clay and dry. Following their removal, soil cores were transported back to the Pacific Northwest Laboratory (PNL) at Richland, Washington, moistened with 1 liter deionized water, and covered until used.

The $25.5-\mathrm{cm}$-diameter $(60$-cm-deep) intact soil cores were obtained from a native sagebrush-bunchgrass plant community near West Pasco, Washington. The soil is classified as a Burbank sandy loam (sandy, skeletal, mixed, xeric Torriorthent) a soil type commonly used for irrigated agriculture in the Columbia Basin of south-central Washington State. Cores were

(BDriscopipe is a trademark of Phillips Petroleum Co., Dallas, Texas. 
removed as previously described except that a large front-end-loading tractor was used to drive the steel core barrel into the soil. Moisture had penetrated to a depth of approximately $15 \mathrm{~cm}$ in the sandy loam soil but the core barrel readily penetrated the soil. The dry unconsolidated material at the bottom of the core did not remain in the polyethylene pipe liner upon removal, requiring backfilling the bottom of the soil cores with the material that remained in the hole. This soil was homogeneous and unconsolidated with no distinct soil horizons and therefore heterogeneities among the replicate cores from the uneven recovery of subsoil were unlikely. Cores were transported back to PNL where they received 1 liter of deionized water. Table 2.1 lists the physical and chemical characteristics of the 0 - to $15-\mathrm{cm}$ depth of the two soils used in this study.

The soil cores were placed on Buchner funnels (24-cm polypropylene from Dyna Lab, Rochester, New York; or $20-\mathrm{cm}$ porcelain from Coors, Golden, Colorado); the porous plates were lined with glass wool placed in plywood boxes with slots for six microcosms. The Buchner funnels were connected to sterile, acid-washed, deionized-water-rinsed, 2-liter Erlenmeyer flasks for leachate collection. Common local seed varieties [NC+3390 field com (Wilbur-Ellis Seed Co., Pasco, Washington) and Edwall spring wheat (USDA Research Station, Pullman, Washington)] were seeded into 25.5 - and 17.8 -cm-diameter intact soil cores, respectively. Soil cores were

Table 2.1. Selected Properties of Soil Types Used as Intact Soil-Core Microcosms

\begin{tabular}{lcc}
\hline \multicolumn{1}{c}{ Soil Property } & Burbank Sandy Loam & Palouse Silt Loam \\
\hline \% sand & 45 & 1 \\
\% silt & 51 & 78 \\
\% clay & 4 & 21 \\
pH & 7.4 & 5.6 \\
Organic carbon $(\%)$ & 0.5 & 2.0 \\
Total sulfur $(\%)$ & 0.05 & 0.04 \\
Total N $(\%)$ & 0.06 & 0.16 \\
Total P $(\mu \mathrm{g} / \mathrm{g})$ & 2400 & 3770 \\
Phosphate-P $(\mu \mathrm{g} / \mathrm{g})$ & 4.8 & 5.8 \\
Ammonium- $\mathrm{N}(\mu \mathrm{g} / \mathrm{g})$ & 6.1 & 18.3 \\
CEC (meq/100 g) & 5.5 & 23.8 \\
\hline
\end{tabular}


inoculated with two strains of Azospirillum lipoferum or heat-killed cells as a control. These microorganisms and the details of inoculation are described elsewhere (1). The four treatments were replicated six times in a completely randomized design, and two-way analysis-of-variance tables were calculated to determine if statistically significant differences $(p \leq .05)$ existed between measured parameters in inoculated versus control microcosms and between soil types.

Microcosms were maintained at a water potential of approximately $-0.03 \mathrm{MPa}$ and temperature of $22^{\circ} \mathrm{C}$ as monitored by soil temperature and moisture probes on line to a datalogger (21x, Campbell Scientific Co., Logan, Utah). Photoperiod was set for $12 \mathrm{~h}$ with initial light intensity at the soil surface 400 microeinsteins $/ \mathrm{m}^{2}$ (4100 K Ultralume Lamps, Phillips Lighting Corp., Bloomfield, New Jersey). Soil-core leachate was collected at 33 and 67 days after seeding. Deionized water was added slowiy over time to the microcosms to saturate and leach the soil cores. Leachate was collected in acid-washed, 250-ml Erlenmeyer flasks. Leachate was decanted into sterile acid-washed containers, its volume determined, and placed at $4^{\circ} \mathrm{C}$ within $12 \mathrm{~h}$ after soil breakthrough and entry into the flasks.

\section{LEACHATE NUTRIENT ANALYSIS}

Filtrates were analyzed for the inorganic ions $\mathrm{PO}_{4}^{3-}, \mathrm{SO}_{4}{ }^{2-}, \mathrm{NO}_{3}{ }^{1-}$, and $\mathrm{NO}_{2}{ }^{1-}$ by ion chromatography. Samples were analyzed on AS1 anion-exchange columns (Dionex Corp., Sunnyvale, California) using $3 \mathrm{mM} \mathrm{NaHCO} 3$ and $2.4 \mathrm{mM} \mathrm{Na}_{2} \mathrm{CO}_{3}$ as eluents of at flow rates of approximately $2.3 \mathrm{ml} / \mathrm{min}$. Normal configuration of the ion chromatograph (Dionex Model 10) consisted of the anion exchanger followed by a membrane eluent suppressor using $0.025 \mathrm{~N}$ $\mathrm{H}_{2} \mathrm{SO}_{4}$ to neutralize the basic eluent stream, followed by conductivity detection over the 1- to 100$\mu \mathrm{S}$ ranges (full scale) with detection limits of about $0.06 \mathrm{ppm}$ or better for $\mathrm{NO}_{2}{ }^{1-}, \mathrm{NO}_{3}{ }^{1-}, \mathrm{PO}_{4}{ }^{3-}$, and $\mathrm{SO}_{4}{ }^{2}$. Ammonium was determined by ion-specific electrode (ISE) using the Orion model 9512 gas-sensing electrode (Orion Research Inc., Cambridge, Massachusetts) after $\mathrm{pH}$ adjustment according to the manufacturer's protocol.

Dissolved organic carbon was determined by acidifying filtered leachate to $\mathrm{pH} 2$ with phosphoric acid, sparging to remove inorganic carbon as $\mathrm{CO}_{2}$, and injecting the sample into a Dohrmann Model DC-80 Carbon Analyzer (Xertex, Santa Clara, California). Total carbon (TC) was determined on filtered leachate by direct injection into the carbon analyzer, and inorganic carbon was calculated as the difference between TC and organic carbon. The loss of purgeable organics during the sparging of acidified aliquots was assumed to be negligible. 


\section{PLANT NUTRIENT ANALYSIS}

Plant sampling and preparation of tissue for analysis followed the methods of Jones and Steyn (8). Corn was sampled at the tasseling stage by removing the first fully developed leaf below the whorl from two plants in each microcosm. For spring wheat, the four uppermost leaves were temoved before heading from four plants in each microcosm. Plant leaves were dried at $60^{\circ} \mathrm{C}$ for $48 \mathrm{~h}$ and then ground (40 mesh) using a mechanical mill with stainless steel surfaces to minimize contamination with trace metals.

Ground plant material was ashed using a modified wet procedure in which $0.1 \mathrm{~g}$ of dried plant material was placed in a Teflon bomb with $2.5 \mathrm{ml}$ of concentrated $\mathrm{HNO}_{3}$ and put in an oven at $140^{\circ} \mathrm{C}$ for $6 \mathrm{~h}$ to overnight. The ashed tissue was brought to $20 \mathrm{ml}$ with deionized water and analyzed directly for $\mathrm{P}, \mathrm{S}, \mathrm{Zn}, \mathrm{Fe}, \mathrm{Mn}$, and Mo by inductively coupled plasma spectrometry (Applied Research Laboratories Model 3560). Total nitrogen content of plant tissue was determined by Schwartzkopf Microanalytical Laboratories (Woodside, New York).

\section{RESULTS AND DISCUSSION}

\section{Microcosm Leachate Analysis}

Between $750 \mathrm{ml}$ and 3 liters of sterile deionized water were required to leach the soil cores; the larger Burbank soil cores (25.5-cm diameter) required more water than the Palouse soil cores (17.8-cm diameter). Because the Burbank soil microcosms were twice the volume of the Palouse soil-cores, twice as much soil volume was leached, therefore requiring a greater volume of water. The volume of leachate that was collected from the first leaching ( $t=33$ days) ranged from 40 to $380 \mathrm{ml}$ in the Palouse soil cores and from 30 to $270 \mathrm{ml}$ in the Burbank soil cores. The nutrient analysis from the first leaching is shown in Table 2.2. The values are presented as concentration $(\mu \mathrm{g} / \mathrm{ml})$ rather than the total amount of nutrient leached because both representations showed similar significant differences between soil types or inoculation treatment. A two-way ANOVA table was calculated for the individual nutrient analyses; the two factors were soil type and bacterial inoculation (live versus heat-killed cells). For all nutrients except ammonium and nitrite, there was a statistically significant difference $(p \leq .05)$ between the two soil types at the 33-day leaching (Table 2.2). Leachate ammonium and nitrite concentrations were low for both soils, and 
Table 2.2. Leachate Analyses from First Sampling (33 days)

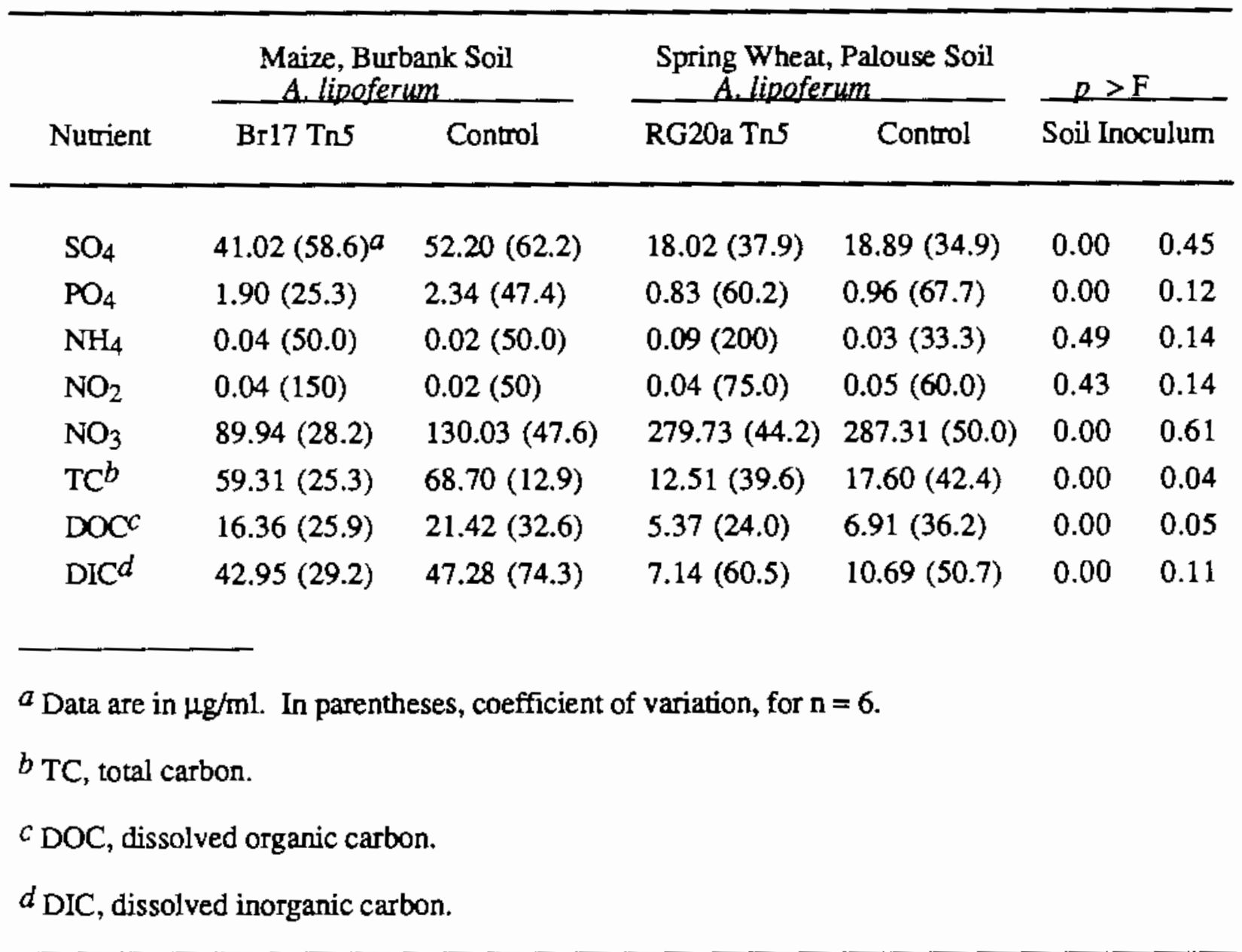

approached the analytical detection limits. In addition, because ammonium is a cation, it would be held on cation-exchange sites in the soil and would not leach to a great extent with the water percolating through the soil profile.

Microcosm inoculation with the Azospirillum transposon mutants had no significant effect on the levels of soluble nutrients in the microcosm leachates at day 33 or 67 (Tables 2.2 and 2.3) with the exception of total carbon and dissolved organic carbon at day 33 (Table 2.2). The concentrations of total carbon and dissolved organic carbon were significantly higher in the controls than in the microcosms receiving the live inoculum. This difference likely results from the addition of dead microbial biomass to the microcosms as heat-killed Azospirillum cultures. Between 4 and $5 \mathrm{ml}$ of $8.5 \times 10^{8}$ cells $/ \mathrm{ml}$ of heat-killed Azospirillum culture were added to each microcosm. If we assume that the average hydrated cell mass for Azospirillum is $0.01 \mathrm{ng}$, the cells 
Table 2.3. Leachate Analyses from Second Sampling (67 days)

\begin{tabular}{|c|c|c|c|c|c|c|}
\hline \multirow[b]{2}{*}{ Nutrient } & \multicolumn{2}{|c|}{$\begin{array}{l}\text { Maize, Burbank Soil } \\
\text { A. lipoferum }\end{array}$} & \multicolumn{2}{|c|}{$\begin{array}{c}\text { Spring Wheat, Palouse Soil } \\
\text { A. lipoferum }\end{array}$} & \multicolumn{2}{|c|}{$D \geq F$} \\
\hline & $\mathrm{Br} 17 \mathrm{Tn} 5$ & Control & $\mathrm{RG} 20 \mathrm{a} \mathrm{Tn} S$ & Control & Soil Ir & culum \\
\hline $\mathrm{SO}_{4}$ & $70.46(77.6)^{a}$ & $23.50(153)$ & $22.04(150)$ & $3.57(106.7)$ & 0.07 & 0.09 \\
\hline $\mathrm{PO}_{4}$ & $1.04(40.4)$ & $2.94(40.1)$ & $1.51(65.6)$ & $0.78(43.6)$ & 0.11 & 0.68 \\
\hline $\mathrm{NH}_{4}$ & $0.15(133)$ & $0.04(25.0)$ & $0.04(50.0)$ & $0.11(1090$ & 0.68 & 0.93 \\
\hline $\mathrm{NO}_{2}$ & $0.01(100)$ & $0.02(50)$ & $0.14(136)$ & $0.03(66.7)$ & 0.17 & 0.17 \\
\hline $\mathrm{NO}_{3}$ & $0.77(129)$ & $0.53(81.1)$ & $25.98(113)$ & $2.24(114)$ & 0.12 & 0.10 \\
\hline $\mathrm{TC}^{b}$ & $86.05(41.6)$ & $93.25(30.9)$ & $28.10(65.2)$ & $17.00(127)$ & 0.00 & 0.70 \\
\hline $\mathrm{DOC} C$ & $53.30(55.6)$ & $61.02(41.3)$ & $17.00(74.4)$ & $9.10(129)$ & 0.00 & 0.80 \\
\hline $\mathrm{DIC}^{d}$ & $32.75(26.2)$ & $32.23(18.2)$ & $11.11(52.7)$ & $7.89(126.4)$ & 0.00 & 0.56 \\
\hline \multicolumn{7}{|c|}{${ }^{a}$ Data are in $\mu \mathrm{g} / \mathrm{ml}$. In parentheses, coefficient of variation, for $n=6$. } \\
\hline \multicolumn{7}{|c|}{$b_{\mathrm{TC}}$, total carbon. } \\
\hline \multicolumn{7}{|c|}{${ }^{c}$ DOC, dissolved organic carbon. } \\
\hline \multicolumn{7}{|c|}{${ }^{d}$ DIC, dissolved inorganic carbon. } \\
\hline
\end{tabular}

are $60 \%$ water, and the typical dry cell is composed of $50 \%$ carbon (2), then approximately $7 \mathrm{mg}$ of cell carbon was added to the soil cores. For the Burbank soil cores, the difference in organic carbon concentration in the leachate is approximately $5 \mu \mathrm{g} / \mathrm{ml}$ and the average volume of leachate collected was $250 \mathrm{ml}$; thus a total of $1.25 \mathrm{mg}$ of carbon was leached from the soil cores. The amount of carbon added as cell biomass could therefore have accounted for the observed differences in organic carbon content of the leachates from control and inoculated microcosms.

The soil-core microcosms required between 5 and 6 liters of sterile deionized water at the second leaching ( $t=67$ days). After the first leaching, the wheat and com plants rapidly removed moisture from the soil cores, requiring significant quantities of moisture to maintain them at a water potential above wilting point. Between 100 and $700 \mathrm{ml}$ of leachate was recovered from the Burbank microcosms and between 15 and $300 \mathrm{ml}$ from the Palouse soil cores. Total, organic, and 
inorganic carbon concentrations in the leachate from the 67-day leaching (Table 2.3) were significantly different between the two soil types as with the first sampling; however, none of the other elements analyzed differed significantly. A comparison of nutrient concentrations in leachate from the first and second leachings (Tables 2.2 and 2.3) indicates the most soluble nutrients were removed by the first leaching and/or by plant uptake. This is clearly the case for nitrate; the concentration in the 33-day leachates were 10- to 100 fold higher than in the 67-day leachates. There was no significant difference in the concentration of soluble nutrients in the 67-day leachate between microcosms receiving live Azospirillum and those receiving heat-killed cells.

The significant difference between the two soils in inorganic carbon in microcosm leachates at the two samplings (Tables 2.2 and 2.3) would be expected because the Burbank soil typically has $\mathrm{CaCO}_{3}$ coatings on sand and pebble particles in the upper soil horizons while the Palouse soil does not. The organic carbon level of the Palouse surface soil was higher than the Burbank (Table 2.1), although greater amounts of soluble organic carbon were present in the Burbank microcosm leachates (Tables 2.2 and 2.3). This inconsistency likely results from root exudation and sloughing of cells, which contribute greatly to this leachabie soluble $\mathrm{C}$ pool. Extremely soluble carbon compounds are released by plant roots into soil, and their composition and quantity depend on plant species, growth conditions, rooting medium, and stage of plant development (6). Com and wheat grown for $\approx 25$ days in solution culture released 1200 and $342 \mathrm{Hg}$ polysaccharide per plant, respectively (22). Thus corn released greater anounts of polysaccharides, which contribute greatly to the soluble carbon compounds in corn (10) and wheat root (21) exudates. Finally, rootderived carbon was 26 fold more extractable with a mild percolation technique than native soil organic components (12), indicating root-derived carbon is more soluble in soil. The Burbank soil-corn combination may have had greater root carbon produced than the Palouse soil-wheat combination, resulting in the higher soluble organic carbon levels detected in the Burbank corn microcosms (Tables 2.2 and 2.3).

The detection of statistically significant differences between soil types as well as inoculum or organic carbon in the leachate at both sampling times suggests that this would be a sensitive method for evaluating nutrient processing within the soil-core microcosm. Because available organic carbon can be a major factor influencing or limiting the growth of heterotrophic microorganisms in the environment, the efflux of soluble carbon from soil-core microcosms as leachate combined with appropriate controls could be used to evaluate potential ecological effects from the release of genetically engineered microrganisms. The measurement of DOC concentrations has also been suggested as a means of calibrating microcosm function with the field (14). It would also be useful to include, in future studies, fractionation of the DOC to obtain 
general information on the classes of organic compounds (e.g., humic materials, carbohydrates, amino acids) that contribute to the DOC, indicating the source of the carbon as well as its availability to the microbial heterourophic population.

The coefficients of variation (CV) tended to be lower for the analyses from the first than for the second sampling, ranging from $5 \%$ to $200 \%$ (mean, $51 \%$ ) (Table 2.2) as compared to CVs from $18 \%$ to $153 \%$ (mean, $80 \%$ ) (Table 2.3 ). This variation may have resulted partially from differences in the volume of leachate collected from the individual microcosms, and may also reflect real field variability. O'Neill et al. (13) also found large variations (CV $=14 \%$ to $100 \%$ ) in nitrate leaching from replicate soil-core microcosms but the much lower CVs for calcium (6\% to $10 \%$ ) indicated that variability was nutrient dependent. This variability suggests that only large differences in concentration for some nutrients, as was observed between soil types, will be statistically significant. The high CVs of the analyses of some nutrients may limit the sensitivity of measurements of nutrient efflux from soil-core microcosms as indicators of GEM environmental impact. However, because of the importance of carbon and nitrogen to ecosystem function and the extensive information available conceming the processing of these nutrients in ecosystems, the export of DOC and inorganic nitrogen species from soil-core microcosms should be included in microcosm analysis of ecosystem impacts from GEM introduction. These impacts could occur by means of antagonism of microorganisms involved in mineralization of nutrients from soil organic matter or through deleterious effects on plant growth limiting uptake of nutrients from the soil.

\section{Plant Tissue Nutrient Concentrations}

Macro- and trace element concentrations in maize and wheat leaf tissue were not influenced by inoculation with the Azospirillum cultures, but significant differences were detected, as would be expected, between the two soil-plant combinations (Table 2.4). The CVs were typically lower than for nutrient concentrations in the microcosm leachates; the mean $\mathrm{CV}$ for all plant tissue analyses was 16.7. Therefore, nutrient analysis of plant tissue may be useful as a indicator of GEM impacts on plant nutrient assimilation. Plant-beneficial bacteria are organisms that can be improved for use in agricultural biotechnology (4), and monitoring of plant assimilation of nutrients in microcosms may be one means of evaluating the organisms for potential deleterious impacts on target and nontarget plants. Tolle et al. (19) found that microcosms were sensitive predictors of the field for evaluaring plant uptake of trace elements from fly ash-amended soil. 
Table 2.4. Nutrient Concentration in Leaf Tissue of Maize and Spring Wheat at 33 Days

\begin{tabular}{|c|c|c|c|c|c|c|}
\hline \multirow[b]{2}{*}{ Nutrient } & \multicolumn{2}{|c|}{$\begin{array}{c}\text { Maize, Burbank Soil } \\
\text { A. lipoferum }\end{array}$} & \multicolumn{2}{|c|}{$\begin{array}{l}\text { Spring Wheat, Palouse Soil } \\
\text { A. lipoferum. }\end{array}$} & \multicolumn{2}{|c|}{$D>E$} \\
\hline & Br17 Trs & Control & RG20a TnS & Control & Soil Ir & culum \\
\hline $\mathrm{N}$ & $2.97(10.1)^{a}$ & $2.38(30.3)$ & $5.30(1.7)$ & $5.21(4.4)$ & 0.00 & 0.16 \\
\hline B & $21.6(9.7)$ & $20.4(15.7)$ & $18.5(22.7)$ & $17.1(17.5)$ & 0.17 & 0.16 \\
\hline $\mathrm{Cu}$ & $9.28(7.3)$ & $9.2(37.0)$ & $35.6(85.1)$ & $19.0(53.2)$ & 0.14 & 0.48 \\
\hline $\mathrm{Fe}$ & $153.2(12.6)$ & $181.3(14.0)$ & $282(48.9)$ & $260(70.3)$ & 0.19 & 0.97 \\
\hline $\mathrm{K}$ & $37149(6.8)$ & $38559(7.2)$ & $53748(7.2)$ & $52155(7.1)$ & 0.00 & 0.97 \\
\hline $\mathrm{Mg}$ & $2790(7.4)$ & 2735 (13.6) & 3214 (3.9) & $3020(4.1)$ & 0.06 & 0.47 \\
\hline $\mathrm{Mn}$ & $80.7(4.3)$ & $89.7(16.2)$ & $74.1(4.7)$ & $79.1(5.9)$ & 0.15 & 0.20 \\
\hline $\mathrm{P}$ & $2930(7.5)$ & $2873(6.6)$ & $3200(2.8)$ & $2550(9.9)$ & 0.02 & 0.40 \\
\hline$S$ & $2954(8.4)$ & $2785(11.5)$ & $3821(2.6)$ & $3808(0.9)$ & 0.00 & 0.47 \\
\hline $\mathrm{Zn}$ & $15.73(12.1)$ & $13.9(12.9)$ & $37.3(44.8)$ & $32.2(18.6)$ & 0.21 & 0.44 \\
\hline
\end{tabular}

${ }^{a}$ Data are in $\mu \mathrm{g} / \mathrm{ml}$ of dry plant tissue. In parentheses, coefficient of variation, for $\mathrm{n}=6$.

The rate at which nutrients are leached from soil has been suggested as a method for environmental impact assessment because it is a holistic measurement, representing the functions of numerous microbial groups as well as abiotic processes (13). In a study to evaluate nutrient leaching from microcosms as means for monitoring environmental impact, O'Neill et al. (13) found that effects from the addition of toxic chemicals to microcosms could be detected in nutrient export in leachate from the microcosms but not by changes in population/community parameters. The major factor limiting the usefuiness of microcosms for evaluating the nutrient-related ecosystem impacts from the release of plant associated GEMs is likely to be the bulk volume of soil available for root exploration. In the later stages of crop growth of both maize and wheat, moisture was removed rapidly from the mictocosm soil by the plants; in the field, roots typically explore and withdraw water from a larger volume of soil. A high density of roots will also result in the extraction of a greater concentration of available nutrients, and the nutrient dynamics in the microcosm soil at the later stages of plant growth will likely be different from that which would occur in the field. Therefore, the length of time intact soil-core microcosms can mimic field 
situations in which GEM interactions with plants are being evaluated may be limited, dictated by the soil volume available, the plant species, and plant growth rate.

\section{LITERATURE CITED}

1. Bentjen, S. A., J. K. Fredricison, P. Van Voris, and S. W. Li. 1989. Microcosm evaluation of the fate and ecological impacts from the release of Azospirillum lipoferum transposon mutants. Appl. Environ. Microbiol. (in press).

2. Bratbak, G., and I. Dundas. 1984. Bacterial dry matter content and biomass estimations. Appl. Environ. Microbiol. 48:755-757.

3. Caims, J., and J. R. Pratt. 1986. Ecological consequence assessment: Effects of bioengineered organisms. In Biotechnology Risk Assessment, Issues and Methods for Environmental Introductions, eds. J. Fiskel and V. T. Covello, pp. 88-108. Pergamon Press, New York.

4. Davidson, J. 1988. Plant-beneficial bacteria. Biotechnology 6:282-286.

5. Flor, H. H. 1971. Current status of the gene-for-gene concept. Annu. Rev. Phyopathol. 9:275-296.

6. Hale, M. G., L. D. Moore, and G. J. Griffin. 1978. Root exudates and exudation. In Interactions Between Non-Pathogenic Soil Microorganisms and Plants, eds. Y. R. Dommergues and S. V. Krupa, pp. 163-203. Elsevier Science, New York.

7. Hegazi, N. A., M. Monib, H. A. Amer, and E.-S. Shokr. 1983. Response of maize plants to inoculation with azospirilla and (or) straw amendment in Egypt. Can.J. Microbiol. 29:888-894.

8. Jones, J. B., and W. J. Steyn. 1973. Sampling, handling, and analyzing plant tissue. In Soil Testing and Plont Analysis., eds. L. M. Walsh and J. D. Beaton, pp. 249-270. Soil Science Society of America, Madison, Wisconsin.

9. Kapulnik,Y., S. Sarig, I. Nur, and Y. Okon. 1983. Effect of Azospirillum inoculation on yield of field-grown wheat Can.J. Microbiol. 29: 895-899.

10. Kraffczyk, I., G. Trolldenier, and H. Beringer. 1984. Soluble root exudates of maize: Influence of potassium supply and rhizosphere microorganisms. Soil Biol. Biochem. $16: 315-322$.

11. May, C. 1930. Dutch elm disease in Ohio. Science 72:142-143.

12. Merckx, R., J. H. van Ginkel, J. Sinnaeve, and A. Cremers. 1986. Plant-induced changes in the rhizosphere of maize and wheat. II. Complexation of cobalt, zinc, and manganese in the rhizosphere of maize and wheat. Plant Soil 96:95-107.

13. O'Neill, R. V., B. S. Ausmus, D. R. Jackson, R. I. Van Hook, P. Van Voris, C. Washburne, and A. P. Watson. 1977. Monitoring terrestrial ecosystems by analysis of nutrient export. Water Air Soil Pollut. 8:271-277. 
14. Pritchard, P.H. 1982. Model ecosystems. In Environmental Risk Analysis for Chemicals, ed. R.A. Conway, pp. 257-353. Van Nostrand Reinhold, New York.

15. Pritchard, P. H., and A. W. Bourquin. 1984. The use of microcosms for evaluation of interactions between pollutants and microorganisms. Adv. Microb. Ecol. 7:133-215.

16. Taub, F. B., and M. E. Crow. 1980. Synthesizing aquatic microcosms. In Microcosms in Ecological Research, ed. J. P. Giesy, Jr., pp. 69-104. Department of Energy Symposium, Series 52. U.S. Department of Energy, Washington, D.C.

17. Thomton, F. C., and C. B. Davey. 1983. Response of the clover-Rhizobium symbiosis to soil acidity and Rhizobium strain. Agron. J. 75:557-561.

18. Tolle, D. A., M. F. Arthur, and P. Van Voris. 1983. Microcosm/field comparison of trace element uptake in crops grown in fly ash-amended soil. Sci. Total Environ. 31:243261.

19. Tolle, D. A., M. F. Arthur, J. Chesson, and P. Van Voris. 1985. Comparison of pots versus microcosms for predicting agroecosystem effects due to waste amendment. Environ. Toxicol. Chem. 4:501-509.

20. U.S. Congress Office of Technology Assessment. 1988. New Developments in Biotechnology--Field-Testing Engineered Organisms: Genetic and Ecological 1ssues. OTA-BA-350, U.S. Government Printing Office, Washington, D.C.

21. Vancura, V., and A. Hanzlikova. 1972. Root exudates of plants. IV. Differences in chemical composition of seed and seedling exudates. Plant Soil 36:271-282.

22. Vancura, V., Z. Prikryl, L. Kalachova, and M. Wurst. 1977. Some quantitative aspects of root exudation. Ecol. Bull. (Stockholm) 25:381-386.

23. Van Voris, P. 1988. Standard guide for conducting a terrestrial soil-core microcosm testStandard E-1197. In Annual Book of ASTM Standards, Vol. 11.04, pp. 743-755. American Society for Testing Materials, Philadelphia, Pennsylvania.

24. Van Voris, P., M. F. Arthur, D. A. Tolle, J. P. Morris, and M. Larson. 1983. Use of microcosms for monitoring nutrient-cycling processes in agroecosystems. In Nutrient Cycling in Agricultural Ecosystems, eds. R. Lowrance, R. Todd, L. Asmussen, and R. Leonard, pp. 171-182. Spec. Pub. 23, College of Agricultural Experimental Stations, University of Georgia, Athens. 



\title{
3.0 FATE OF ROOT GROWTH-INHIBITING PSEUDOMONAS SP. TIS MUTANTS IN INTACT SOIL-CORE MICROCOSMS
}

\author{
J. K. Fredrickson, H. Bolton, Jr., S. W. Li, and P. Van Voris \\ Pacific Northwest Laboratory, Richland, Washington
}

\section{S. A. Bentjen}

Department of Bacteriology and Biochemistry, University of Idaho, Moscow, Idaho

\section{CONTENTS}

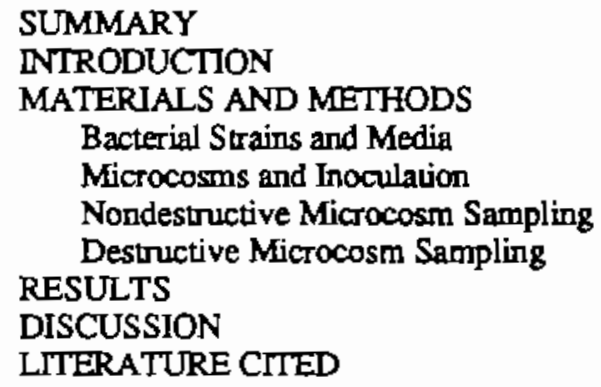

\section{SUMMARY}

Transposon $\operatorname{Tn} 5$ mutants of a wheat root growth-inhibiting nonfluorescent Pseudomonas sp. were inoculated into intact soil cores to determine the fate and potential impacts from the release of this organism into agricultural ecosystems. Transposon mutants that no longer inhibited the growth of wheat roots or Escherichia coli through the production of a toxin (tox ${ }^{-}$) as well as $\operatorname{Tn}^{5}$ mutants similar to the wild type (tox ${ }^{+}$) were inoculated into the surface soil of intact soil-core microcosms; the soil was spring wheat planted, and Tn5 mutant populations were monitored over time in the bulk soil, rhizosphere, and rhizoplane with depth. Populations were also monitored in core leachate and in the gut of earthworms. The popularion of the introduced Tn 5 mutants declined over time in the surface soil but was present in significant numbers in the wheat rhizosphere and Thizoplane throughout the $60-\mathrm{cm}$ soil-core depth. Rhizoplane populations of the tox ${ }^{+} \mathrm{Tn} 5$ mutants were significantly higher than populations of tox- mutants at the seedling stage but were not significantly different at the flowering stage. The $\operatorname{Tn} 5$ mutants were transported through the core with percolating water and were present in the gut of earthworms. Plant growth as well as indigenous rhizoplane populations of Rhizobium leguminosarum, associative $\mathrm{N}_{2}$-fixing bacteria, and nitrifying bacteria were not affected by inoculation with the TnS mutants. These experiments 
indicate that intact soil cores may have utility for assessing the fate and potential ecosystem impacts from the release of genetically engineered microorganisms to the environment.

\section{INTRODUCTION}

Plant-associated, and in particular rhizosphere-associated, bacteria have great potential for biotechnological applications in agriculture for biological control of plant diseases and for improving plant nutrition and providing plant growth factors (10). Microorganisms used in these applications may be improved through genetic engineering; however, concern about the release of genetically engineered microorganisms (GEMs) to the environment requires that the environmental risks be evaluated before a large-scale release. Microcosms have been identified as potential tools for both research and risk assessment concerning the release of GEMs to the environment (7). Microcosms have previously been used to assess the fate and impacts of released chemicals to the environment $(40,19)$ and the interactions between pollutants and microorganisms $(30)$. The intact soil-core inicrocosm was developed to evaluate the fate and ecological effects of chemicals in the environment (39) and, more recently, modified to evaluate the fate and environmental impacts from the release of GEMs (3). This research investigates the use of intact soil-core microcosms for evaluating the fate and potential environmental impacts from a genetically altered root-colonizing pseudomonad.

The use of no-till cultivation for wheat, and cool, wet weather in the spring months, favors the growth of nonfluorescent $P$ seudomonas sp. that inhibit wheat root growth (13). These bacteria can heavily colonize the rhizoplane of winter wheat and sunt root growth $(15,16)$ and can achieve high population densities on crop residues $(17,36)$. These wheat root growth-inhibiting Pseudomonas sp. have been shown to produce a low molecular weight toxin that inhibits the growth of wheat plants as well as some bacteria and fungi (4). This toxin appears to be a secondary metabolite, because activity can be detected in culnures grown under a wide range of conditions (5). These bacteria extensively colonize peas, oats, and lentils, but are not deleterious to these plants (17). Mutants that no longer produce the toxin (15) may have potential as a biocontrol agent to displace the wild type, as has been accomplished for ice nucleation-minus Pseudomonas syringae for control of frost damage (24). Also, other root-colonizing bacteria have been isolated that specifically inhibit the growth of weeds (8). Because these bacteria can exhibit a deleterious effect to a narrow host range and are aggressive root colonizers, they may also have potential for biotechnological applications in agriculture. 
The specific objectives of this study were to measure the colonization of Pseudomonas sp. Tn5 tox ${ }^{+}$and tox- phenotypes in the wheat rhizoplane, rhizosphere, and bulk soil with depth; determine the potential for transport of the introduced bacteria through the intact soil cores with percolating water and root growth; determine the potential for antagonism of several physiological groups of rhizosphere bacteria; and to determine if earthworms can serve as vectors of the introduced bacteria in soil.

\section{MATERIALS AND METHODS}

\section{Bacterial Strains and Media}

Toxin-producing (tox ${ }^{+}$) and toxin-deficient (tox-) TnS mutants of wheat root growthinhibiting Pseudomonas sp. isolate RCI were obtained from Dr. Lloyd F. Elliott [U.S. Department of Agriculture, Agriculture Research Service (USDA-ARS), Pullman, Washington]. The toxphenotype indicates the mutant is unable to inhibit root and $E$. coli growth. Described elsewhere are the procedures and vectors used for generation of transposon mutants (6), screening for toxin production (5), mutant growth characteristics (4), and chromosomal location of Tns insertion in the bacterial genome (45). Three mutants of each phenotype (tox ${ }^{+}$or tox ${ }^{-}$) with unique $\operatorname{Tn}^{5}$ insertions were selected for inoculation of soil cores to increase the probability of introducing an organism that was not severely debilitated in its competitive ability (3). The medium of Sands and Rovira (31) amended with $500 \mu \mathrm{g} / \mathrm{ml}$ of kanarnycin (Sands $\mathrm{Km}^{500}$ ) was used for enumeration of mutants in microcosm samples and for routine culturing. Tryptic soy agar (TSA) (27) was used to enumerate total bacterial numbers.

\section{Microcosms and Inoculation}

Intact cores $(17.5 \times 60 \mathrm{~cm}$ ) of Palouse soil (fine-silty, mixed mesic Pachic Ultic Haploxerolls) were obtained for use as microcosms and maintained as previously described (3). Briefly, intact soil cores were collected using a steel coring apparatus containing polyethylene pipe (Phillips Petroleum Co., Dallas, Texas). The intact soil cores, held inside the plastic pipe after removal from the driving tube, were placed in a housing on $20-\mathrm{cm}$-diameter Buchner funnels that were connected to sterile, acid-washed, deionized water-rinsed, 2-liter Erlenmeyer flasks for leachate collection. Six replicates of each treatment, including tox ${ }^{+}$, tox ${ }^{-}$, and uninoculated control, were arranged in a completely randomized design. The top $15 \mathrm{~cm}$ of soil was removed from each of six replicate mictocosms and combined. The soil was mixed for $15 \mathrm{~min}$ in a rotating soil mixer 
then placed at $4^{\circ} \mathrm{C}$ until inoculated. Six $150 \times 25 \mathrm{~mm}$ Sands $\mathrm{Km}^{500}$ agar plate cultures of each mutant were harvested separately, $48 \mathrm{~h}$ after inoculation, by adding $10 \mathrm{ml}$ of sterile deionized water and dislodging the cells with a glass rod. The bacterial suspensions were transferred to a sterile bottle, diluted with sterile deionized water, mixed, and placed on ice. Optical density (600 nm) of each inoculum was measured and adjusted to obtain the same relative cell concentrations for each culture. Inoculated treatments consisted of a mixture of three tox ${ }^{+}$mutants (A4-6, B4-7, 13-4) or a mixture of three tox mutants (RC-D, RC-E, RC-F). The three different mutants for each phenotype (tox ${ }^{+}$or tox) were mixed in equal portions and diluted to $200 \mathrm{ml}$ final volume before soil inoculation. The control treatment received $200 \mathrm{ml}$ of sterile deionized water.

Soils were inoculated and mixed in a rotating mixer for $30 \mathrm{~min}$, stopping twice to break up the soil aggregates, to ensure a thorough mixing of soil and inoculum. Equal amounts (approximately $2.3 \mathrm{~kg}$ ) of inoculated soil were retumed to the replicate microcosms. Six seeds of spring wheat (Triticum aestivum L. Edwall) were planted in each microcosm and thinned to four plants after germination. Microcosms were watered with sterile deionized $\mathrm{H}_{2} \mathrm{O}$ to maintain a water potential of approximately $-0.03 \mathrm{MPa}$ with a growth temperature of $22^{\circ} \mathrm{C}$, as monitored by soil temperature and moisture probes on line to a datalogger (21x, Campbell Scientific Co., Logan, Utah). Photoperiod was set for $12 \mathrm{~h}$ with an initial light intensity at the soil surface of 400 microeinsteins/cm ( $4100 \mathrm{~K}$ Ultralume Lamps, Phillips Lighting Corp., Bloomfield, New Jersey). Two earthworms (Lumbricus sp.) were introduced into microcosms after 3 weeks of wheat growth to assess their potential as vectors of the introduced bacteria.

\section{Nondestructive Microcosm Sampling}

Pseudomonas sp. Tn5 mutant populations in the surface soil were measured over time. Approximately $15 \mathrm{~g}$ of soil was removed from the top $15 \mathrm{~cm}$ of the microcosms at each sampling point, taking care not to remove or disturb plant roots; $10 \mathrm{~g}$ was used for bacterial enumerations and $5 \mathrm{~g}$ for moisture content analysis. Two wheat seedlings with intact roots were removed on day 21 to determine the extent of root colonization by the $\mathrm{Tn} 5$ mutants. Methods used for rhizosphere and rhizoplane sampling are described in detail eisewhere (15). Briefly, for rhizosphere soil samples, the soil adhering to roots was washed off the root into a sterile dilution blank. The washed roots were then macerated with a mortar and pestle for the rhizoplane samples. Initial dilutions were shaken for 20 min on a gyratory shaker at $250 \mathrm{rpm}$. Rhizosphere populations of native Rhizobium leguminosarum were determined by the most-probable-number infectivity method using Pisum sativum as the host plant (41). 
Twenty-five days after inoculation, microcosms were leached with sterile deionized water ( $250 \mathrm{ml}$ ) applied twice daily ( 9 to $12 \mathrm{~h}$ apart) until leachate was observed in 2-liter Erlenmyer leachate collection flasks. Leachate was decanted into a sterile container and placed at $4^{\circ} \mathrm{C}$ within 12 $\mathrm{h}$ of soil breakthrough and entry into the flasks. Leachate samples were serially diluted and plated onto Sands $\mathrm{Km}^{500}$ to enumerate Pseudomonas Tn5 mutant populations.

\section{Desuructive Microcosm Sampling}

Microcosms were sacrificed on day 54 , or the boot stage of wheat. Wheat plants were cut at the soil surface and above-ground plant biomass determined. Two cuts were made along the length of the polyethylene pipe enclosing the intact soil cores; the pipe was removed, and the intact core was separated into five sections according to depth $(0-15,15-25,25-35,35-45$, and $45-55 \mathrm{~cm})$. The outer $1 \mathrm{~cm}$ of soil, which was next to the pipe, was pared to remove soil and roots at the pipe interface. Roots with adhering soil were removed from each section and processed as previously described for day 21, except rhizoplane sample roots were macerated for $90 \mathrm{sec}$ in a tissue homogenizer (Sorvall Omni-Mixer, E. I. Du Pont De Nemours and Co., Newtown, Connecticut). At each depth the soil remaining in the soil core after rhizoplane and rhizosphere sample collection was mixed and retained as a bulk soil sample.

Pseudomonas sp. Tn5 mutant populations in the thizoplane, rhizosphere, and bulk soil were determined at each depth by dilution plating on Sands $\mathrm{Km}^{500}$ medium. Total bacterial numbers in the rhizoplane were determined by dilution plating on TSA. Rhizoplane populations of $\mathrm{N}_{2}$-fixing bacteria in the soil-core surface layer $(0$ to $15 \mathrm{~cm}$ ) were enumerated by the MPN-acetylene reduction method (22), and $R$. leguminosarum was enumerated as described earlier (day 21). Ammoniumoxidizing bacteria on the shizoplane were determined by the MPN method of Schmidt and Belser (32).

Earthworms were removed from the soil cores during sampling and placed in autoclaved (40 min, 2 consecutive days) Palouse soil containing $1 \%$ ground wheat straw (a water potential of $-0.03 \mathrm{MPa}$ ) and incubated at $4^{\circ} \mathrm{C}$ to enrich (17) for the introduced bacteria. Pseudomonas sp. Tn 5 mutant populations were measured in this soil on Sands $\mathrm{Km}^{500}$ after a 7-day incubation. Earthworms were removed after 23 days in the wheat straw-amended soil, washed, surface disinfected by placing in $1 \%$ Chloramine T (Sigma Chemical Co., St. Louis, Missouri) for 1 min., and dissected to sample the gut for the presence of the introduced bacteria. 
Data were analyzed as a completely randomized design with six replicates. A protected least significant difference (LSD) was conducted at the $p \leq .05$ level of significance for all treatment mean comparisons (35).

\section{$\underline{\text { RESULTS }}$}

The insertion site of $\operatorname{Tn} 5$ into the genome was unique for each of the three tox ${ }^{+}$or tox mutants selected for each treatment (data not shown), thereby increasing the probability of including mutants that were not severely impaired in competitive ability. Sands $\mathrm{Km}^{500}$ provided excellent selection for the Tn5 mutant bacteria because no growth occurred on plates from dilutions of the control microcosms. This level of kanamycin was chosen because it was the highest level that could be used without reducing the plating efficiency of the transposon mutants (data not shown). The stability of $\operatorname{Tn} 5$ in these bacteria was not investigated in this study; however, previous studies have shown that $\operatorname{Tn} 5$ was relatively stable with regards to excision and loss from the chromosome of $P$. putida and $R$. leguminosarum cv, phaseoli grown in soil (18).

Bulk surface soil ( 0 to $15 \mathrm{~cm}$ depth) populations of the Pseudomonas $\mathrm{Tn} S$ mutants declined slowly from approximately $1 \times 10^{8} \mathrm{CFU}$ per dry gram of soil at the time of inoculation to $4 \times 10^{5}$ CFU/dry g after 30 days and $3 \times 10^{4} \mathrm{CFU} / d r y$ g after 54 days (Figure 3.1). Populations of tox ${ }^{+}$ and tox ${ }^{-}$mutants declined in the surface bulk soil at an identical rate. The LSD of the mean bulk soil populations of the Tn5 mutants in the inoculated soil layer at the day 54 sampling (Figure 3.2) were considerably larger than the same value in Figure 3.1. This difference in the LSD value occurred because all depths were statistically analyzed together for Figure 3.2. A marked increase in variability occurred below the inoculated 0 - to $15-\mathrm{cm}$ layer; some bulk soil samples in the lower seccions of the soil core had populations less than the detection level of $200 \mathrm{CFU} / \mathrm{dry} g$ soil.

At the day 21 sampling, the wheat seedling rhizoplane population of Pseudomonas $\mathrm{T} n 5$ mutants was more than 10 fold higher than in the rhizosphere, which was 10 fold higher than in the bulk surface soil (Figure 3.3). The mean tox ${ }^{+}$populations in the bulk or rhizosphere soil were not significantly different from tox- populations (Figure 3.3). However, mean rhizoplane populations of tox ${ }^{+}$bacteria were significantly higher than tox populations. Leachate appeared in the collecion flasks after approximately 5 days of leaching. Between 2.5 and 3.5 liters of sterile water was used to leach each microcosm, and the volume collected was consistently between 90 and $150 \mathrm{ml}$. Eleven of 12 inoculated microcosms had detectable populations of TnS mutants in their leachate, which averaged more than $10^{3} \mathrm{CFU} / \mathrm{ml}$ (Figure 3.3). 


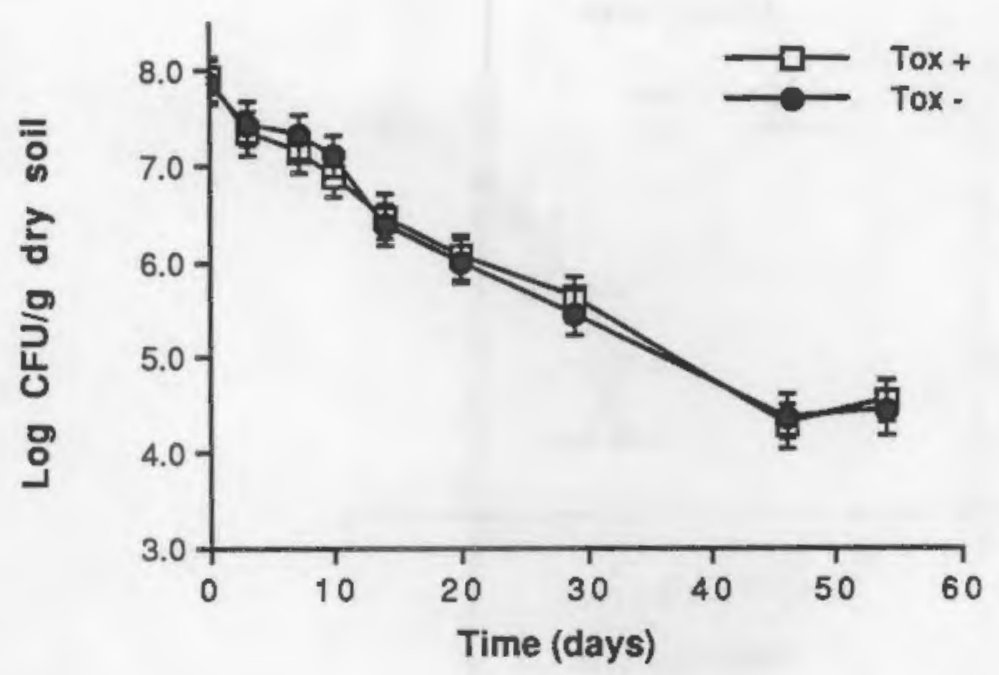

Figure 3.1. Populations of Pseudomonas sp. $\mathrm{Tn} 5 \mathrm{Tox}^{+}$and Tox${ }^{-}$Mutants in the Inoculated Surface Soil of Soil-Core Microcosms Over Time. ErTor bars represent significant differences $(p \leq .05)$.

Distribution of Pseudomonas Tn5 mutants by depth in the rhizoplane, rhizosphere, and in bulk soils at day 54 is shown in Figure 3.2. Differences in rhizoplane populations of tox ${ }^{+}$or toxTn 5 mutants were less than $1.5 \mathrm{log}$ units over the length of the soil core. The rhizosphere populations of the $\operatorname{Tn} 5$ mutants at each depth paralleled those of the rhizoplane but were approximately 10 fold lower. Bulk soil populations declined sharply from approximately $3 \times 10^{4}$ $\mathrm{CFU} / \mathrm{g}$ in the inoculated surface soil to approximately $10^{2} \mathrm{CFU} / \mathrm{g}$ in the four deeper sections. There was no significant difference between $\mathrm{Tn} 5$ mutant tox ${ }^{+}$and tox- thizoplane, rhizosphere, or bulk soil populations with depth except in the rhizosphere at the 15- to $25-\mathrm{cm}$ depth. At microcosm harvest (day 54), there was no sigmificant difference in plant biomass between treatments. Average shoot biomass was $7.83 \mathrm{~g}$ (dry weight) per microcosm for control, 8.41 for tox ${ }^{-}$, and 9.08 for tox ${ }^{-}$ treatments with an LSD value ( $p \leq .05$ ) of $1.89 \mathrm{~g}$. Because all wheat roots were not recovered, a total root mass could not be calculated. However, bacterial inoculation caused no obvious stunting of root growth.

Total bacterial populations (on TSA) in the rhizoplane tended to follow a pattern similar to that observed for the transposon mutants (Figure 3.4). Populations declined 10 fold or less on roots from the surface to those sampled from the lower sections. The total population tended to be lower in the tox ${ }^{-}$treatments at all depths, but significant differences were found only at the 15- to $25-\mathrm{cm}$ depth. Extreme variability was found when the tox ${ }^{+}$and tox populations on the rhizoplane 

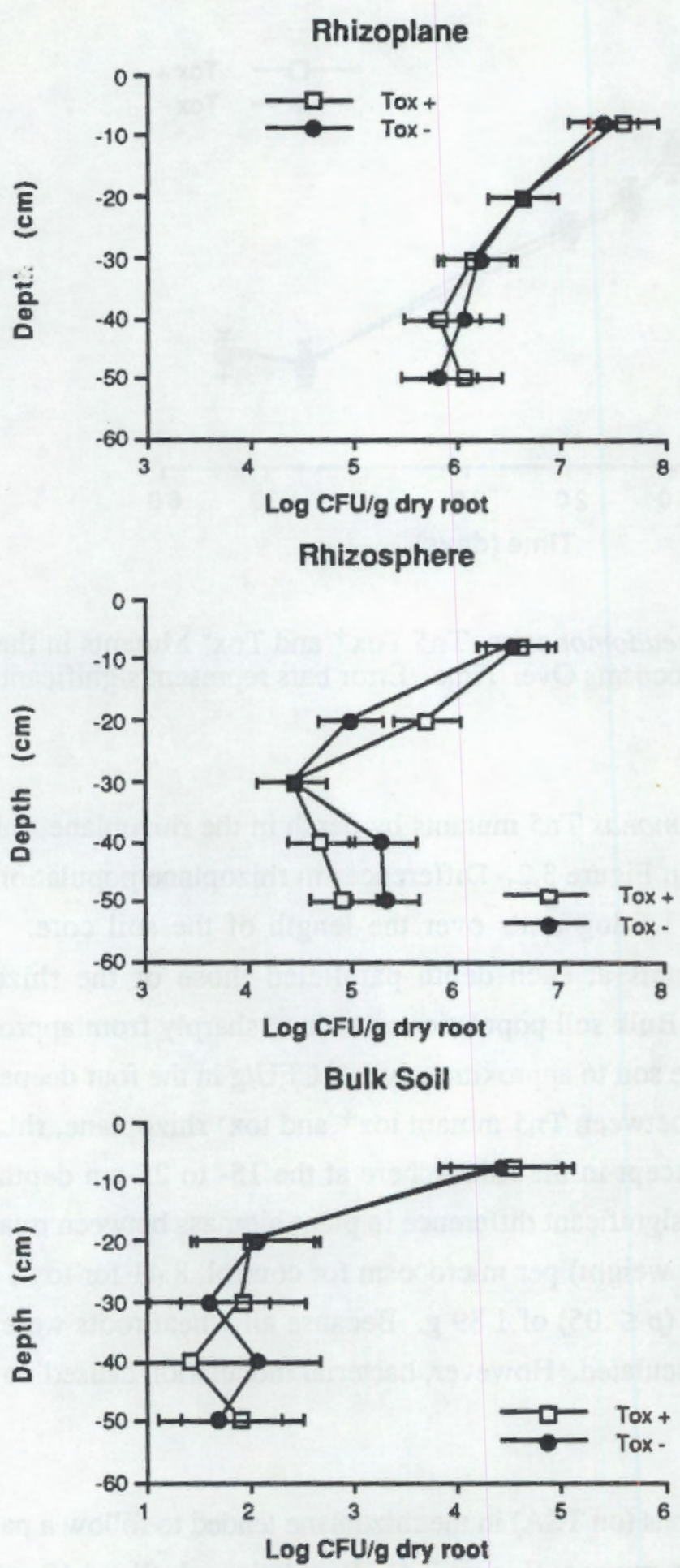

Figure 3.2. Rhizoplane, Rhizosphere, and Bulk Soil Populations of Pseudomonas sp. Tn5 $\mathrm{Tox}^{+}$and Tox- Mutants with Depth in the Intact Soil Cores at Day 54. Error bars represent significant differences $(p \leq .05)$. 


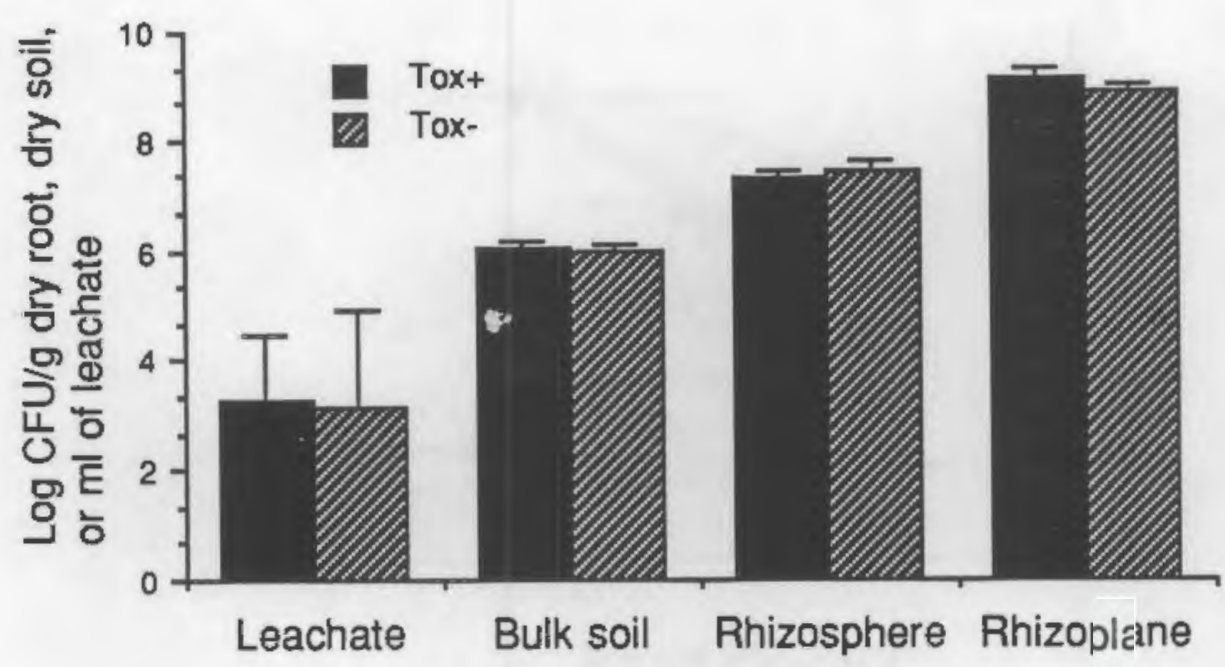

Figure 3.3. Populations of Pseudomonas sp. Tns Tox ${ }^{+}$and Tox ${ }^{-}$Mutants in Microcosm Leachate, Bulk, and Rhizosphere Soil and in the Rhizoplane at the Wheat Seedling Stage (day 21). Error bars represent significant differences $(p \leq .05)$.

represented as a percent of the total bacterial population as determined on TSA. Values ranged from $8 \%$ to virtually $100 \%$ for both, demonstrating that both inoculated bacteria constituted a significant portion of the total bacterial population on the rhizoplane.

Inoculation with the different inhibitory pseudomonad $\mathrm{Tn} 5$ mutants had no significant $(p \leq$ .05 ) effect on rhizoplane population sizes of $R$. leguminosarum, $\mathrm{N}_{2}$-fixing bacteria, or ammoniumoxidizing bacteria in the surface ( 0 to $15 \mathrm{~cm}$ ) soil. Rhizoplane populations of Rhizobium leguminosarum biovar viceae ranged between $7.23 \pm 0.43$ and $7.43 \pm 0.35 \log$ MPN/g dry root, free-living $\mathrm{N}_{2}$-fixing bacteria ranged between $4.82 \pm 0.29$ and $5.05 \pm 0.51 \log$ MPN/g dry root, and populations of ammonium-oxidizing bacteria ranged from $4.25 \pm 0.24$ to $4.66 \pm 0.20 \mathrm{log}$ $\mathrm{MPN} / \mathrm{g}$ dry root. In addition, $R$. leguminosarum populations in the rhizosphere of tox ${ }^{+}$treatments ( $7.17 \log$ MPN/g dry soil) were not significantly different (LSD $=0.52 ; p \leq .05$ ) from populations in the tox treatments (7.37) or in the uninoculated microcosms (6.91) at the day 21 sampling.

In the autoclaved and wheat straw-amended soil, populations of tox ${ }^{+}$and tox ${ }^{-} \mathrm{Tn} 5$ mutant bacteria were $10^{5} / \mathrm{g}$ dry soil or greater 7 days after earthworms from microcosms were added. Three of six earthworms sampled after 23 days had Pseudomonas $\mathrm{Tn} 5$ mutants present in their gut. No growth was observed on Sands $\mathrm{Km}^{500}$ receiving dilutions from earthworms sampled from uninoculated microcosms or their straw-amended soil. 


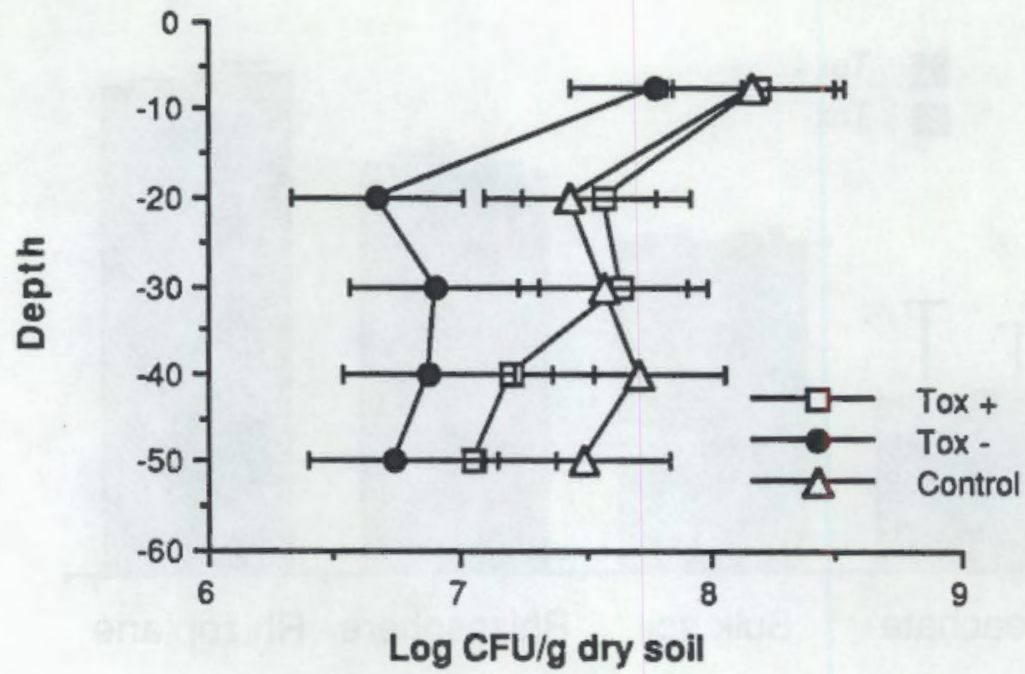

Figure 3.4. Rhizoplane Populations of Total Bacteria (on TSA) with Depth at Day 54 in SoilCore Microcosms Inoculated with Tn 5 Mutants and Uninoculated Controls. Error bars represent significant differences $(p \leq .05)$.

\section{DISCUSSION}

Inoculation of plow layer soil with the three genotypically distinct $\mathrm{Tn} 5$ mutants of tox ${ }^{+}$or tox ${ }^{-}$root inhibitory pseudomonads resulted in colonization of the wheat rhizosphere and rhizoplane of roots sampled from all depths. The use of Sands $\mathrm{Km}^{500}$ provided excellent selection for the Pseudomonas Tn5 mutants, thus eliminating background growth even at the lowest dilutions. There was no difference between tox ${ }^{+}$and tox ${ }^{-}$mutant populations in the bulk soil at any sampling time. Populations of tox ${ }^{+}$mutants colonizing the wheat rhizoplane were significantly higher than populations of tox mutants 21 days after seeding and inoculation. Rhizosphere populations of tox ${ }^{+}$and tox $x^{-}$mutants were not statistically different at either sampling. The rhizoplane represents the region of the root zone where the density of inhibitory pseudomonads is highest (15) and the concentration of the antibiotic produced by these bacteria would probably be greatest. Thus, the greatest potential for antagonism of the indigenous microflora would be in the rhizoplane.

The root-colonizing pseudomonads introduced at high population densities in the surface soil of the microcosms declined more than 1000 fold over a 54-day period (see Figure 3.1). These results agree with the decline of Pseudomonas sp. in bulk soil after the introduction of large populations of laboratory-cultured bacteria into uncropped soil in other studies $(38,28)$. In the later stages of plant growth, that is, the boot stage, the rhizoplane as well as the rhizosphere population 
densities of the Tn5 mutants in the surface layer had declined by 10 fold or greater (see Figures 3.2 and 3). The rhizosphere bacterial population of wheat has been shown to decrease with the age of the plant and to decline sharply during flowering (33). A rifampicin- and nalidixic acid-resistant fluorescent pseudomonad mutant introduced as a seed inoculum on wheat declined from approximately $10^{8}$ to less than $10^{4} \mathrm{CFU} / \mathrm{g}$ root from germination to harvest (42). However, it cannot always be predicted a priori that bacteria introduced into soil will rapidly die off $(12,9)$, indicating that bacterial decline in soil is dependent on the type of bacteria as well as environmental conditions.

Results of this study indicate that inoculation of soil with either tox ${ }^{+}$or tox ${ }^{-}$wheat root growth-inhibiting $P$ seudomonas sp. did not affect $R$. leguminosarum rizosphere populations at the seedling stage or thizoplane populations of $R$. leguminosarum, $\mathrm{N}_{2}$-fixing bacteria, or ammoniumoxidizing bacteria at boot stage. The Pseudomonas sp.-produced toxin has been shown not to affect the growth of Rhizobium sp. in vitro (unpublished data).

Toxins have long been assumed to provide a selective advantage to microorganisms that produce them. While there have been many demonstrations of antibiosis in vitro, experimental evidence for the selective advantage of toxin-producing bacteria in natural systems is, with a few exceptions $(1,23)$, limited. The use of intact soil cores as microcosms provides a means to evaluate such interactions in the laboratory while retaining complexity analogous to the field. Evaluation of intact soil cores as microcosms to study the effect of fly ash on plant uptake of trace elements demonstrated that soil-core microcosms could serve as reasonable analogs of the field $(37,40)$.

The Tn5 mutant bacteria introduced into the surface soil layer moved through the soil core with percolating water, as evidenced by the presence of these bacteria in the leachate (see Figure 3.3). Because the cores were gradually saturated by the application of small quantities of water over a long period of time, it is unlikely that significant volumes of water channeled along the soilpipe interface and into leachate collection flask. If channeling had occurred, water would likely have been observed after the first few volumes $(250 \mathrm{ml})$ of water had been added rather than after the fourth day when 2.5 to 3.5 liters of water had been added to the various microcosms. This evidence, plus the tight fit of the soil core in the polyethylene pipe and the fact that the soil expands as it absorbs water, indicate bacterial transport through the soil core. In addition, distribution with depth of Pseudomonas Tn5 mutants in bulk soil (see Figure 3.3) indicates bacterial movement occurs through the core itself. At sampling, soil and roots at the soil-polyethylene pipe interface were pared to eliminate any influence from bacteria transported by channeled water. Smith et al. (34) 
concluded that $E$. coli and $\mathrm{Cl}^{-}$moved through the center of intact cores faster than at core edges and that transport potential through intact soil cores is greater than through soil that has been mixed and packed.

Experiments using sieved, packed soil columns demonstrate that pseudomonads are more susceptible to water-mediated transport than other bacteria. Madsen and Alexander (25) found no vertical dispersal of bacteria occurred below the inoculated layer without some transporting agent (i.e., water) and that $P$. putida was transported farther and in greater numbers than $R$. japonicum. Other studies have demonstrated Pseudomonas spp. to be more prone to movernent through soil than other bacterial species such as Bacillus and Azotobacter (44). However, even the movement of $P$. fluorescens through sterile soil was restricted in all but very wet conditions (44).

Populations of nonfluorescent $\operatorname{Tn} 5$ mutants found in leachates of the intact soil-core microcosms are comparable to those observed by Martin (26) in a study evaluating the leaching of bacteria from wheat roots. That study also found fluorescent pseudomonads to be partitioned into leachate to a greater degree than other thizosphere bacteria. Earlier work with intact soil-core microcosms of the same soil type used in this study as well as with a more coarsely textured soil showed that Azospirillum lipoferum Tn5 mutants introduced as a seed inoculum on wheat or com roots were not detected in leachate. However, the size and method of the inoculum and the extent of root colonization was considerably less in that study (3).

The pseudomonad $\operatorname{Tn} 5$ mutants colonized roots in the lower section of the soil core $(55 \mathrm{~cm})$; however, the mode of transport to roots in this zone is unknown. Because the soil cores were leached at day 25 and the bacteria were present in the bulk soil of the lower core sections at day 54, bacterial colonization of roots in these zones may have resulted from percolating water. In a field study with potato plants, irrigation increased thizosphere populations of $P$. fluorescens 10 fold whereas no increase was found in nonrhizosphere soil (2). The decline in populations of the introduced bacteria on wheat roots with depth is typical of that observed in other studies and is not indicative of the mode of movement of bacteria to a particular root segment. Bacteria introduced as seed inoculants on wheat were present in progressively lower numbers with increasing depth from the seed in the absence of vertical water movement in a laboratory system designed to control soil matric potential (21). A similar decline with depth of inoculated root-colonizing fluorescent pseudomonads has been observed in the field (43).

Deleterious effects on plant growth were not observed in this study because population densities were considerably less than the $10^{6} \mathrm{CFU} / \mathrm{mg}$ dry root necessary for growth inhibition 
(15). In addition, other factors that contribute to optimal root colonization and growth inhibition, such as low temperature (14), susceptible wheat cultivar (13), or the presence of crop residues (18), were not provided.

The presence of the Pseudomonas $\mathrm{Tn} 5$ inutants in the digestive tract of earthworms present in the soil cores suggests that earthworms may act as vectors in disseminating bacteria introduced into soils. Also, the population of introduced bacteria could be significantly increased upon passage through the earthworm; Parle (29) found that bacterial and actinomycete numbers increased by more than 100 fold over numbers found in the soil during passage of food through the worm gut. Earthworms have been shown to increase the transport of bacteria in soil as weil (25).

The transposon $\operatorname{Tn} 5$ has been shown in this study and others (38) to provide an excellent phenotypic tag for tracking the fate of microorganisms in the environment. Tn5 could provide a genotypic tag as well, and may be used for direct (20) and indirect (18) analysis of populations in soils using DNA-hybridization techniques. Further, transposons can create clean mutations that may be of use in studying the effect of specific mutations on environmental competency or pathogenicity of a microorganism $(23,11,45)$. Such transposon mutants could also have potential for commercial applications in agriculnural biotechnology (23).

This study has demonstrated that toxin production can influence the rhizoplane population of a root-colonizing Pseudomonas sp. The fact that no differences in rhizoplane, rhizosphere, or bulk soil populations of tox ${ }^{+}$or tox ${ }^{-}$root growth-inhibiting Pseudomonas sp. Tn5 mutants were observed except in the rhizoplane of wheat seedlings suggests that the tox- phenotype may be used as a biocontrol agent to suppress such deleterious bacteria in the rhizoplane.

Intact soil cores have been used in this study as analogs of the field to study microbial fate and effects of root-associated bacteria on indigenous bacterial populations in an agricultural ecosystem. The dissemination, survival, and impacts of an introduced genetically altered microorganism should be of value in future research involving genetically engineered microorganisms in intact soil-core microcosms intended for release to the environment. Calibration of microcosm with the field environment would improve the utility of microcosms for predicting behavior in the field (30), and, thus, risk assessment. 


\section{LITERATURE CITED}

1. Axelrood, P. E., M. Rella, and M. N. Schroth. 1988. Role of antibiosis in competition of Erwinia strains in potato infection courts. Appl. Environ. Microbiol. 54:1222-1229.

2. Bahme, J. B., and M. N. Schroth. 1987. Spatial-temporal colonization patterns of rhizobacterium on underground organs of potato. Phytopathology 77:1093-1100.

3. Bentjen, S. A., J. K. Fredrickson, P. Van Voris, and S. W. Li. 1989. Intact soil-core microcosms for evaluating the fate and ecological effects from the release of genetically engineered microorganisms. Appl. Environ. Microbiol. (in press).

4. Bolton, H., Jr., and L. F. Elliott. 1989. Toxin production by a rhizobacterial Pseudomonas sp. that inhibits winter wheat (Triticum aestivum L.) growth. Plant Soil (in press).

5. Bolton, Jr., H., L. F. Elliott, S. Gurusiddaiah, and J. K. Fredrickson. 1988. Characterization of a toxin produced by a rhizobacterial Pseudomonas sp. that inhibits wheat growth. (Submitted for publication.)

6. Bolton, H., Jr., J. K. Fredrickson, H. F. Stroo, L. F. Elliott, and A. C. Kennedy. 1988. Generation and characterization of $\mathrm{Tn} 5$ toxin- mutants of winter wheat root inhibitory rhizobacteria. (In manuscript.)

7. Cairns, J., and J. R. Pratt. 1986. Ecological consequence assessment: Effects of bioengineered organisms. In Biotechnology Risk Assessment, Issues and Methods for Environmental Introductions, eds. J. Fiskel and V. T. Covello, pp. 88-108. Pergamon Press, New York.

8. Cherrington, C. A., and L. F. Elliott. 1987. Incidence of inhibitory pseudomonads in the Pacific Northwest. Plant Soil 101:159-165.

9. Danso, S. K. A., and M. Alexander. 1974. Survival of two strains of Rhizobium in soil. Soil Sci. Soc. Am. Proc. 38:86-89.

10. Davidson, J. 1988. Plant-beneficial bacteria. Biotechnology 6:282-286.

11. De Weger, L. A., C. I. M. van der Vlugt, A. H. M. Wijfjes, P. A. H. M. Bakker, B. Schippers, and B. Lugtenberg. 1987. Flagella of a plant-growth-stimulating Pseudomonas fluorescens strain are required for colonization of potato roots. J. Bacteriol. 169:2769-2773.

12. Dupler, M., and R. Baker. 1984. Survival of Pseudomonas putida, a biological control agent, in soil. Phytopathology 74:195-200.

13. Elliott, L. F., and J. M. Lynch. 1984. Pseudomonads as a factor in the growth of winter wheat (Triticum aestivum L.). Soil Biol. Biochem. 16:69-71.

14. Elliot, L. F., and J. M. Lynch. 1985. Plant growth-inhibitory pseudomonads colonizing winter wheat (Triticum aestivum L.) roots. Plant Soil 84:57-65. 
15. Fredrickson, J. K., and L. F. Elliott. 1985. Colonization of winter wheat roots by inhibitory rhizobacteria. Soil Sci. Soc. Am. J. 49:1172-1177.

16. Fredrickson, J. K., and L. F. Elliott. 1985. Effect on winter wheat seedling growth by toxin-producing rhizobacteria. Plant Soil 83:399-409.

17. Fredrickson, J. K., L. F. Elliott, and J. C. Engibous. 1987. Crop residues as substrate for host-specific inhibitory pseudomonads. Soil Biol. Biochem. 19:127-134.

18. Fredrickson, J. K., D. F. Bezdicek, F. J. Brockman, and S. W. Li. 1988. Enumeration of TnS mutant bacteria in soil by using a most-probable-number-DNA hybridization procedure and antibiotic resistance. Appl. Environ. Microbiol. 54:446-453.

19. Gile, J. D., J. C. Collins, and J. W. Gillett 1982. Fate and impact of wood preservatives in a terrestrial microcosm. J. Agric. Food Chem. 30:295-301.

20. Holben, W. E., J. K. Jansson, B. K. Chelm, and J. M. Tiedje. 1988. DNA probe method for the detection of specific microorganisms in the soil community. Appl. Environ. Microbiol. 54:703-711.

21. Howie, W. J., R. J. Cook, and D. M. Weller. 1987. Effects of soil matric potential and cell motility on wheat root colonization by fluorescent pseudomonads suppressive to takeall. Phytopathology 77:286-292.

22. Knowles, R. 1982. Free-living dinitrogen-fixing bacteria. In Methods of Soil Analysis, Part 2, Chemical and Microbiological Properties, 2d ed., eds. A. L. Page, R. H. Míller, and D. R. Keeney, pp. 1071-1092. American Society of Agronomy, Madison, Wisconsin.

23. Lam, B. V. S., G. A. Strobel, L. A. Harrison, and S. T. Lam. 1987. Transposon mutagenesis and tagging of fluorescent Pseudomonas: Antimycotic production is necessary for control of Dutch elm disease. Proc. Natl. Acad. Sci. USA 84:6447-6451.

24. Lindow, S. E. 1985. Integrated control and role of antibiotics in biological control of fireblight and frost injury. In Biological Control on the Phylloplane, eds. C. Windels and S. E. Lindow, pp. 83-115. American Phytopathological Society Press, Minneapolis, Minnesota.

25. Madsen, E. L., and M. Alexander. 1982. Transport of Rhizobium and Pseudomonas through soil. Soil Sci. Soc. Am. J, 46:557-560.

26. Martin, J. K. 1971. Influence of plant species and plant age on the rhizosphere microflora. Aust. J. Biol. Sci. 24:1143-1150.

27. Martin, J. K. 1975. Comparison of agar media for counts of viable soil bacteria. Soil Biol. Biochem. 7:401-402.

28. Nesmith, W. C., and S. F. Jenkins, Jr. 1983. Survival of Pseudomonas solanacearum in selected North Carolina soils. Phytopathology 73:1300-1304.

29. Parle, J. N. 1963. Micro-organisms in the intestines of earthworms. J. Gen. Microbiol. 31:1-11.

30. Pritchard, P. H., and A. W. Bourquin. 1984. The use of microcosms for evaluation of 
interactions between pollutants and microorganisms. Adv. Microb. Ecol. 7:133-217.

31. Sands, D. C., and A. D. Rovira. 1970. Isolation of fluorescent pseudomonads with a selective medium. Appl. Microbiol. 20:513-514.

32. Schmidt, E. L., and L. W. Belser. 1982. Nitrifying bacteria. In Methods of Soil Analysis, Part 2, Chemical and Microbiological Properties, 2d ed., eds. L. Page, R. H. Miller, and D. R. Keeney, pp. 1027-1042. American Society of Agronomy, Madison, Wisconsin.

33. Sivasithamparam, K., C. A. Parker, and C. S. Edwards. 1979. Rhizosphere microorganisms of seminal and nodal roots of wheat grown in pots. Soil Biol. Biochem. 11:155-160.

34. Smith, M. S., G. W. Thomas, R. E. White, and D. Ritonga. 1985. Transport of Escherichia coli through intact and disturbed soil columns. J. Environ. Qual. 14:87-91.

35. Steel, R. G. D., and J. H. Torrie. 1980. Principles and Procedures of Statistics. A Biometrical Approach. McGraw-Hill, New York.

36. Stroo, H, F., L. F. Elliott, and R. I. Papendick. 1988. Growth, survival and toxin production of root-inhibitory pseudomonads on crop residues. Soil Biol. Biochem. 20:201-207.

37. Tolle, D. A., M. F. Arthur, and P. Van Voris. 1983. Microcosm/field comparison of trace elements uptake in crops grown in fly ash-amended soil. Sci. Total Environ. 31:243261.

38. van Elsas, J. D., A. F. Dijkstra, J. M. Govaert, and J. A. van Veen. 1986. Survival of Pseudomonas fluorescens and Bacillus subtilis introduced into two soils of different texture in field microplots. FEMS Microbiol. Ecol. 38:151-160.

39. Van Voris, P., D. A. Tolle, and M. F. Arhur. 1983. Experimental terrestrial soil-core microcosm test protocol. A method for measuring the potential ecological effects, fate, and transport of chemicals in terrestrial ecosystems. EPA/600/3-85/047, PNL-5450, Corvallis Environmental Research Laboratory, Corvallis, Oregon.

40. Van Voris, P., D. A. Tolle, M. F. Arthur, and J. Chesson. 1985. Terrestrial microcosms: Applications, validation, and cost-benefit analysis. In Multispecies Toxicity Testing, ed. J. Caims, pp. 117-142. Pergamon Press, New York.

41. Weaver, R. W., and L. R. Frederick. 1982. Rhizobium. In Methods of Soil Analysis, Part 2, Chemical and Microbiological Properties, 2d ed., eds. A. L. Page, R. H. Miller, and D. R. Keeney, pp. 1043-1071. American Society of Agronomy, Madison, Wisconsin.

42. Weller, D. M. 1983. Colonization of wheat roots by a fluorescent pseudomonad suppressive to take-all. Phytopathology 73:1548-1553.

43. Weller, D. M. 1984. Distribution of a take-all suppressive strain of Pseudomonas fluorescens on seminal wheat roots. Appl. Environ. Microbiol. 48:897-899.

44. Wong, P. T. W., and D. M. Griffin. 1976. Bacterial movement at high matric potentials. I. In artificial and natural soils. Soil Biol. Biochem. 8:215-218. 
45. Xu, G.-W., and D. C. Gross. 1988. Evaluation of the role of syringomycin in plant pathogenesis by using Tn5 mutants of Pseudomonas syringae pv, syringae defective in syringomycin production. Appl. Environ. Microbiol. 54:1345-1353. 

APPENDDX A

STANDARD OPERATING PRQCEDURES 
STANDARD OPERATING PROCEDURE - TD 2369 - SOP1

Sampling and Equilibration of Soil-Core Microcosms

Project Title: $\quad$ Evaluation of Terrestrial Microcosms for Assessing the Fate and Effects of Generically Engineered Microorganisms on Ecological Processes

Project

Manager:

Dr. Peter Van Voris

Principal

Investigator:

Dr. James K. Fredrickson

\section{INTRODUCTION}

Terrestrial microcosm systems have been developed for assessing the transport, fate, and ecological impacts associated with the release of toxic and hazardous chemicals to the environment. It has been suggested that microcosms may be ideal ecosystern-level test systems for assessing these same parameters after the environmental release of generically engineered microorganisms (GEMs). A set of recently published terrestrial microcosm test protocols and guidelines suggests procedures for performing a multitiered screening of the potential toxicity of a chemical or hazardous substance (Van Voris 1988; Van Voris et al. 1984, 1985a,b). These protocols for sampling and maintenance of microcosms will be followed for this project.

\section{Microcosm Collection}

Microcosm soil cores are extracted from a homogeneous field so that soil properties are not highly variable among the different cores. Steel driving tubes are used to extract the 17.8- and 25.5-cm-diameter by $60-\mathrm{cm}$-long cores. Polyethylene (Driscopipe ${ }^{\circledR}$ ), tubes line the steel driving tubes (Figure A.1). The cutting edge of the driving tubes is slightly smaller in diameter than the Driscopipe to allow for soil expansion during the coring process. A backhoe is used to push the driving tube into the soil and then to remove the cores by wrapping a chain from the backhoe bucket around the handles and pulling the tube out. The soil cores and polyethylene rube are removed as a single unit. Topsoil from the field is then added to fill the top $10 \mathrm{~cm}$ of the microcosms before they are transported back to the laboratory.

(B) Phillips Petroleum Co., Bartlesville, Oklahoma. 


\section{Microcosm Maintenance}

The microcosm cores rest on Buchner funnels covered with a thin layer of glass wool. These units are placed in carts or in the microcosm containment systems (MCS) described elsewhere. Spring wheat (Triticum aestivum) and com (Zea mays) are seeded into 17.8- and $25.5-\mathrm{cm}$-diameter intact soil cores, respectively. Soils are periodically brought to a water potential of approximately -0.3 bar, near optimum for plant and microbial growth. Measurement of water potential is monitored with tensiometers or gypsum blocks placed in several of the soil cores, and filtered $(0.2-\mu \mathrm{m})$, ion-free water is added when the potential declines to -1 bar.

\section{MATERIALS}

Polyethylene Pipe

Driscopipe ${ }^{\circledR}$, a product of the Phillips Petroleum Company, is the material of choice for the soil-core mictocosms. Composed of ultrahigh molecular weight, high-density, nonplasticized polyethylene, it is impermeable, lightweight, tough, rigid, and highly resistant to acids, bases, and biological degradation. It is used commercially for underground gas pipelines and can be buried for 50 years with no expected structural changes. Driscopipe ${ }^{\circledR}$ can be purchased from MaskellRobbins, Inc., of Mountlake Terrace, Washington. Specifications for the 17.8- and 25.5-cmdiameter microcosms are listed below:

1. 25.5-cm Driscopipe 8600 , ultrahigh molecular weight, high-density polyethylene pipe, SDR $29.5,56 \mathrm{psi}$, OD 10.75 in., W 10.022 in., wall thickness 0.364 in.; each piece $60 \mathrm{~cm}$ long and edges smoothed.

2. 17.8-cm Driscopipe 1000 , high-density, high molecular weight polyethylene pipe, SDR 26 , 65 psi, OD 7.125 in., ID 6.577 in., wall thickness 0.274 in.; each piece $60 \mathrm{~cm}$ long and edges smoothed. 


\section{REFERENCES}

Van Voris, P., D. A. Tolle, M. F. Arthur, J. Chesson, and T. C. Zwick. 1984. Development and validation of a terrestrial mictocosm test system for assessing ecological effects of utility wastes. EA-3672. Final Project Report, Electric Power Research Institute, Palo Alto, Califomia.

Van Voris, P., D. A. Tolle, M. F. Arthur, and J. Chesson. 1985a. Temestrial microcosms: Applications, validation and cost-benefit analysis. In Multispecies Toxicity Testing, ed. J. Cairns, pp. 117-142. Pergamon Press, New York.

Van Voris, P., D. A. Tolle, and M. F. Arthur. 1985b. Experimental terrestrial soil-core microcosm test protocol. PB85-21338, EPA/600/3-85/047. U.S. Environmental Protection Agency, Corvallis, Oregon.

Van Voris, P. 1988. Standard guide for conducting a terrestrial soil-core microcosm test. Standard E 1197. In Annual Book of ASTM Standards, Vol. 11.04, pp. 743-755. American Society for Testing Materials, Philadelphia, Pennsylvania. 
STANDARD OPERATING PROCEDURE - TD2369 - SOP2

\section{Plant Productivity and Tissue Analysis}

Project Title: $\quad$ Evaluation of Terrestrial Microcosms for Assessing the

Fate and Effects of Genetically Engineered Microorganisms on

Ecological Processes

Project

Manager: $\quad$ Dr. Peter Van Voris

Principal

Investigator: $\quad$ Dr. James K. Fredrickson

\section{INTRODUCTION}

Soil microorganisms are integral catalysts in the cycling of essential plant nutrient elements in soils. Ecological impact upon an ecosytem from introduction of genetically engineered or novel microoganisms could result in changes in nutrient flow processes. Changes in ecosystem nutrient status may be reflected in plant productivity or yield and plant nutrient content. To determine if introduced bacteria have influenced ecosystem nutrient dynamics, the productivity and nutrient content of the above-ground portion of spring wheat (Triticum aestivum) and corn (Zea mays) from both inoculated and control microcosms can be measured.

\section{PROCEDURES}

\section{Nutrient Analysis}

Standard procedures are used for plant sampling and analysis (Jones and Steyn 1973). Com is sampled before tasseling by removing the entire leaf fully developed below the whorl from two plants in each microcosm; the four uppermost leaves of spring wheat are sampled before heading from four plants in each microcosm. Plant leaves are dried at $60^{\circ} \mathrm{C}$ for $48 \mathrm{~h}$ before grinding. Dried plant material is ground ( $40 \mathrm{mesh}$ ) using a mechanical mill with stainless steel surfaces to minimize contamination with trace metals. 
Ground plant material is ashed using a modified wet ash procedure in which $0.1 \mathrm{~g}$ of dried plant material is accurately weighed and placed in a Teflon container with $2.5 \mathrm{ml}$ of concentrated $\mathrm{HNO}_{3}$ at $80^{\circ} \mathrm{C}$ for $12 \mathrm{~h}$. The ashed tissue is then brought to $20 \mathrm{ml}$ and analyzed directly for $\mathrm{P}, \mathrm{S}$, $\mathrm{Zn}, \mathrm{Fe}, \mathrm{Mn}$, and Mo by inductively coupled plasma (ICP) spectrometry. Total nitrogen content of plant tissue is measured by standard Kjeldahl procedure (Bremner and Mulvaney 1982) or, alternarively, by a Leco CHN analyzer.

\section{Productivity Analysis}

Plant biomass production is assessed by harvesting the above-ground portion of the plant, drying it at $60^{\circ} \mathrm{C}$, and weighing. Plant biomass is expressed as grams of dry weight per plant.

\section{REAGENTS AND MATERIALS}

Concentrated $\mathrm{HNO}_{3}$ (Mallinckrodt Inc., of Paris, Kentucky)

Teflon bombs

Inductively Coupled Plasma Spectrometry (Applied Research Laboratories Inc., Sunland, Califomia \& Jarrell-Ash) (Thermo Jarrell-Ash Corp., Franklin, Maine)

Mettler PL1200 electronic balance, reading range $0.01 \mathrm{~g}$ (Mettler lnstruments Corp., Highstown, New Jersey)

Mettler AE 163 electronic balance, dual weighing range, readability 0.0001

\section{REFERENCES}

Bremner, J. M., and C. S. Mulvaney. 1982. In Methods of Soil Analysis, Part 2 - Chemical and Microbiological Properties, 2d ed., eds. A. L. Page, R. H. Miller, and D. R. Keeney, pp. 595624. American Society of Agronomy, Madison, Wisconsin.

Jones, J. B., and W. J. A. Steyn. 1973. Sampling, handling, and analyzing plant tissue. In Soil Testing and Plant Analysis, eds. L. M. Walsh and J. D. Beaton, pp. 249-270. Soil Science Society of America, Madison, Wisconsin. 
STANDARD OPERATING PROCEDURE - TD2369 - SOP3

\section{Rhizosphere and Endorhizosphere Sampling}

Project Tille: Evaluation of Terrestrial Microcosms for Assessing the

Fate and Effects of Generically Engineered Microorganisms on

Ecological Processes

Project

Manager: $\quad$ Dr. Peter Van Voris

Principal

Investigator: $\quad$ Dr. James $\mathrm{K}$. Fredrickson

\section{INTRODUCTION}

More than 80 years ago, Hilmer (1904) described the rhizosphere as the zone of soil around roots where microbial growth is stimulated by organic compounds released by roots. Since then, the region of plant root interaction with microorganisms has been extended to include the rhizoplane or root surface and the endorhizosphere, in and between cells of the root cortex (Patriquin et al. 1983). Azospirillum spp. are preferentially enriched in the rhizosphere and rhizoplane and appear to readily establish in the endorhizosphere of maize and wheat (Patriquin and Dobereiner 1978). The rhizosphere is inherently a zone not physically well defined, and thus there are a variety of procedures for obtaining rhizosphere samples. The main objective of this Standard Operating Procedure is to clearly delineate the procedures that will be used for rhizosphere and endorhizosphere sampling.

\section{RRQCEDURES}

\section{Rhizosphere Sampling}

Rhizosphere samples for microbiological analysis are obtained following a standard soil analysis procedure described by Wollum (1982). Corn (Zea mays) and spring wheat (Triticum 
aestivum) roots and rhizosphere soil are carefully excavated with a hand trowel from soil-core microcosms. Samples are placed in sterile whirl-pak bags, transported on ice to the laboratory, and processed the same day.

Roots are shaken lightly to remove loosely adhering soil. For each sample, approximately $5 \mathrm{~g}$ of root with adhering soil is transferred to a $99-\mathrm{ml}$ blank dilution bottle containing sterile physiological saline. Because variability within each bulk sample is possible, numerous subsamples are used in the first dilution. Dilution bottles are shaken on a mechanical reciprocating shaker at $150 \mathrm{rpm}$ for $10 \mathrm{~min} ; 10 \mathrm{ml}$ of diluent is immediately removed and transferred to a $90-\mathrm{ml}$ sterile saline dilution blank (alternatjvely, $1 \mathrm{mi}$ of diluent is added to $9 \mathrm{ml}$ of sterile saline) to establish the $10^{-3}$ dilution. The dilution series is then continued to $10^{-8}$ or to extinction. The GEM models are then enumerated according to GEM Detection and Enumeration Standard Operating Procedure 835-SOP5. Bulk soil samples are handled in a similar manner; however, $10 \mathrm{~g}$ of soil is placed in a $95-\mathrm{ml}$ dilution blank for the $10^{-1}$ dilution.

\section{Endorhizosphere}

Endorhizosphere samples are taken from the same bulk samples obtained for rhizosphere soil samples. Roots are washed free of soil with sterile deionized water. Nodal roots are then surface sterilized (Patriquin and Dobereiner 1978) by immersing the roots, except the proximal 2 cm of cut ends, in $1 \%$ chloramine-T (Sigma) solution for $1 \mathrm{~h}$. The root pieces are then immersed for $30 \mathrm{~min}$ in sterile $0.05 \mathrm{MpH} 7$ phosphate buffer and rinsed three times with sterile deionized water. Approximately $3 \mathrm{~g}$ of fresh root is macerated in $99 \mathrm{ml}$ of sterile physiological saline, or variations there of with the same weight-to-volume ratio, in a blender to free bacteria residing in the endorhizosphere. A dilution series of the root macerate is prepared in sterile saline blanks as described above.

\section{REAGENTS}

Purity of all reagents is analytical grade, and all solutions are made with deionized water. 


\section{Sterile Physiological Saline}

Dissolve $8.5 \mathrm{~g}$ of $\mathrm{NaCl}$ (J.T. Baker, Phillipsburg, New Jersey) in $1000 \mathrm{ml}$ of deionized water; dispense appropriate volume into dilution bottles, and autoclave at $121^{\circ} \mathrm{C}$ and $15 \mathrm{psi}$ for $20 \mathrm{~min}$.

\section{Chloramine - T}

Dissolve $1 \mathrm{~g}$ of chloramine- $\mathrm{T}$ ( $\mathrm{N}$-chloro-p-toluenesulfonamide; Sigma) in $100 \mathrm{ml}$ of deionized water.

Phosphate Buffer

Phosphate buffer $\mathrm{pH} 7$ is prepared by mixing $195 \mathrm{ml}$ of stock $0.1 \mathrm{M} \mathrm{NaH}_{2} \mathrm{PO}_{4}$ (J.T. Baker) with $305 \mathrm{ml}$ of $0.1 \mathrm{M} \mathrm{Na}_{2} \mathrm{HPO}_{4}$ (J.T. Baker) and diluting to $1 \mathrm{~L}$ with distilled water. Buffer is sterilized by autoclaving as described earlier.

\section{Equipment}

Instruments and equipment used for these procedures include: Mettler PL1200 electronic balance, reading range $0.01 \mathrm{~g}$; Mettler AE163 electronic balance, dual weighing range, readability $0.01 \mathrm{mg}$; New Brunswick portable reciprocating shaker Model G-2 (New Brunswick Scientific Co., New Brunswick, New Jersey); Osterizer blender Model 854-04 (John Oster, Manufacturing, Milwaukee, Wisconsin). 


\section{REFERENCES}

Hiltner, L. 1904. Uber neure erfahrungen und probleme auf dern gebiet der bodenbacteriologie and unter besonderer berucksichtigung der rundugung und brache. Arb. Dtsch. Landw. Berlin 98:59-78.

Patriquin, D. G., J. Dobereiner, and D. K. Jain. 1983. Sites and processes of association between diazotrophs and grasses. Can. J. Microbiol. 29:900-915.

Patriquin, D. G. and J. Dobereiner. 1978. Light microscopy observations of tetrazoliumreducing bacteria in the endorhizosphere of maize and other grasses in Brazil. Can.J. Microbiol. 24:734-742.

Wollum, A. G. 1982. Cultural methods for soil microorganisms. In Methods of Soil Analysis, Part 2 - Chemical and Microbiological Properties, 2d ed., eds. A. L. Page, R. H. Miller, and D. R. Keeney, pp.781-802. American Society of Agronomy, Madison, Wisconsin. 
STANDARD OPERATING PROCEDURE - TD 2369 -SOP4

\section{Leachate Analysis}

Project Title: $\quad$ Evaluation of Terrestrial Microcosms for Assessing the

Fate and Effects of Genetically Engineered Microorganisms on Ecological Processes

Project

Manager.

Dr. Peter Van Voris

Principal Investigator.

Dr. James K. Fredrickson

\section{INTRODUCTION}

Microbiological and chemical analysis of microcosm leachates provides information as to the movement of mutant constructs through the soil/plant continuum and their influence on soil nutrient cycling processes. Binding of microorganisms to soil clay and organic particles can limit their movement through the profile. Empirical observations such as the lack of leaching of microbes through soil during periods of heavy rain, failure to wash substantial numbers of cells from soils in perfusion or leaching experiments, and increased release of microbes upon sonication or treatment with surfactants are cited as evidence for binding of microorganisms to soil particles (Stotzky and Burns 1982). However, movement of genetically engineered microorganisms through soil and into groundwater could be an important pathway for their environmental dissemination and potential exposure to humans. Hypothesized ecological impacts resulting from the release of genetically engineered microorganisms to the environment include effects upon nutrient cycling. Changes in ecosystem nutrient cycling processes may be reflected in soluble nutrient ( $\mathrm{PO}_{4}{ }^{3-}$, $\mathrm{SO}_{4}{ }^{2-}, \mathrm{NO}_{3}{ }^{-}$, soluble organic carbon) levels in soil. 


\section{PROCEDURES}

\section{Leachate Collection}

Leachate from microcosms are collected in sterile containers and transported on ice to the laboratory. Aliquots of leachate are analyzed for microorganisms on the same day, and leachates for chemical analysis are immediately filtered through a Millex ${ }^{-G V} 0.22-\mu \mathrm{m}$ filter unit (Millipore Co., Bedford, Massachusetts) and frozen $\left(-20^{\circ} \mathrm{C}\right)$ until analyzed.

\section{Microbiological Analysis}

Tenfold serial dilutions (to $10^{-8}$ or extinction) of aliquots of microcosm leachates are prepared in sterile physiological saline. Enumeration of $A$. lipoferum $\operatorname{Tn} 5$ mutant constructs are conducted according to GEM Detection and Enumeration Standard Operating Procedure TD 2369 SOP5.

\section{Chernical Analysis}

Filtrates are analyzed for inorganic anions, $\mathrm{PO}_{4}{ }^{3-}, \mathrm{SO}_{4}{ }^{2-}$, and $\mathrm{NO}_{3}{ }^{1-}$ by ion chromatography (Dionex Model 10, Dionex Corp., Sunnyvale, California). Samples are routinely analyzed on AS1 (Dionex Corp., Sunnyvale, Califormia) anion-exchange columns having a wide working range for these common anions using an eluent of $3 \mathrm{~m} M \mathrm{NaHCO}_{3}$ and $2.4 \mathrm{mM} \mathrm{Na} 2 \mathrm{CO}_{3}$ at flow rates of about $2.3 \mathrm{ml} / \mathrm{min}$. Normal configuration of the IC (Dionex Model 10) consists of the anion exchanger followed by a membrane eluent suppressor that uses $0.025 \mathrm{~N} \mathrm{H}_{2} \mathrm{SO}_{4}$ to neutralize the basic eluent stream, and is followed by conductivity detection over the 1 - to $100-\mu \mathrm{S}$ ranges, full scale, with detection limits (twice baseline noise) of about $0.06 \mathrm{ppm}$ or better for $\mathrm{NO}_{3}{ }^{1-}, \mathrm{PO}_{4}{ }^{3-}$, and $\mathrm{SO}_{4}{ }^{2-}$. The elution order and detection limits can be altered or improved as necessary by supplemental use of other available columns (AS3, AS4a), eluents (commonly carbonatebicarbonate-hydroxide ratios), and LC systems (Models 16, $2120 \mathrm{IC}$ systems, Dionex). The routine system employs a Wisp (Waters Associates, Milford, Massachusetts) autosampler using volumes up to $200 \mu \mathrm{l}$. Usually no sample pretreatment other than filtration is necessary, unless low-level fluoride analyses are required; in that case, adjustment of the sample to the eluent composition is needed. Extemal standardization using bracketing of sample concentrations is done routinely, with calibration curves constructed by linear power-curve fits, as appropriate. Standard stock solutions (1-2 $\mathrm{g} / \mathrm{L}$ ) are prepared from the appropriate reagent-grade chemicals (oven-dried and stored under desiccation, as necessary), and the stock solutions are stored at $4^{\circ} \mathrm{C}$ in the dark 
Working standards are prepared by dilution of stock solutions. If the sample matrix is suspected to cause alteration of response, standards may be prepared into a background solution simulating the sample matrix; however, the wide working range of the AS1 column usually makes matrix matching unnecessary for most samples.

As necessary, the IC analysis may be supplemented by alternative specific detection methods. Nitrate/nirrite may be determined colorimetrically using the automated cadmium reduction method (APHA/AWWA/WPCF 1975), which determines nitrite directly and nitrate plus nitriite after reduction. Detection limit is $0.01 \mu \mathrm{g} / \mathrm{ml}$ as nitrite. Fluoride may be determined by ion specific electrode (ISE), with a detection limit of about $0.02 \mu \mathrm{g} / \mathrm{ml}$. Analysis of F- with Orion model 9609 (Orion Research Inc., Cambridge, Massachusetts) combination electrode involves addition of commercial total ionic strength adjustment buffer (TISAB III, Orion) according to the manufacturer's recommendations, followed by direct comparison of the milivolt sample reading to a standard curve. In addition, a standard curve can be used to monitor for matrix effects. Typical minimum volume required for analysis is $0.05 \mathrm{ml}$, plus $0.05 \mathrm{ml}$ TISAB III.

Ammonia is determined by ISE using the Orion model 9512 gas-sensing electrode after adjustment of $\mathrm{pH}$ according to manufacturer's recommendations. Direct reading comparison to a standard curve and standard addition techniques will be used. Typical minimum volumes required are $2 \mathrm{ml}$ of sample and $0.025 \mathrm{ml}$ of $10 \mathrm{M} \mathrm{NaOH}$.

Dissolved organic carbon (DOC) are determined by acidifying the filtered leachate to $\mathrm{pH}<2$ with phosphoric acid, sparging to remove inorganic carbon as $\mathrm{CO}_{2}$, and injecting the sample into a Dohrmann (Santa Clara, California) Model DC-80 Carbon Analyzer, which uses UV-enhanced acidified persulfate oxidation of the organics to $\mathrm{CO}_{2}$, followed by infrared detection. Total carbon is determined by direct injection of the filtered leachate, with inorganic carbon quantified by the difference between total and organic carbon. If purgeable organics are suspected, inorganic carbon may be determined directly by injection into an acidified solution, bypassing the UV-oxidation step, and proceeding to the detector. NBS-grade ground, oven-dried potassium hydrogen phthalate (KHP) is used to make the $2-\mathrm{g} \mathrm{DOC/L}$ stock, which is preserved by adding $1 \mathrm{mM} \mathrm{NaN} 3$ and storing at $4^{\circ} \mathrm{C}$ in the dark. Dilutions of the stock solution are nuade into 18 -megaohm water (Milli-Q system, Millipore Co., Bedford, Massachusetts), with the concentration of the dilutions corrected for any conrribution by the water (normally $\leq 0.25 \mu \mathrm{g} / \mathrm{ml}$ ). Dilutions below $50 \mu \mathrm{g} / \mathrm{ml}$ are prepared fresh daily, and dilutions of $50-$ to $100 \mu \mathrm{g} / \mathrm{ml}$ are kept for no more than 4 days. Although the instrument possesses single-point calibration, time and use cause some deterioration of the electronic calibration, so a standard curve bracketing the observed sample values is always used. 


\section{REFERENCE}

Stotzky, G., and R. G. Bums. 1982. The soil environment: Clay-humus-microbe interactions. In Experimental Microbial Ecology, eds. R. G. Burns and J. H. Slater, pp. 105-133. Blackwell Scientific Publications, London. 
STANDARD OPERATING PROCEDURE - TD 2369-SOP5

\section{Genetically Engineered Microorganism (GEM) Detection and Enumeration}

Project Title: $\quad$ Evaluation of Terrestrial Microcosms for Assessing the Fate and Effects of Genetically Engineered Mictoorganisms on Ecological Processes

Project

Manager. Dr. Peter Van Voris

Principal

Investigator: $\quad$ Dr. James K. Fredrickson

\section{INTRODUCTION}

The assessment of risks involved in the release of genetically engineered microorganisms to the environment requires tracking the environmental fate of the organism to determine its survival, growth, and dissemination. A variety of standard methods have been applied to the detection and enumeration of microorganisms in the environment including direct plating, enrichment cultures, identification of characteristic cell components (e.g., fatty acids, proteins, rRNAs), direct microscopy, immunofluorescence, and immunoradiography. The advantages and disadvantages have been the subject of much discussion and are reviewed by McCormick (1986). Recently, DNA probes have been used to detect Salmonella spp. (Fitts et al. 1983) and Yersinia spp. (Hill et al. 1983) in foods and microorganisms with specific catabolic genes in sediments (Sayler et al. 1985). The advantage to using gene probes for environmental detection is that they are very specific and have the potential for detection of gene transfer. Described herein is a procedure for DNA hybridization we have used to successfully enumerate $P$ seudomonas purida and Rhizobium spp. transposon (TnS) mutants in soil (Fredrickson et al. 1988).

\section{PROCEDURES}

Spot-Blot DNA Hybridization

Enumerations of Azospirillum lipoferum Sp Br17 (ATCC 29709) and A. lipoferum RG 20a (ATCC 29708) model GEMs (mutants expressing Tn5 insertion-associated kanamycin 
resistance) inoculated into microcosms are made by a spot-blot most-probable-number (MPN) technique (Fredrickson et al. 1988). After inoculating microcosms with the model GEMs, samples are obtained from the rhizosphere and endorhizosphere (TD2369-SOP3), leachate (835-SOP4), plant xylem fluid (TD2369-SOP6), and insect gut (TD2369-SOP8). Initial sample dilutions are made as described in TD2369-SOP3, except that modified Spirillum Nitrogen Fixing medium (MNFM) is used for the diluent, and aliquots of $277.5 \mu \mathrm{l}$ are removed and added to five wells in a sterile microtiter plate. Serial 1:10 dilutions $(27.5 \mu \mathrm{J})$ are made to extinction $\left(10^{-8}\right)$ to obtain a total volume of $277.5 \mu \mathrm{l} \mathrm{MNFM}$ broth per well. MNFM medium is amended with $100 \mu \mathrm{g} / \mathrm{ml}$ each kanamycin and cyclohexamide for added selection against indigenous microorganisms.

After incubation of microtiter plates at $27^{\circ} \mathrm{C}$ for 4 days, the entire contents of each well is quantitatively transferred to individual wells of a microsample filtration manifold (Schleicher \& Schuell Co., Keene, New Hampshire), taking care to avoid disturbing and transferring sedimented soil particles, and filtered onto GeneScreenPlus (New England Nuclear Corp., Boston, Massachusetts). Celis are lysed, DNA denatured, fixed by addition of $250 \mu \mathrm{l}$ of $0.5 \mathrm{~N} \mathrm{NaOH}$ to the individual wells, and filtered two times, followed by identical treatment with $1 M \mathrm{Tris} \mathrm{pH} 7.5$ and air-drying of filters. After DNA-DNA hybridization and autoradiography, positive blots indicating the presence of target DNA are scored for each dilution and the MPN value for a fivereplicate 10-fold dilution series is calculated (Alexander 1982). Uninoculated microcosm samples serve as controls to discern any background homology or nonspecific binding of probe. Altematively, colony blots from appropriate sample dilutions on MNFM agar plates amended with kanamycin and cyclohexamide can be used to identify the model GEMs. The procedures used for colony blots with Whatman \#541 filter paper are described by Gergen et al. (1979).

\section{Plasmid DNA and Probe Preparation}

E. coli MV12, harboring the suicide vector plasmid pGS9 containing $T n 5$, is cultured in LB broth with $50 \mu \mathrm{g} / \mathrm{ml}$ each chloramphenicol and kanamycin (Sigma), which selects for the plasmid pGS9 and maintenance of the transposon Tn5. Large-scale plasmid DNA preparations were performed as described by Maniatis et al. (1982). Purified plasmid DNA for use as probes is prepared by ultracentrifugation of plasmid preparations on $\mathrm{CsCl}(1.0 \mathrm{~g} / \mathrm{ml})$ density gradients with $0.5 \mathrm{mg} / \mathrm{ml}$ ethidium bromide at $55,000 \mathrm{rpm}$ for $17 \mathrm{~h}$ at $20^{\circ} \mathrm{C}$ followed by $1 \mathrm{~h}$ at $45,000 \mathrm{rpm}$ at $20^{\circ} \mathrm{C}$. Plasmid bands are removed and extracted four times with isopropanol:5 $\mathrm{M} \mathrm{NaCl}(1: 1)$ in Tris $\mathrm{pH} 8.0$ buffer to remove ethidium bromide. DNA is recovered by ethanol precipitation. [32P] DNA probe is made using a nick transiation kit (Bethesda Research Laboratories, Gaithersburg, Maryland) following the suggested protocol. [32P]dCTP at $3000 \mathrm{Ci} / \mathrm{mmol}$ (New England Nuclear) 
is used as the labeling nucleotide. Labeled probe is separated from unincorporated nucleotides by using a spun-column procedure (Maniatis 1982), and activity is quantified by liquid scintillation counting.

\section{DNA-DNA Hybridization}

GeneScreenPlus filters are placed back to back in a heat-sealable plastic bag with $15 \mathrm{ml}$ of the manufacturer's suggested prehybridization solution and incubated for 6 to $8 \mathrm{~h}$ at $65^{\circ} \mathrm{C}$. Whatman 541 filter colony blots are saturated with 6x SSC (SSC is $0.15 M \mathrm{NaCl}, 0.15 M$ sodium citrate) and washed for 1 to $2 \mathrm{~h}$ in $50 \mathrm{mM}$ Tris $\mathrm{pH} \mathrm{8,1} \mathrm{M} \mathrm{NaCl}, 1 \mathrm{mM}$ EDTA, and $0.1 \%$ SDS at $37^{\circ} \mathrm{C}$ with constant agitation to remove cell debris. Prehybridization is done as described previously for GeneScreenPlus with 5x SSC substituting for the prehybridization solution. Salmon sperm carrier DNA and [32P] DNA probe are denatured by heating in boiling water for 10 $\min$; they are cooled and added to plastic bags containing filters and solutions at $150 \mu \mathrm{g} / \mathrm{ml}$ and $10^{5} \mathrm{cpm} / \mathrm{ml}$ hybridization solution, respectively. Plastic bags are resealed and incubated at $65^{\circ} \mathrm{C}$ for 12 to $14 \mathrm{~h}$ with agitation.

Filters are washed according to manufacturer's directions for GeneScreenPlus filters. Alternatively, Whatman 541 colony blots are washed three times in $2 x \mathrm{SSC}$ at $65^{\circ} \mathrm{C}$ (20 min each) followed by one wash in $0.2 x \mathrm{SSC}$ at $55^{\circ} \mathrm{C}$ for $20 \mathrm{~min}$. Autoradiography is carried out at $-70^{\circ} \mathrm{C}$ using XAR-5 X-ray film (Eastman Kodak Co., Rochester, New York).

\section{REAGENTS}

All reagents and media used in this program are prepared from chernicals of analytical grade or of the highest purity available. A detailed chemical inventory listing chemical lot number and manufacturer stock number is kept on a computer file. Water for preparation of all solutions is distilled and deionized by the Milli-Q (Millipore Co., Bedford, Massachusetts) water purification system. 
Modified Spirillum Nitrogen Fixing Medium (MNFM)

Medium \#838 ATCC Culiure Handbook

$\begin{array}{ll}\mathrm{KH}_{2} \mathrm{PO}_{4} & 0.4 \mathrm{~g} \\ \mathrm{~K}_{2} \mathrm{HPO}_{4} & 0.1 \mathrm{~g} \\ \mathrm{MgSO}_{4} \cdot 7 \mathrm{H}_{2} \mathrm{O} & 0.2 \mathrm{~g} \\ \mathrm{NaCl} & 0.1 \mathrm{~g} \\ \mathrm{CaCl}_{2} & 0.02 \mathrm{~g} \\ \mathrm{FeCl}_{3} & 0.01 \mathrm{~g} \\ \mathrm{NaMoO}_{4} \cdot 2 \mathrm{H}_{2} \mathrm{O} & 0.002 \mathrm{~g} \\ \text { Na malate } & 5.0 \mathrm{~g} \\ \text { Distilled water } & 1.0 \mathrm{~L}\end{array}$

Adjust $\mathrm{pH}$ to 7.2-7.4 and autoclave for $20 \mathrm{~min}$. Kanamycin sulfate and cycloheximide (Sigma Chemical Co., St. Louis, Missouri) are made as stock solutions ( $25 \mathrm{mg} / \mathrm{ml}$ ) in distilled water, filter sterilized $(0.2 \mu \mathrm{m})$, and added to cooled media to achieve the desired final concentration.

Luria-Bertani (LB)Broth

Tryptone (Difco Labs., Detroit, Michigan) $10.0 \mathrm{~g}$

Yeast extract

$5.0 \mathrm{~g}$

$\mathrm{NaCl}$

$5.0 \mathrm{~g}$

Distilled water

$1.0 \mathrm{~L}$

Adjust $\mathrm{pH}$ to 7.5 and autoclave for $20 \mathrm{~min}$. Chloramphenicol (Sigma) is made as a stock solution in ethanol and stored at $-20^{\circ} \mathrm{C}$.

\section{$\underline{0.5 N \mathrm{NaOH}}$}

$20.0 \mathrm{~g} \mathrm{NaOH}$ (J. T. Baker)/L

\section{$1.0 M$ Tris-pH 8.0}

Dissolve $121.1 \mathrm{~g}$ Tris base in $800 \mathrm{ml}$ of water. Adjust $\mathrm{pH}$ to 8.0 by adding approximately $42 \mathrm{ml}$ concentrated $\mathrm{HCl}$ and raise the final volume to $1 \mathrm{~L}$. 
Ethidium Bromide

Add $1 \mathrm{~g}$ of ethidium bromide (Sigma) to $100 \mathrm{ml}$ of water. Stir on a magnetic stimer for several hours until dissolved; store in the dark at $4^{\circ} \mathrm{C}$.

\section{Isopropanol: $5 \mathrm{MNaCl}$ in Tris $\mathrm{pH} 8.0$}

$10 \mathrm{~m} M$ Tris base (Sigma) is prepared by dissolving $0.121 \mathrm{~g}$ Tris in $80 \mathrm{ml}$ water, adjusting the $\mathrm{pH}$ to 8.0 with concentrated $\mathrm{HCl}$, and diluting to $100 \mathrm{ml} ; 100 \mathrm{ml}$ isopropanol and $29.22 \mathrm{~g}$ $\mathrm{NaCl}$ are added to the $10 \mathrm{mM}$ Tris and the solution is shaken.

Nick Translation Kit (Bethesda Research Laboratories)

[32P] dCTP $3000 \mathrm{Ci} / \mathrm{mmol}$ (New England Nuclear)

$\underline{\text { SSC }}$

Stock 20x SSC is prepared by dissolving $175.3 \mathrm{~g}$ of NaCl and $88.2 \mathrm{~g}$ of sodium citrate in $800 \mathrm{ml}$ of water, adjusting the $\mathrm{pH}$ to 7.0 , and bringing the volume to $1.0 \mathrm{~L}$.

\section{Salmon Sperm DNA}

A solution of $10 \mathrm{mg} / \mathrm{ml}$ salmon sperm DNA is prepared by adding $100 \mathrm{mg}$ salmon sperm DNA (Sigma) to $10 \mathrm{ml}$ water and placing on a magnetic stirrer for several hours until dissolved. Aliquots of $1 \mathrm{ml}$ are dispensed into microfuge tubes and frozen at $-20^{\circ} \mathrm{C}$.

$50 \mathrm{~m} M$ T Tis pH $8.0,1 M \mathrm{NaCl}, 1 \mathrm{mM}$ EDTA. $1 \%$ SDS

With distilled water, $50 \mathrm{ml}$ of $1 M$ Tris $\mathrm{pH} 8.0,200 \mathrm{ml}$ of $5 \mathrm{M} \mathrm{NaCl}, 1 \mathrm{ml}$ of $1.0 M$ EDTA, and $100 \mathrm{ml}$ of $10 \%$ SDS are made to $1 \mathrm{~L}$. 


\section{MATERIALS AND EQUIPMENT}

GeneScreen Plus hybridization membrane (New England Nuclear Corp., Boston, Massachusetts)

XAR-5 x-ray film (Eastman Kodak Co., Rochester, New York)

Microsample filtration manifold (Shleicher \& Schuell Co., Keene, New Hampshire)

Whatman \#541 filter paper (Fischer Scientific, Pittsburgh, Pennsylvania)

Cenurifuge, 21,000 rpm, Beckman J2-21M (Beckman Instrument Corp., Palo Alto, Califomia)

Ultracentrifuge, 60,000 rpm, Beckman L8-80M

$-80^{\circ} \mathrm{C}$ Biofreezer, Model 8236 (Forma Scientific, Marietta, Ohio)

pH meter, Model 701A (Orion Research Inc., Cambridge, Massachusetts)

Water bath shaker/incubator, ambient to $85^{\circ} \mathrm{C}$ (Precision Scientific Co., Chicago, nlinois) 


\section{REFERENCES}

Alexander, M. 1982. Most probable number method for microbial populations. In Methods of Soil Analysis, Part 2 - Chemical and Microbiological Properties, 2 d ed., eds. A. L. Page, R. H. Miller, and D. R. Keeney, pp. 815-820. American Society of Agronomy, Madison Wisconsin.

Fitts, R., M. Diamond, C. Hamilton, and M. Neri. 1983. DNA-DNA hybridization assay for the detection of Salmonella spp. in foods. Appl. Environ. Microbiol. 46: 1146-1151.

Fredrickson, J. K., D. F. Bezdicek, F. J. Brockman, and S. W. Li. 1988. Enumeration of Tn5 mutant bacteria in soil by using a most-probable-number-DNA hybridization procedure and antibiotic resistance. Appl. Environ. Microbiol. 54:446-453.

Gergen, J. P., R. H. Stern, and P. C. Wensink. 1979. Filter replicas and pernanent collections of recombinant DNA plasmids. Nucleic Acids Res. 7:2115-2137.

Hill, W. E., W. L. Payne, and C. C. G. Aulisio. 1983. Detection and enumeration of virulent Yersinia enterocolitica in food by DNA colony hybridization. Appl. Environ. Microbiol. 46:636641.

Maniatis, T., E. F. Fritsch, and J. Sambrook. 1982. Molecular Cloning: A Laboratory Manual. Cold Spring Harbor Laboratory, Cold Spring Harbor, New York

McCormick, D. 1986. Detection technology: The key to environmental biotechnology. Biotechnology 4:419-422.

Sayler, G. S., M. S. Shields, E. T. Tedford, A. Breen, S. W. Hooper, K. M. Sirotkin, and J. W. Davis. 1985. Application of DNA-DNA colony hybridization to the detection of carabolic genotypes in environmental samples. Appl. Environ. Microbiol 49:1295-1303. 
STANDARD OPERATING PROCEDURE - TD2369 - SOP6

Plant Xylem Exudate Sampling

Project Title: $\quad$ Evaluation of Terrestrial Mictocosms for Assessing the Fate and Effects of Genetically Engineered Mictoorganisms on Ecological Processes

Project

Manager: $\quad$ Dr. Peter Van Voris

Principal

Investigator: $\quad$ Dr. James K. Fredrickson

Subtask

Investigator: Dr. Robert J. Fellows

\section{INTRODUCTION}

The phenomenon of sap (xylem) exudation from cut or broken stems was observed and chronicled even before Hales (1927) quantitated root pressure in trees. The origin of this fluid is usually attributed to an influx of water into the roots, which act as an osmometer through the accumulation of solutes within their sap (Kramer 1983).

Flux rates for exudation from the xylem vary widely both between species and diumally in a single plant (Parsons and Kramer 1974). Environmental effects such as soil water potential and root temperature also alter the rate of flow (Clarkson 1976). To maximize the amount of material to be collected, it is therefore important to standardize the procedures and sampling times to be employed.

\section{PRQCEDURES}

\section{Collection of Xylem Exudate}

The basic technique employed in these experiments is a modification of that of Cataldo et al. (1978). Samples are collected from wheat (Triticum aestivum) and corn (Zea mays) at two 
stages of development. Wheat is sampled during the boot stage (vegetative) and during mid-grain fill (reproductive); corn is sampled when the plants are 1 to $2 \mathrm{ft}$ tall (30-45 days after planting) (vegetative) and at tasseling (reproductive).

A minimum of three plants is used at each sampling period. Sampling is begun within the first $2 \mathrm{~h}$ of the light period when maximum flow rates can be expected (Clarkson 1974; D.A. Cataldo, personal communication). To further enhance the potential flux, the plants are watered with filtered $(0.2-\mu \mathrm{m})$, ion-free water just before the dark period immediately preceding sampling.

In chamber plants selected for sampling from both species, the leaf blade and sheaths are removed from the lower one-third of the shoot using sterile scalpels, forceps, and gloves. The exposed stem is then fitted with a circular (presterilized) cuvette through which ethylene oxide $\left(\mathrm{C}_{2} \mathrm{H}_{4} \mathrm{O}, 99.7 \%\right.$ min. $)$ is passed at a flow rate of $500 \mathrm{ml} / \mathrm{min}$ for $30 \mathrm{sec}$ for surface sterilization.

The gas is vented out of the chamber during this time and is followed by a 1 -min flush with sterile filtered air before cuvette removal. The stem is then cut with a sterile scalpel blade and a presterilized $2.0-\mathrm{cm}$ length of gum rubber tubing (the tubing diameter depends on the stem diameter and is chosen to ensure a secure fit). The open end of the gum rubber tube is fitted with a sterile $18-1 / 2$-gauge needle to which is attached a $30.0-\mathrm{cm}$ length of presterilized $1.0-\mathrm{mm}-\mathrm{ID}$ polyethylene tubing. The tubing is placed in a sterile $5.0-\mathrm{ml}$ vial cooled to $4^{\circ} \mathrm{C}$ either on a cooling plate or in an ice bucket.

Collection of exudate proceeds for a minimum of $4 \mathrm{~h}$ dependent on the flow rate from the cut stem. During this time the collection vial is covered with sterile foil to minimize potential airborne contamination. The vial is flushed with sterile air just before capping at the conclusion of the experiment. The samples are then analyzed for GEM content as described elsewhere.

\section{EOUIPMENT}

Equipment to be used for these procedures includes presterilized gloves, scalpel biades, and needles (18-1/2 gauge) (VWR Scientific). Latex rubber tubing (1/8- to $1 / 2$-in. ID), polyethylene tubing (1-mm ID), and 5-ml vials (VWR Scientific, Seattle, Washington) are sterilized by autoclaving. Ethylene oxide (Matheson Gas Products, Portland, Oregon) is regulated 
with a Union Carbide two-stage regulator (UPC 125 510). Vials are cooled on a Themoelectric Unlimited cooling plate while filling. The design for the stem sterilization cuvette is given elsewhere.

\section{REFERENCES}

Cataldo, D. A., T. R. Garland, R. E. Wildung, and H. Drucker. 1978. Nickel in plants. II. Distribution and chemical form in soybean plants. Plant Physiol. 62:566-570.

Clarkson, D. T. 1976. The influence of temperature on the exudation of xylem sap from detached root systems of rye (Secale cereale) and barley (Hordeum vulgare). Planta 132:297-304.

Hales, S. 1927. Vegetable Staticks. W \& J Inneys and T. Woodward, London.

Kramer, P. J. 1983. Water Relations of Plants. Academic Press, New York

Parsons, L. R., and P. J. Kramer. 1974. Diurnal cycling in root resistance to water movement. Physiol. Plant. 30:19-23. 
STANDARD OPERATING PROCEDURE - TD2369 - SOP7

Selection of Microbial Genotypes, Maintenance of Cultures, and Laboratory Safety Procedures

Project Title: $\quad$ Evaluation of Terrestrial Microcosms for Assessing the Fate and Effects of Genetically Engineered Microorganism on Ecological Processes

Project

Manager: $\quad$ Dr. Peter Van Voris

Principal

Investigator. $\quad$ Dr. James K. Fredrickson

\section{INTRODUCTION}

To follow the movement and fate of GEM models introduced to microcosms, the $A$. lipoferum strains are genetically modified in vivo by transposon mutagenesis using the broad host range mobilization plasmid pGS9 containing the transposable element Tn5. Transposons are specific DNA elements with the ability to move as a unit and integrate more or less randomly in the bacterial chromosome. Insertion of a transposon into a gene can cause a complete loss of gene function accompanied by drug resistance. This system has been used successfully to isolate at Tn5 insertion mutants of $A$. lipoferum (Vanstockem et al. 1985, 1987). Insertion mutants obtained from conjugation with pGS9 harboring donor strains are positively identified by hybridization with PGS9 DNA probe (see TD2369-SOP5). Mutants are also fully characterized for growth rate in enriched and $\mathrm{N}$-free minimal salts malate medium in comparison to the wild type to ensure against using a mutant that is severely debilitared.

\section{PROCEDURES}

\section{Bacterial Strains and Plasmids}

Two strains of Azospirillum lipoferum, A. lipoferum SpRG20a (ATCC \#29708) and A. lipoferum SpBr17 (ATCC\#29709), were purchased from American Type Culture Collection 
(ATCC) (Rockville, Maryland) for use as recipients for transposon mutagenesis. Bacterial isolates to be used as conjugative suicide plasmid donors (pGS9) are Escherichia coli MV12 (Leu-, Thr', Thi', Thy', Trp-) from the laboratory of Dr. M. Kahn (Washington State University) and E. coli WA803 (Met-, Thi'), a gift from N. Iyer (Carleton University). A. lipoferum strains are grown at $27^{\circ} \mathrm{C}$ and maintained in nitrogen-fixing medium (NFM) as described in Media \#838 in the ATCC catalog (1980). E. coli strains are grown at $37^{\circ} \mathrm{C}$ on Luria-Bertani (LB) medium amended with 25 ppm kanamycin (Sigma). Stock bacterial cultures are preserved by freezing in $40 \%$ glycerol.

\section{Construction of Azospirillum TnS Inserts}

The method of Vanstockem et al. $(1985,1987)$ is employed to isolate 5 mutants. Azospirillum recipient and $E$. coli (containing pGS9) donor cells are grown to log phase. Donor and recipient cultures are pelleted by centrifugation ( $1500 \times \mathrm{g}$ for $5 \mathrm{~min}$.). Cells are washed twice in sterile physiologic saline and resuspended in saline solution to obtain approximately $10^{9}$ cells $/ \mathrm{ml}$. Recipient cells are heat shocked at $51{ }^{\circ} \mathrm{C}$ in a water bath for $5 \mathrm{~min}$, mixed with donor cells, and placed on sterile 0.01- $\mu \mathrm{m}$ nitrocellulose membrane filters (Sartorius Co.) on LB agar plates. Matings are incubated for $24 \mathrm{~h}$ at $28^{\circ} \mathrm{C}$. Filters containing only recipient or donor cells serve as controls. Following mating, cells are dislodged from filter membranes and resuspended in $0.5 \mathrm{ml}$ sterile saline solution and spread on NFM agar plates $(150 \times 15 \mathrm{~mm})$ amended with 25 $\mu \mathrm{g} / \mathrm{ml}$ kanamycin for the selection of Azospirillum Tn5 inserts. Control cells are resuspended, diluted, and spread on appropriate selective media. Azospirillum TnS inserts are purified by streaking for isolated colonies on NFM agar plates amended with $25 \mu \mathrm{g} / \mathrm{ml}$ kanamycin.

\section{Laboratory Safety}

Although the microorganisms used in these studies are relatively innocuous, safety precautions are used when handling the recombinant bacteria. The NHH Guidelines for Research Involving Recombinant DNA Molecules (Federal Register of May 7, 1986, 52FR16958) are

routinely followed. This includes autoclaving or incinerating all recombinant cultures used in the study in either laboratory media or soil or plant samples. 


\section{REAGENTS AND MEDIA}

Purity of all reagents is analytical grade, and all solutions are made with distilled water.

Sterile Physiological Saline

Dissolve $8.5 \mathrm{~g} \mathrm{NaCl}$ (J.T.Baker Co.) in $1 \mathrm{~L}$ distilled water and autoclave at $121^{\circ} \mathrm{C}$ and 15 psi for $20 \mathrm{~min}$.

\section{Luria-Bertani (LB) Medium}

Mix $10.0 \mathrm{~g}$ tryptone, $5.0 \mathrm{~g}$ yeast extract, and $10.0 \mathrm{~g} \mathrm{NaCl}$ in $\mathrm{l} \mathrm{L}$ distilled water. Adjust $\mathrm{pH}$ to 7.5 with $1 \mathrm{~N} \mathrm{NaOH}$. Add $15 \mathrm{~g}$ agar for solid medium. Autoclave at $121^{\circ} \mathrm{C}$ and $15 \mathrm{psi}$ for 20 min.

Spirillum Nitrogen-Fixing Medium (ATCC Media \#838)

Mix $0.4 \mathrm{~g} \mathrm{KH}_{2} \mathrm{PO}_{4}, 0.1 \mathrm{~g} \mathrm{~K}_{2} \mathrm{HPO}_{4}, 0.2 \mathrm{~g} \mathrm{MgSO}_{4} \cdot 7 \mathrm{H}_{2} \mathrm{O} ; 0.1 \mathrm{~g} \mathrm{NaCl} ; 0.02 \mathrm{~g} \mathrm{CaCl}_{2} ; 0.01 \mathrm{~g}$ $\mathrm{FeCl}_{3} ; 0.002 \mathrm{~g} \mathrm{Na}_{2} \mathrm{MoO}_{4} \cdot 2 \mathrm{H}_{2} \mathrm{O} ; 5.0 \mathrm{~g} \mathrm{Na}$-malate; $1.0 \mathrm{~L}$ distilled water. Adjust $\mathrm{pH}$ to 7.2-7.4 with $5 \mathrm{~N} \mathrm{NaOH}$. For solid medium, add $15 \mathrm{~g} \mathrm{Bacto} \mathrm{agar} \mathrm{(Difco} \mathrm{Labs.,} \mathrm{Detroit,} \mathrm{Michigan).}$ Autoclave at $121^{\circ} \mathrm{C}$ and $15 \mathrm{psi}$ for $20 \mathrm{~min}$.

\section{Nitrogen-Fixing Medium with 25 pom Kanamycin}

Dissolve $250 \mathrm{mg}$ Kanamycin sulfate (Sigma \# K1377) in $10 \mathrm{ml}$ distilled water, filter through a Millix ${ }^{\circledR}$ GS 0.22- $\mu \mathrm{m}$ filter (Millipore Co., Bedford, Massachusetts), and store aliquots in sterile containers at $-20^{\circ} \mathrm{C}$. Add $1 \mathrm{ml}$ to $1 \mathrm{~L}$ of cooled NFM medium for liquid culture or to lukewarm $\left(-48^{\circ} \mathrm{C}\right)$ agar medium before pouring plates.

\section{Modified NFM}

NFM is amended with $1 \mathrm{~g} \mathrm{NH}_{4} \mathrm{Cl}$ and $0.005 \mathrm{~g}$ biotin per liter of medium for more luxuriant growth of Azospirillum spp. 
$\underline{80 \% \text { Glycerol }}$

Add $20 \mathrm{ml}$ of distilled water to $80 \mathrm{ml}$ of glycerol (Difco Lab., Detroit, Michigan) and autoclave at $121^{\circ} \mathrm{C}$ and $15 \mathrm{lb}$ pressure for $20 \mathrm{~min}$. Aseptically dispense $1 \mathrm{ml}$ aliquot into sterile polypropylene freezer vials.

\section{EQUIPMENT}

Instruments and equipment used for these procedures include: Mettler PL1200 electronic balance, readability 0.01g; Mettler AE163 electronic balance, dual weighing range, readability 0.01 mg; Beckman J2-21M centrifuge, 21,000 rpm; Brinkmann Eppendorf microcentrifuge, 5,000 rpm (Brinkmann Instruments, Westburg, New York); dark field Quebec Colony counter (American Optical Co., Buffalo, New York); New Brunswick Model G-27 Controlled Environment Incubator Shaker $\left(0-60^{\circ} \mathrm{C}\right)$ (New Brunswick Science Co., New Brunswick, New Jersey); Environ Clean Hood by Environmental Air Control Inc.; walk-in cold room maintained at $2^{\circ} \mathrm{C}$; Forma model 8326 deep freezer $\left(-85^{\circ} \mathrm{C}\right.$ ), (Forma Scientific, Marietta, Ohio); Milii-Q water purification systems (Millipore Co., Bedford, Massachusetts); Orion Model 701A pH meter (Orion Research Inc., Cambridge, Massachusetts); Cole-Palmer International (Chicago, nlinois); model R1253-00 immersion water circulator-heater $\left(20-85^{\circ} \mathrm{C}\right)$; Shaker-Incubator Water Bath $\left(20-85^{\circ} \mathrm{C}\right)$ (Precision Scientific Co., Chicago, Illinois). (The first two items are serviced regularly by Hanford Standards Laboratory, and the others are usually calibrated by the user.)

\section{REFERENCES}

ATCC. 1980. ATCC Catalog, 14th ed,, eds. H. D. Hatt et al. American Type Culture Collection, Rockville, Maryland.

Vanstockem, M., K. Michiels, J. Vanderleyden, and A. P. Van Gool. 1985. Transfer and random integration of TnS in Azospirillum. In Azospirillum lll: Genetics, Physiology, Ecology, ed. W. Klingmuller. Springer-Verlag, Berlin.

Vanstockem, M., K. Michiels, J. Vanderleyden, and A. P. Van Gool. 1987. Transposon mutagenesis of Azospirillum brasilense and Azospirillum lipoferum: physical analysis of $\operatorname{Tn} S$ and TnS- Mob insertion mutants. Appl. Environ. Microbiol. 53:410-415. 
STANDARD OPERATING PROCEDURE - TD2396-SOP8

\section{Insect Rearing and Sampling for Microbial Analysis}

Project Title: Evaluation of Terrestrial Microcosms for Assessing the Fate and Effects of Genetically Engineered Microorganisms on Ecological Processes

Project

Manager:

Dr. Peter Van Voris

Principal

Investigator: $\quad$ Dr. James K. Fredrickson

Subtask

Investigator: Dr. Lee Rogers

\section{INTRODUCTION}

Phytophagous insects commonly feed on a variety of grass-related plants including wheat (Triticum aestivum) and com (Zea mays). The likelihood of insects acquiring microorganisms from feeding on colonized plants may be dependent on the type of feeding mechanism employed. Representatives from two different insect orders, the Orthoptera and Homoptera, are used in this study. Members of the order Orthoptera have chewing mouth parts, and the Homoptera have piercing-sucking mouth parts.

\section{PROCEDURES}

After 12 and 21 days for corn borers and aphids, respectively, insects were sampled, macerated in sterile deionized water, and assayed for A. Lipoferum $\mathrm{Tn} 5$ mutants. Approximately 25 aphids were removed from the wheat leaf surface, and 4 to 9 corn borers were removed from the maize stem interior. 


\section{Orthoptera Experimental Procedures}

European corn borers (Ostrinia nubialis) (French Agricultural Research Service, Lamberton, Minnesota) at the third to fourth instar were placed on individual maize plants and were confined to the lower stalk by loosely wrapping with chiffon. All microcosms receiving insects are covered with insect netting to prevent the movement of individual insects between treatments. Individuals are then removed from the plants and their gut contents are removed according to procedures described by Kindler and Spomer (1986). The foregut or crop of grasshoppers contains undigested materials. The crops are removed from five grasshoppers from each microcosm to which the insects were introduced and placed in sterile blender cups containing $0.85 \%$ saline. Grasshopper crops are macerated by blending for $2 \mathrm{~min}$, and a dilution series is prepared for each microcosm sampling as described in SOP 3. Analysis of macerated crops for A. lipoferum Tn5 mutants is executed according to SOP 5.

\section{Homoptera Experimental Procedures}

Approximately 50 to 100 aphids (Schizaphis sp.) indigenous to eastern Washington State were introduced onto wheat plants. Aphids (15-20 individuals) are placed on the plants within the microcosms; aphids are sampled from the microcosms after 2 days and macerated as described earlier. Initially, the entire insect bodies are macerated to analyze for $A$. lipoferwn TnS mutants. If analysis (SOP 5) indicates the presence of the model genetically engineered microorganisms (GEMs), then an attempt is made to dissect out individual insect guts to determine if the model GEMs were ingested.

\section{REFERENCE}

Kindler, S. D., and S. M. Spomer. 1986. Biotypic status of six greenbug (Homoptera: Aphididae) isolates. Environ. Entomol. 15:567-572. 
STANDARD OPERATING PROCEDURE - TD2396-SOP9

Operation of Microcosm Containment Chamber (MCS)

Project Title: $\quad$ Evaluation of Terrestrial Mictocosms for Assessing the

Fate and Effects of Genetically Engineered Microorganisms on

Ecological Processes

Project

Manager:

Dr. Peter Van Voris

Principal

Investigator: Dr. James K. Fredrickson

Subtask

Investigator: $\quad$ Mr. Michael W. Ligotke

\section{INTRODUCTION}

One of the major benefits of using microcosms for the initial testing of GEMs for potential ecological effects is that a greater degree of containment can typically be achieved $\mathrm{n}$ comparison to the field. However, in some situations test facilities such as growth chambers or greenhouses may not provide the degree of containment that may be required or desired for a particular GEM. Therefore, a prototype chamber was developed, as part of a project option, that may be used to achieve a greater degree of containment for recombinant bacteria being tested in soil-core microcosms. The main purpose of the initial design was to develop a chamber that could be used for soil-core microcosm evaluations of the fate and ecological impacts from a GEM, yet limit the transport of the test organisms outside of the microcosm, rather than to achieve a certain level (i.e., P3) of containment. On the basis of the initial design and construction exercise, the prototype MCS design was reevaluated and plans were modified (Appendix B consists of MCS revised plans). This SOP is intended to provide guidance on operation of the MCS and on safety concerns and potential areas for QA/QC consideration. Because the MCS was not used in any experiments as part of this project, modifications will likely be necessary as experience is gained with its use and modifications in its design are made. 


\section{PROCEDURES}

The prototype chamber was designed to contain up to 6.25 - or 18.8 -cm-diameter by 60 $\mathrm{cm}$-long intact soil cores. The cores are placed on the Buchner funnels that rest in the slots near the base of the chamber. Leachate collection vessels are then attached to the funnels with Tygon or Teflon tubing, and the front panel of the chamber is then replaced and sealed. Entry to the interior of the chamber after sealing the front panel is through an airlock mounted on the side of the chamber. The interior of the airlock can be disinfected with ethylene oxide, in a manner analogous to an anaerobic chamber airlock, to limit the contamination of the exterior of the chamber with the test organism during sampling, inoculation, etc. All manipulations in the interior of the MCS are conducted through the three glove ports, which are located at positions on the face of the chamber such that there is access to all areas within the chamber.

At the completion of a particular experiment the cores can be bagged and sealed, and the chamber flushed with ethylene oxide for disinfestation. The process for bagging the cores requires a pulley or winch to be installed on the interior of the chamber frame to allow the raising and bagging of the individual cores. Once the cores have been bagged and the chamber disinfested, the front panel can be removed and the bagged cores removed for incineration.

\section{Chamber Integrity Tests}

The containment chamber(s) can be evaluated in several ways to determine the integrity of the chamber. Pressure or vacuum tests can be performed to determine if the chamber has been adequately sealed. These tests can be conducted under normal operating conditions (slight negative pressure) or under extremes to determine the pressure at which there is significant failure. A second type of test that can be conducted would involve the release of a particulate racer material within the chamber and then monitoring for release of the particles during normal operation. This could be done by operating the chamber in a clean room equipped with a particle analyzer and monitoring for particle transport from the chamber. This can serve as both a check on the probability of microbial contamination of the outside atmosphere and for training purposes. A material such as zinc sulfide, highly fluorescent under a black light, has been used in these types of tests. These types of tests are suggested as areas for QA/QC pertaining to chamber operation. 
Leachate Collection

Although not included on the prototype chamber, a system was designed for the aseptic collection of leachate form the soil cores while they reside in the chamber. This requires a line of Teflon tubing from the base of the interior of the individual leachate collection vessels to a manifold on the side of the chamber. At the manifold, a stainless steel hose connector exits to the exterior of the chamber. At the exterior face is a stainless steel plug valve (NUPRO P4T) with a hose connector to attach a vacuum flask. This flask is then connected to the leachate collection line with Teflon tubing, and the vacuum line attached to the sidearm which is stopped with cotton to prevent the movement of microorganisms with the air flow. This allows the syphoning of leachate form the individual microcosms into a sterile vessel. After disconnection, the valve can then be removed, replaced by a sterile valve, and autoclaved. The residual material that is left in the lines and leachate collection vessel in the bottom of the chamber presents a problem for sampling the leachate more than once during the course of the experiment. However, it may be possible, by means of several rinse cycles with a disinfectant solution and sterile water, to disinfest the lines to prevent cross-contamination of leachate between sampling times. 
APPENDIX B

MICROCOSM CONTAINMENT CHAMBER DESIGN 


\section{APPENDIX B \\ MICROCOSM CONTAINMENT CHAMBER DESIGN}

\section{B.1 PROTOTYPE MCS CHAMBER}

In ecological testing of GEMs, one priority is to provide a means for containing the recombinant microorganisms being tested in facilities such as growth chambers and greenhouses that were not specifically designed for containing microorganisms. In fulfillment of an optional task in the original project proposal, a microcosm containment system (MCS) was designed and constructed. Construction of the first prototype chamber was successful in that it completes the major goal of this task listed in the project proposal. However, the process of design, construction, and postconstruction review led to the development of a list of several important design modifications that were not described in the original proposal but which are thought to be important for inclusion in the revised designs.

It should be noted that the important design modifications recommended for inclusion in the planned second chamber, which would increase costs significantly, were recommended because experience and insights gained during design and construction indicated that a greater degree of microbe containment and system usefulness might be achieved by incorporating additional features into a second-generation MCS system.

The protorype MCS was designed to contain as many as six large (25-cm diameter) and 18 small (17.8-cm diameter) soil cores, each about $60 \mathrm{~cm}$ long, for GEM tests. Because standard glove boxes cannot provide support for the estimated 140 - to $230-\mathrm{kg}$ (300- to 500-lb) total soil microcosm mass, all parts of the new chamber were especially constructed, with the exception of the sample interchange, which was purchased from a manufacturer of glove boxes. In addition to containing the large soil microcosms, the chamber provides sufficient free space over the tops of the soil cores to permit growth of tall plants such as grains and com. Air passing into and exhausting from the chamber is filtered using double sets of HEPA (high-efficiency particulate air) filters achieving filtration effectivenesses of greater than $99.97 \%$. Three glove ports allow working access to the chamber. Ethylene oxide gas may be injected into the chamber and interchange to sterilize equipment and samples being removed. 
A three-dimensional sketch of the constructed MCS is shown in Figure B.1. Construction drawings are included in Section B.3. The system was constructed of painted steel and Lexan ${ }^{\circledR}$ in two parts. The top section may be removed to facilitate chamber modification, relocation, and cleaning. Eye bolts were installed on the top to provide support for lifting the top section off the base. Connection between the top section and the base may be quickly dissasembled by slitring the seal and removing eight bolts. Additional access to the inside of the system may be obtained with or without the top section in place by removing the soil-column top stabilizer grid and placing it on the lower soil-column support grid. The inside of the chamber may then be accessed via the front panel on the base.

The top section was constructed of Lexan ${ }^{\otimes}$ suported by a steel base consisting primarily of 1-in.2 tubing. Lexan ${ }^{\circledR}$ was selected for durability and its resistance to corrosive materials. Some solvents such as xylene can degrade the transparency of the material, however. Three glove ports provide working access to all parts of the upper chamber, and a transfer box (Coy Laboratory Products Inc., Ann Arbor, Michigan) is connected to the lower right-hand side of the chamber. Because Lexan ${ }^{\circledR}$ filters ultraviolet light, the top window of the chamber may be replaced with UVtransparent plexiglass, or UV lamps may be operated within the chamber. Flanges for HEPA filters are located on each upper side panel of the top section.

The base of the chamber provides housing and structural support for soil microcosms, and is mounted on four multidirection, heavy-duty casters to allow the chamber to be easily moved. The base consists of a steel tube frame and 16-gauge sheet metal panels. All steel surfaces were coated with an epoxy paint. A grid of 1.5-in.-thick steel tubing supports soil columns; six panels placed on the grid are used to support a variety of soil column sizes, numbers, and configurations. A large front panel may be removed for easy access to the soil columns. Space is provided beneath the soil columns for leachate collectors, and leachate may be collected via valved ports near the bottom of the chamber.

Drawings and detailed construction instructions are provided in Section 1.3 for the prototype MCS. As experience was gained designing and constructing the first prototype chamber, a list of important modifications was prepared and is included in Section 1.2. Designs for a second MSC will include these suggested modifications.

${ }^{2}$ Lexan is a registered trademark of General Electric Corporation, Mount Vernon, Indiana. 


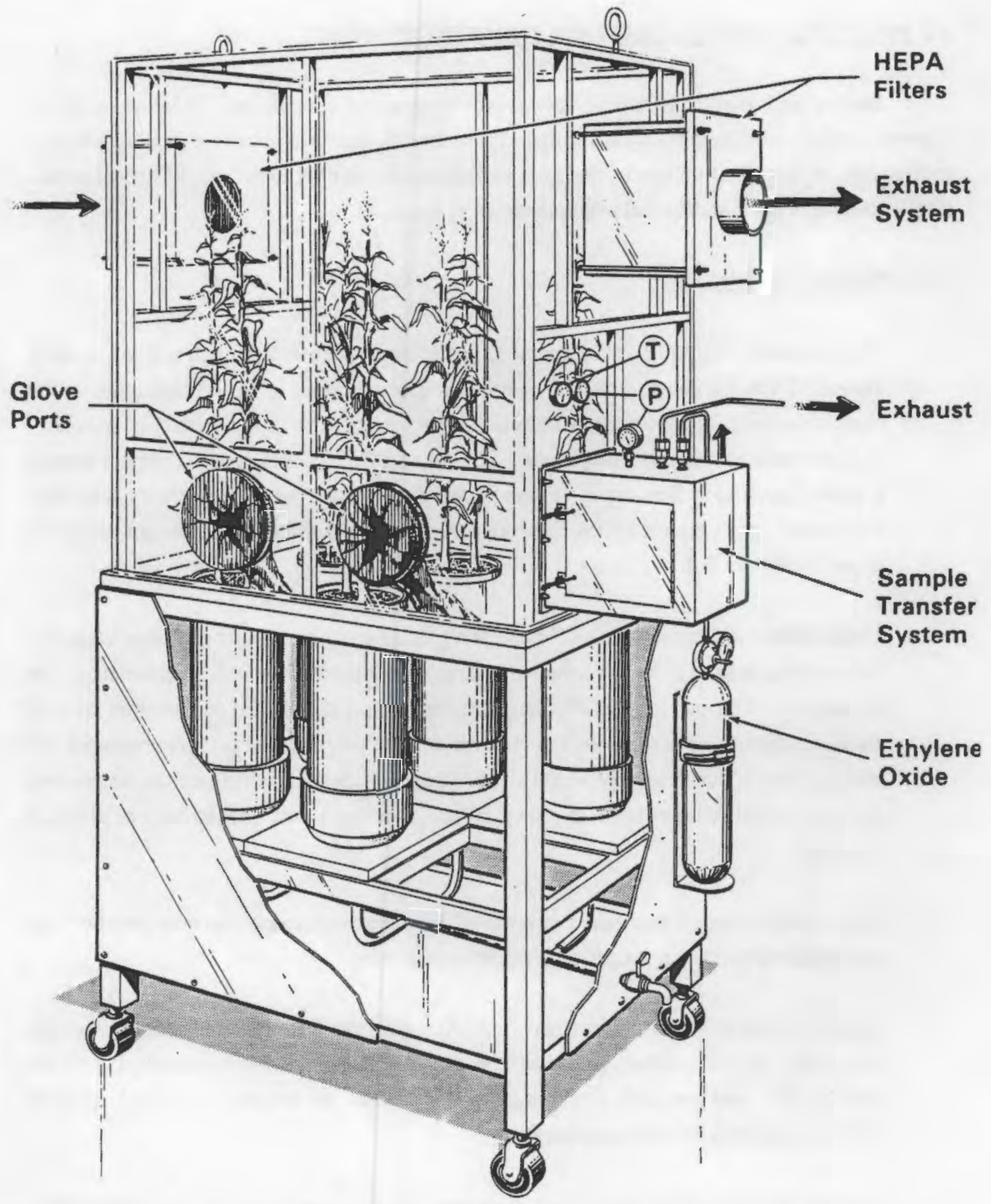

Figure B.1. Prototype microcosm containment chamber. 


\section{B.2 PROPOSED MODIFICATIONS FOR THE PROTOTYPE MCS}

During and after construction of the prototype GEM containment chamber, a list of important design considerations was prepared. These modifications will improve flexibility of use; sterilization of large soil columns; chemical resistance of chamber materials; electrical power supply; climate control; and special instrumentation systems.

\section{B.2.1 Proposed Modifications}

1. The chambers should be self-contained, rather than exhausted through a filter or other system. Thus, the chambers could be used for greater hazard levels. At a minimum, the chambers should be constructed with sealable ports for future connection to climate-control and special instrumentation systems. The second GEM containment chamber should support closed-loop flow ducts, air conditioning, a negative pressure line with automatic sterilization, and a double HEPA filter inlet. A schematic drawing of this design concept is shown in Figure B.2.

2. Use stainless steel construction. The use of a paint coating on the first prototype chamber, although the paint was a good grade of epoxy, revealed that paint will soon wear from or be scraped off the steel frame. Furthermore, the extra materials and construction costs of stainless steel would actually be less than the costs of painting and paint maintenance. In addition, use of stainless steel would provide superior chemical resistance, a noncorroded base for special coatings (such as epoxy, silicon, or teflon ), and reduced costs of chamber cleaning.

3. Add stronger support members to the top of the steel frame to support core isolation and sterilization procedures. Attach pulleys above each core.

4. Provide electrical power (approximately $20 \mathrm{~A}$ ) within the chamber. Power is required for UV lamps, electric winches, and other devices. Seal the electrical connection using vaportight sealers, and use high-temperature silicon sealant on the leads (to block microbe migration through the wire insulators).

5. Purchase of interchange boxes from manufacturers of glove boxes will probably remain cost-effective. Prepare designs in accordance with interchange mounting and operation requirements. 


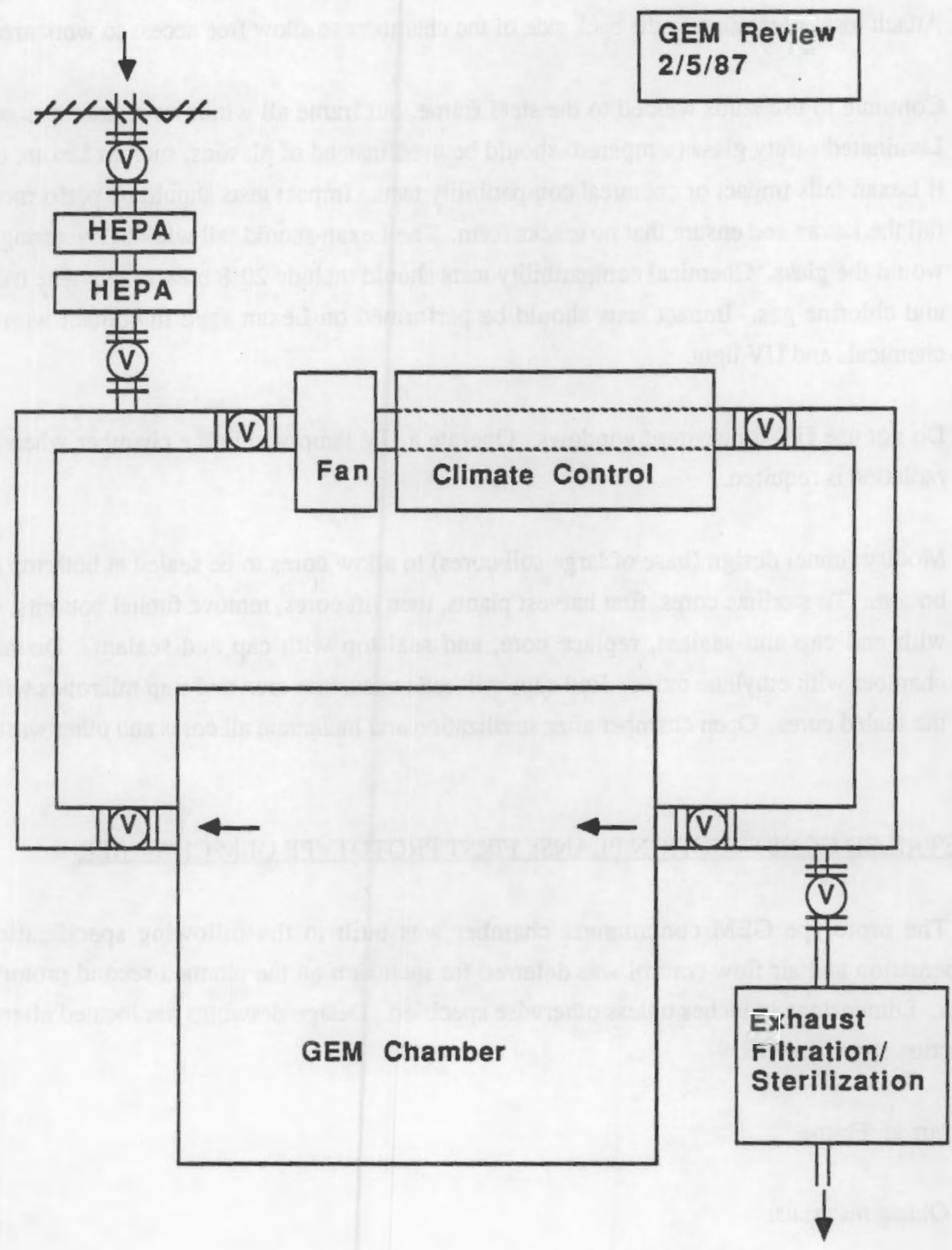

Figure B.2. Flow system in microcosm containment chamber.

B.5 
6. Limit the windows as much as is feasible. At a minimum, portions of the two side windows and all the back windows should be replaced with stainless steel sheet metal. Attach instrumentation to the back side of the chambers to allow free access to work areas.

7. Continue to use studs welded to the steel frame, but frame all windows in stainless steel. Laminated safety glass (tempered) should be used instead of plastics, such as Lexan, only if Lexan fails impact or chemical compatibility tests. Impact tests should be performed to fail the Lexan and ensure that no cracks form. The Lexan should fail without fracturing--as would the glass. Chemical compatibility tests should include $20 \%$ bleach, ethylene oxide, and chlorine gas. Impact tests should be performed on Lexan aged in contact with the chemicals and UV light.

8. Do not use UV-transparent windows. Operate a UV lamp within the chamber when UV radiation is required.

9. Modify funnel design (base of large soil cores) to allow cores to be sealed at both top and bottom. To sterilize cores, first harvest plants, then lift cores, remove funnel bottoms, seal with end cap and sealant, replace core, and seal top with cap and sealant. Disinfect chamber with ethylene oxide. End caps will reduce surface area and trap microbes within the sealed cores. Open chamber after sterilization and incinerate all cores and other wastes.

\section{B.3 DETAILED CONSTRUCTION PLANS: FIRST PROTOTYPE GEM CHAMBER}

The prototype GEM containment chamber was built to the following specifications. Instrumentation and air flow control was deferred for inclusion on the planned second prototype chamber. Dimensions in inches unless otherwise specified. Design drawings are located after the construction specifications.

\section{B.3.1 Part 1: Frame}

1. Obtain materials:

Steel tubing $1 / 8 \times 2 \times 2$, length $=20 \mathrm{ft}$

Steel tubing $1 / 8 \times 2 \times 1$, length $=40 \mathrm{ft}$.

Steel tubing $1 / 8 \times 1 \times 1$, length $=100 \mathrm{ft}$. 
Angle iron $1 / 8 \times 1 \times 1$, length $=20 \mathrm{ft}$.

Sheet metal $1 / 16$ gauge, area $=50 \mathrm{ft}^{2}$.

Lexan 1/4, area $=64 \mathrm{ft}^{2}$.

Epoxy paint, special brand.

Bolts, nuts, washers.

Metal plate, light-duty to cap tubing, heavy-duty for casters.

Casters, 4 each, heavy duty (approx 500-lb capacity each).

Bar stock, $1 / 4$ in. $\times 2$ in. $\times 20 \mathrm{ft}$.

2. Cut tubing for chamber legs.

Four each, $2 \times 2 \times 36.5$.

3. Cut angle iron for Elevation A.

Angle [ $1 \times 1]$; two each 26.0 in., two each 42.0 in.

4. Cut tubing for Elevation B.

Tubing [ $2 \times 1$ ] : 2 each 26.0 in., 2 each 42 in., 3 each 14.0 in., 2 each 28.0 in.

5. Cut tubing and angle iron for Elevation C.

Tubing [ $2 \times 1$ ] : 2 each 28.0 in., 2 each 46.0 in.

Tubing [ $1 \times 1$ ]: 2 each 28.0 in., 3 each 14.0 in.

Angle $[1 \times 1]$ : 8 each 6.0 in.

6. Assemble base of prototype chamber.

Do not assemble the inner five pieces of Elevation $\mathrm{C}$ at this time.

Do not attach the eight 6.0-in. angle iron supports at this time.

Weld together outer four pieces of Elevation $C$.

Cap bothends of all four chamber base legs with 3/16-in. sheet metal.

Weld these caps in place so that the wotal length of each chamber leg is 36.5 in. 
Weld this part of Elevation $C$ to the tops of the four $2 \times 2$ legs, position outer four pieces of Elevation $B$ to ensure proper alignment of legs.

Weld outer four pieces of Elevation $B$ to the legs. The tops of the members of

Elevation B should be 22.5 in below the tops of the $2 \times 2$ base legs ( 24.5 in below top of elevation C).

Weld the inner four $2 \times 1$ pieces of Elevation $B$ into place.

Weld the four angle iron pieces of Elevation A into place.

The angle iron should be oriented with the two flat faces to the outside and to the bottom. The bottom of the angle iron should be 4.0 -in. above the bottom of the $2 \mathrm{x}$ 2 legs.

7. Assemble inner parts of Elevation C.

Cap all six tube ends without changing their lengths. Attach inner and outer parts using six bolts (tap thread into tube caps). The top of the inner part of Elevation $C$ shall be 0.5 in. below the top plane of Elevation $C$. (Upon removal of the six bolts, the inner part of Elevation $\mathrm{C}$ will be lowered to rest on top of Elevation B.) Weld the eight 6.0-in. angle iron supports into place. One flat face should be located against the $2 \times 1$ tubes and the other should be oriented on top with its top elevation 0.5 in. below the top plane of Elevation C. Spacing is shown in Drawing D.

8. Cut tubing for top legs.

Tubing [ $1 \times 1$ ]: 4 each 48.75 in.

9. Cut tubing for Elevation D.

Tubing [ $1 \times 1]$ : 2 each 28.0 in., 2 each 46.0 in.

10. Cut tubing for Elevation $\mathrm{E}$.

Tubing [ $1 \times 1$ ] : 3 each 26.0 in., 2 each 44.0 in. 
11. Assemble top section of prototype containment chamber.

Weld the four pieces of Elevation $D$ together.

Weld the five pieces of Elevation $\mathrm{E}$ together.

Cap the bottom end of each of the four legs as was done for the base legs (see No. 6).

Weld the four top legs to the inside corners of Elevation D.

The bottom of Elevation D should be 1.75 in. above the bottom of the legs.

Weld Elevation $E$ to the top legs.

The upper ends of the legs should be attached exactly at the botrom of the four comers of Elevation $\mathrm{E}$. The vertical distance between the bottom of Elevation $\mathrm{E}$ and the top of Elevation D should now be 46.0 in.

12. Verify fit of top into base sections.

Place the top section into the chamber base by inserting the lower 1.75 in. of the four top section legs into the inside corners of Elevation $C$ so that they rest on the tops of the $2 \times 2$ chamber legs. Grind the ends of the $1 \times 1$ legs if Elevation $D$ does not rest directly on top of Elevation C. Elevation D should rest directly on top of Elevation C. After fit is verified, remove the top section from the chamber base.

13. Cut tubing $\left[\begin{array}{lll}1 & \times & 1\end{array}\right]$ for top section structural supports.

Back face: 1 each $46.5 \mathrm{in}$.

Front face: 1 each 46.5 in., 2 each 20.5 in.

Left side: 1 each $26.0 \mathrm{in} ., 2$ each $22.5 \mathrm{in.}$

Right side: 1 each 26.0 in., 2 each 22.5 in., 1 each 23.0 in.

14. Cap one end of both 46.5 -in. and 23.0-in. lengths of tubing.

These tubes will be used as the vertical structural supports for the back, front, and right sides of the top section of the chamber. 
15. Make three each metal flanges using $1 / 4 \times 2$ bar stock, or $1 / 4$-in. plate.

Outer dimensions: 14 in. $\times 14$ in.

Inner dimensions: 10 in. $x 10$ in.

Round edges by grinding.

Weld four each 7.5-in. studs (3/16-in.-dia., threaded) perpendicular to one side of two of these flanges. Position these studs in the center of each side and 1.50 in. from the inside face.

16. Assemble top section structural supports.

Back Face:

Weld the $1 \times 1$ support between elevations $\mathrm{D}$ and $\mathrm{E}$. The tube should be positioned vertically and welded to the bottom of Elevation $E$ and on the inside face of Elevation D. The bottom of this tube should then be located 0.5 in above the bottom face of Elevation $D$.

Front Face:

Repeat the procedure listed above for the Back Face, and then weld two each 20.5in. $1 \times 1$ tubes horizontally between the top section legs and the $1 \times 1$ mid-face support. The bottom side of the 20.5 -in. tubes should be positioned parallel to and 11.0 in. above the top face of Elevation $D$.

Left Side:

Weld one 26.0-in. $1 \times 1$ tube horizontally between the top section legs. The bottom face of the tube should be positioned parallel to and 22.5 in. above the top face of Elevation D. Next weld two each 22.5-in. tubes from the top face of the 26.0-in. tube to the bottom of Elevation $\mathrm{E}$. These vertical tubes should be positioned with their inside faces 14.0 in. apart. Spacing is shown in Drawing G. Next weld a square flange (with the 7.5-in. studs facing outward) between the two 22.5-in. tubes. The top of the flange should be welded to the bottom face of Elevation $\mathrm{E}$. Tack weld the flange into place and then weld (continuous) the two side and the top of the flange to the $1 \times 1$ tubes. The outer face of the flange should be on the same 
plane as the outer faces of all $1 \times 1$ tubes on the left side. All welds are to be located on the inside face of the flange (i.e., not the face with the studs).

\section{Right Side:}

Repeat the procedure listed above for the Left Side.

Next, weld a 23.0 -in. $1 \times 1$ tube vertically between the 26.0 -in. tube and the inside face of Elevation $D$. The distance between the back side of the right-side front leg and the front face of the 23.0 -in. tube should be 14.0 in (see Drawing G). Next weld (continuous) the flange that was constructed without studs to the inside of the right-side front leg, the 23.0-in. vertical tube, and the inside face of Elevation $D$. The outer face of this flange should be in the same plane as the outer faces of the 1 $x 1$ tubes of the Right Side and the outer face of the upper flange.

17. Attach the Top Section to the Base.

Lift the Top Section into place on the Base. Connect the two sections together using two bolts at the base of each leg.

\section{B.3.2 Part 2: Sheet Metal}

Approximately 1/16-in.-thick sheet metal will cover the base of the containment chamber between Elevation $A$ and Elevation $C$. Sheet metal covering the bottom (of Elevation A) and the back and sides (between Elevations $A$ and $C$ ) will be welded in place. The sheet metal covering the front face between Elevations $A$ and $C$ will be held in place by studs to allow occasional removal. Drawing $\mathrm{H}$ shows the correct sizes of all five sheet metal parts.

1. Cut five pieces of sheet metal.

Bottom: 1 each, $45.0 \times 29.0$.

Sides: 2 each, $27.0 \times 32.5$.

Back: 1 each, $43.0 \times 32.5$.

Front: 1 each, $44.0 \times 33.5$. 
2. Install Bottom.

Notch approximately 2 in. square out of each comer to fit around the base legs. If feasible, place the sheet metal on top of the angle iron comprising Elevation $A$. Otherwise, invert the base section and attach the sheet metal to the bottom of the flat portion of Elevation A. Tack weld the sheet metal in place and then continuous weld all edges of the metal to Elevation $A$ and the base section $2 \times 2$ legs.

3. Install Back and Sides.

Position the sheet metal on the outside of the base section. The sheet metal should be positioned so that it covers the lower 0.5 in. of Elevation $C$, and the upper 0.5 in. of Elevation A. In the horizontal plane, the sheet metal should cover 0.5 in. of the base section leg on each side. Weld all seams as done for the bottom piece of sheet metal. Tack weld the sheet metal to Elevation B as required for support

4. Install Front Sheet Metal.

The border of this piece should be positioned so that the outer 1.0 in covers the base legs, Elevation A, and Elevation C. Weld 3/4-in. studs (stainless steel, approximately $1 / 4 \times 20$ ) to the base legs, Elevation $A$, and Elevation $C$ to fit the pattem shown on Drawing $H$. Drill holes for the studs and verify fit by placing the sheet metal piece onto the base section. Next, prepare a stiffening frame using 3/16 $x 1$ bar stock. The outer dimensions of this frame should be $33.5 \times 44$. Place the frame over the sheet metal and tack weld the pieces together so that the outer edges are positioned squarely over each other. Drill the stud holes through the stiffening frame. Prepare a rubber gasket the same size as the stiffening frame. Glue the gasket to the inside face of the sheet metal (i.e., not the same side as the stiffening frame). Atach the front face to the chamber base by positioning the sheet metal with the gasket side in and the stiffening frame out, and fix into place using a washer and nut on each stud. 


\section{B.3.3 Part 3: Lexan Windows}

Lexan sheets of $1 / 4$-in. thickness will cover the top section of the containment chamber. These sheets will be cut to size as shown in Drawing I by the manufacturer. Widely spaced studs will be used to hold the Lexan sheets in place. Silicone sealant will be used to provide a seal and will be applied from the inside as a last step.

1. Verify that the Lexan sheets were cut to the appropriate sizes and tolerances as shown in Drawing I.

2. Drill stud holes in all five Lexan sheets. Take care not to fracture the sheets.

3. Attach 3/4-in. studs (stainless steel, approximately $1 / 4 \times 20$ ) to the top section legs, Elevation $E$, and the top section structural supports. The studs should be positioned to fit the stud holes, this will be approximately $3 / 8$ in. from the inside edge of steel tubes.

4. Drill five holes in the top Lexan sheet, as shown in Drawing I. Tap 1/4-in., 3/8-in., or 1/2in. NPT threads into Elevation $\mathrm{E}$ at the locations of these five holes.

5. Assemble the Lexan sheets using an untightened nut and a washer on each stud. The sheets should rest on top of Elevation $D$ at the bottom, and should overlap all edges by approximately $3 / 4$ in. Do not seal with silicone at this time.

6. Next, disassemble the Lexan sheets to prepare for painting.

\section{B.3.4 Part 4: Painting}

Paint all exposed metal surfaces with two coats of a spray epoxy paint. To paint the front door of the base section, remove it and cover the flat face of the gasket material with masking tape. 
PNL-6850

UC-11

\section{DISTRIBUTION}

No. of

Copies

OFFSITE

10 DOE/Office of Scientific and Technical Information

\section{ONSITE}

DOE Richland Operations Office

E. G. Norman

Westinghouse Hanford Company

R. D. Budd
No. of

Copies

23 Pacific Northwest Laboratory

H. Bolton, Jr.

J. W. Falco

J. K. Fredrickson (2)

J. M. Hales

P. C. Hays

S. A. Kreml

S. Li

R. G. Riley

L. E. Rogers

R. L. Skaggs

P. Van Voris (5)

R. E. Wildung

Publishing Coordination

Technical Report Files (5) 
